INTITUTO DE CIÊNCIAS BIOLÓGICAS

\title{
ABUNDÂNCIA E DISTRIBUIÇÃO ESPAÇO-TEMPORAL DE MESOPREDADORES NA CAATINGA do PIAUí.
}

Gabriel Penido de Oliveira

Orientador: Prof. Dr. Jader Marinho Filho

Tese apresentada ao Programa de PósGraduação em Ecologia da Universidade de Brasília como parte dos requisitos para a obtenção do Título de Doutor em Ecologia.

Brasília, agosto de 2016. 

Esta tese é o resultado do esforço não apenas meu, mas também de várias outras pessoas que estiveram ao meu lado e me auxiliaram em diversas etapas do trabalho. Ocuparia o tamanho de outra tese se eu fosse incluir o nome e a importância de cada um neste espaço, portanto gostaria de agradecer especialmente a aquelas que me ajudaram de forma direta e continua durante este curto, porém proveitoso tempo.

Ao meu Orientador, Prof. Dr. Jader Marinho Filho, que me ajudou a crescer como pesquisador. Pela orientação cedida, desde a primeira versão do projeto de pesquisa do mestrado, a qual foi inteiramente riscada e criticada, até a versão final desta tese, (após 6 anos de trabalho conjunto). À Coordenação de Aperfeiçoamento de Pessoal de Nível Superior (CAPES) e ao Conselho Nacional de Desenvolvimento Científico e Tecnológico (CNPq) pela concessão da bolsa de doutorado. Aos professores, Dr. Flávio Henrique Guimarães Rodrigues, Dr. Adriano Garcia Chiarello, Dr. Ricardo Bonfim Machado, Dr. Eliécer Gutierrez e Dr. Paulo César Motta, por aceitarem compor a banca examinadora deste trabalho.

À Dra. Rahel Sollmann por toda a paciência para esclarecer e me auxiliar em quaisquer dúvidas em relação as análises de captura-recaptura e por ter sido um ponto seguro durante meu período no doutorado-sanduíche. À Dra. Beth Gardner, minha supervisora do sanduíche, por ter me recebido e feito com que me sentisse em casa durante minha estadia na North Carolina State University. Ao Dr. Samuel Astete, pela ajuda constante durante o decorrer do projeto em cada etapa, desde o auxílio incomensurável durante as atividades de campo e pela companhia durante todo o decorrer do projeto.

Aos companheiros do Laboratório de Mamíferos da UnB e demais amigos que sempre estiveram à disposição e prontos a ajudarem em qualquer problema. A Ana Martins, Babi Zimbres, Clarisse Rocha, Alexandre Portella, Dani Behs, Vivian Ribeiro e inúmeras outras pessoas que participaram comigo deste caminho. Ao Fred e Angelita por todos os momentos que passamos juntos, o que tornou esse caminho muito menos penoso de trilhar.

Agradeço a Camila, minha companheira, presente em todas as etapas da elaboração deste trabalho, incentivando e vigiando para que a procrastinação não dominasse este autor. A minha família em Belo Horizonte, minha mãe, meu pai e meu irmão.

E por fim, agradeço a todos que se sentirem agradecidos. 
Índice Geral

$\begin{array}{lr}\text { Apresentação } & \mathbf{1} \\ \text { Resumo } & \mathbf{3} \\ \text { Introdução Geral } & \mathbf{6} \\ \text { Mesocarnívoros } & 8 \\ \text { A jaguatirica (Leopardus pardalis, Linnaeus 1758) } & 10 \\ \text { O gato-do-mato } & 13 \\ \text { O lobinho } & 15 \\ \text { A Caatinga } & 18 \\ \text { O Parque Nacional da Serra da Capivara } & 19 \\ \text { Justificativa } & 19 \\ \text { Objetivos e delineamento } & 20 \\ \text { Referências Bibliográficas } & 22\end{array}$

Capítulo 1 - VARIAÇÃo POPULACIONAL DE TRÊS ESPÉCIES DE MESOCARNÍVOROS NA CAATINGA DO PIAUÍ, BRASIL.

1. Introdução 31

2. Material e métodos 35

Coleta de dados 36

Análise dos dados 38

3. Resultados $\quad 40$

$\begin{array}{lr}\text { 4. Discussão } & 43\end{array}$

$\begin{array}{lr}\text { 5. Referências Bibliográficas } & 49\end{array}$

Capítulo 2 - PADRÕES DE ATIVIDADE DE MESOCARNÍVOROS NO SEMIÁRIDO DA CAATINGA, BRASIL.54

$\begin{array}{lr}\text { 1. Introdução } & 54\end{array}$

2. Material e Métodos $\quad 56$

$\begin{array}{lr}\text { Coleta de dados } & 56\end{array}$

Análise dos dados $\quad 58$

$\begin{array}{lr}\text { 3. Resultados } & 59\end{array}$

$\begin{array}{lr}\text { 4. Discussão } & 66\end{array}$

5. Referências Bibliográficas. $\quad 72$

Capítulo 3 - OCUPAÇÃO DE TRÊS MESOCARNÍVOROS NO SEMIÁRIDO BRASILEIRO: EFEITOS DE FATORES AMBIENTAIS E BIOLÓGICOS.

$\begin{array}{ll}\text { 1. Introdução } & 76\end{array}$

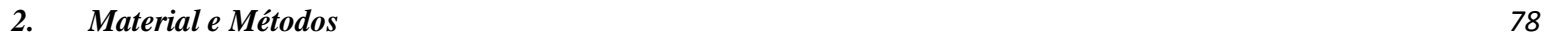

$\begin{array}{lr}\text { Coleta de dados } & 79\end{array}$

$\begin{array}{lr}\text { Estruturação dos dados } & 80\end{array}$

Análise dos dados $\quad 82$

$\begin{array}{llr}\text { 3. } & \text { Resultados } & 85 \\ \text { 4. } & \text { Discussão } & 89 \\ \text { 5. } & \text { Referências Bibliográficas. } & 94\end{array}$

$\begin{array}{lr}\text { Epílogo } & 101\end{array}$

$\begin{array}{lr}\text { Apêndice } & 103\end{array}$ 
Índice de Figuras

Figura A: jaguatirica (Leopardus pardalis) destacando o padrão característico das rosetas formando faixas longitudinais.

Figura B: Distribuição geográfica da jaguatirica (Leopardus pardalis), que ocorre desde o sul dos Estados Unidos até a porção norte da Argentina (Oliveira e Cassaro 2005).

Figura C: jaguatirica (Leopardus pardalis) com filhote, no Parque Nacional da Serra da Capivara, Piauí, Brasil...

Figura D: O gato-do-mato (Leopardus tigrinus) pode ser encontrado em formações abertas no semiárido da caatinga.

Figura E: Distribuição geográfica das duas espécies de gato-do-mato (Leopardus tigrinus e L. guttulus em conjunto) - (Oliveira and Cassaro 2005).

Figura F: O lobinho (Cerdocyon thous) e é frequentemente observado nas margens de estradas e trilhas.

Figura G: Distribuição geográfica do lobinho (Cerdocyon thous) - (Berta 1982) ............................. 17

Figura H: O forrageamento de pares ou mesmo grupos maiores de lobinhos (Cerdocyon thous), é frequente em áreas naturais.

Figura 1-1: Parque Nacional da Serra da Capivara, com a localização das armadilhas fotográficas. . 37

Figura 1-2: Estação de captura, composta por duas armadilhas fotográficas (em destaque)...............38

Figura 2-1: Parque Nacional da Serra da Capivara, com a localização das armadilhas instaladas durante a amostragem de 2007

Figura 2-2: Padrões de atividade dos três mesocarnívoros obtidas durante a amostragem de 2007....60 Figura 2-3: Padrões de atividade dos três mesocarnívoros em relação à atividade dos dois predadores de topo na amostragem de 2007.

Figura 2-4: Padrões de atividade dos três mesocarnívoros obtidas durante as amostragens de 2009 e 2010.

Figura 2-5: Padrões de atividade dos três mesocarnívoros em relação à atividade da Onça-pintada nas amostragens de 2009 e 2010.

Figura 2-6: Padrões de atividade dos três mesocarnívoros em relação à atividade da Onça-parda nas amostragens de 2009 e 2010.

Figura 2-7: Padrões de atividade dos três mesocarnívoros em relação à atividade das espécies de roedores nas amostragens de 2009 e 2010.

Figura 3-1: Parque Nacional da Serra da Capivara, com a localização das armadilhas fotográficas utilizadas no estudo de ocupação durante as amostragens de 2009-2011. 
Índice de Tabelas

Tabela 1-1: Resultado da seleção de modelos para a estimativa de abundância da jaguatirica através do método SECR.

Tabela 1-2: Resultados da estimativa de abundância obtida através dos modelos $R N$, para as três espécies nos dois anos de amostragem.

Tabela 2-1: Coeficiente de sobreposição temporal $\left(\Delta_{1}(95 \% \mathrm{CI})\right)$ entre as diferentes espécies de carnívoros amostradas no Parque Nacional da Serra da Capivara em 2007.

Tabela 3-1: Seleção de modelos de detecção (p) para a análise de ocupação da Jaguatirica no

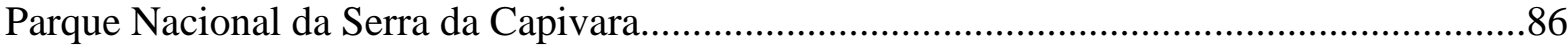

Tabela 3-2: Seleção de modelos de detecção (p) para a análise de ocupação do lobinho no

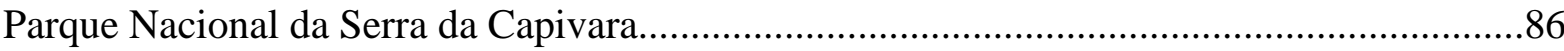

Tabela 3-3: Seleção de modelos de detecção (p) para a análise de ocupação do Gato-do-mato

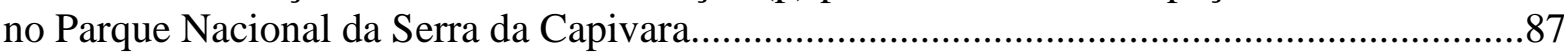

Tabela 3-4: Seleção de modelos de ocupação (psi) para a análise da distribuição da jaguatirica no Parque Nacional da Serra da Capivara (Detecção fixada em Altitude)............88 Tabela 3-5: Seleção de modelos de ocupação (psi) para a análise da distribuição do lobinho no Parque Nacional da Serra da Capivara (Detecção fixada em jaguatirica) . .88 Tabela 3-6: Seleção de modelos de ocupação (psi) para a análise da distribuição do Gato-domato no Parque Nacional da Serra da Capivara (Detecção fixada em Densidade de Pontos de água + Altitude) 


\section{Apresentação}

Esta tese de Doutorado pode ser considerada como uma sequência de minha dissertação de mestrado. Naquela ocasião, eu apresentei uma primeira visão sobre as características da jaguatirica na Caatinga do Piauí. Durante a dissertação, foi realizada a estimativa da abundância deste felino de médio porte e uma descrição geral do quadro ecológico deste predador em um ambiente tão escasso de conhecimentos. Nesta tese, o estudo iniciado no mestrado é expandido com a inclusão de uma amostragem maior, abrangendo mais anos de coleta de dados, e a análise de não apenas para outras características ecológicas da jaguatirica, mas também apresenta a inclusão de dois outros mesocarnívoros: o gato-do-mato e o lobinho, criando assim uma visão sobre diferentes mesocarnívoros e suas relações e populações na Caatinga do Piauí.

Para isto este trabalho foi dividido em duas seções principais: a descrição das espécies e das populações amostradas (Introdução Geral e Primeiro Capítulo) e a distribuição espaçotemporal delas (Segundo e Terceiro Capítulos). Desta forma, a primeira parte da tese consiste em um estudo descritivo destas três espécies, incluindo uma introdução geral sobre o estado do conhecimento acerca destes animais e do ambiente estudado, seguido do primeiro capítulo, no qual é realizado a estimativa de uma abundância populacional relativa destes mesocarnívoros no Parque Nacional da Serra da Capivara, com o objetivo de verificar a variação populacional entre duas amostragens em anos distintos. A densidade da jaguatirica foi reanalisada, através de métodos mais modernos e refinados de resultados mais precisos e confiáveis, com o intuito tanto de realizar a comparação interna entre diferentes métodos de análises, quanto o de atualizar os valores obtidos anteriormente, durante o mestrado. Assim, esta primeira seção visa estabelecer uma base para o estudo destas espécies neste ambiente árido.

A partir disto, a segunda parte do trabalho foca na distribuição temporal e espacial destes carnívoros na Serra da Capivara, e a relação destas distribuições com variáveis e fatores locais. Assim, o segundo capítulo inicia com a descrição dos padrões de atividade dos três 
carnívoros amostrados e, a partir disto, procura relacionar estes padrões de atividade com diferentes grupos de espécies que ocorrem juntos na Serra da Capivara, sejam predadores ou presas. O terceiro e último capítulo estima a probabilidade de ocupação destas espécies e o efeito que diferentes grupos de variáveis - ambientais, predadores, presas e efeitos humanos podem ter em suas distribuições e probabilidades de detecção no ambiente árido da Caatinga.

Finalmente, com os resultados obtidos nos capítulos anteriores, será possível identificar elementos críticos para a ocorrência destes animais não apenas no semiárido da Caatinga, mas também em outros ambientes nos quais estas espécies ocorrem, auxiliando assim, na construção de uma base sólida para futuros estudos relativos a estes animais e para todo o ecossistema no qual estão inseridos. 


\section{Resumo}

Este trabalho avalia os aspectos ecológicos e populacionais de três espécies de mesocarnívoros, a jaguatirica (Leopardus pardalis), o lobinho (Cerdocyon thous) e o gato-do-mato-Pequeno ( $L$. tigrinus) no Parque Nacional da Serra da Capivara, localizado na Caatinga do Piauí. No primeiro capítulo é realizado a estimativa da variação populacional destas espécies durante dois anos de amostragem. Através da utilização de modelos estatísticos que não necessitam da identificação individual de cada registro, foi estimado um índice de abundância relativa, que considera a probabilidade de detecção, para cada espécie em cada ano de amostragem. Os resultados apontaram que a população da jaguatirica apresentou um grande declínio no segundo ano, enquanto que a população do lobinho permaneceu estável. A população do gato-do-mato também apresentou um declínio, porém este foi menor e não é possível identificar se a diminuição foi real ou apenas uma variação presente no intervalo de confiança da análise. No segundo capítulo foi verificado os padrões de atividade destas espécies em três anos. Em 2007 foi estimada a atividade durante $24 \mathrm{~h}$, estabelecendo assim os padrões de atividade destas espécies no Parque Nacional da Serra da Capivara. As amostragens seguintes, durante os anos de 2009 e 2010, foram conduzidas apenas no período noturno, possibilitando a comparação entre os picos de atividade destas espécies nos horários em que se encontram mais ativas. $\mathrm{Na}$ amostragem de 2007, todos os mesocarnívoros foram noturnos, em especial a jaguatirica, que apresentou apenas um registro durante o dia. Na amostragem maior de 2009 e 2010, não houve uma clara distinção na atividade entre os mesocarnívoros e outras espécies de predadores de topo. No entanto, foi identificado que os mesocarnívoros ajustam seus picos de atividade àquele de espécies de potenciais presas. Por último, no terceiro capítulo foram estimadas as probabilidades de ocupação destas três espécies de carnívoros e a sua relação com diferentes grupos de variáveis. A jaguatirica apresentou valores de ocupação menores em locais em que a Onça-Pintada possuiu maior frequência de registros. No entanto sua ocupação foi maior em 
locais com maior frequência de roedores. Da mesma forma, o lobinho também se distribuiu preferentemente em locais cuja presença de roedores e tatus foi maior. O gato-do-mato, no entanto, evitou os locais com a presença de animais domésticos e de cães, sugerindo uma maior sensibilidade a atividades humanas. Assim, a distribuição destas espécies no semiárido da Caatinga é ditada principalmente pela presença de presas, com o efeito conjunto de fatores topdown, proveniente da presença de predadores maiores e de espécies domésticas, afetando as duas espécies de felinos. Por fim, o conjunto deste trabalho mostra a importância de diferentes variáveis na distribuição espaço-temporal de mesocarnívoros na Caatinga, servindo de um ponto inicial para posteriores estudos neste ambiente ou em outras áreas áridas.

\section{Abstract}

This work focuses ecological and biological aspects of three mesocarnivore species, ocelot, crab-eating fox and oncilla in the National Park of Serra da Capivara, located in the Caatinga of Piauí state. The first chapter addresses an estimate of abundance variation between two years of survey. Through analytical methods that do not require individual recognition, we detected that ocelot populations declined in numbers, while crab-eating fox abundance was stable. Oncilla abundances also declined. However, because of the large confidence interval of the analysis, it was not possible to verify if this reduction was real or just an artifact of the method. The second chapter addresses the temporal patterns of these species and their relationship to other predators and prey. All mesocarnivores were extremely nocturne animals. The overlap indexes identified a high degree of overlapping between all carnivore species, however, mesocarnivores seems to be adjusting their activity peaks to that of prey species. Lastly, the third chapter estimated occupancy patterns for these mesocarnivores and the effect of different variables on these occurrence probabilities. Ocelots had lower occupancy rates in places where 
jaguar had higher frequencies. However this mesopredators had a higher occupancy in regions where prey species were more frequent. Likewise, the crab-eating fox had a higher occupancy in the same places that prey species were more frequent. The oncilla appears to avoid the presence of domestic animals and dogs, indicating a higher sensibility to human induced interference. It seems that top-down effects are important for both felid species occupancy, while bottom-up factors - prey availability - is also a key factor for the ocelot and crab-eating foxes. 


\section{Introdução Geral}

A distribuição das espécies em seu ambiente é um dos principais focos dos estudos em ecologia (Kéry 2011; Collier et al. 2012). Isto pode ser compreendido na própria definição da Ecologia como sendo o estudo das interações que determinam distribuição e abundância de $\operatorname{organismos}^{1}$ (Krebs 1972). Uma das abordagens para investigar a ocorrência de uma espécie é através do conceito do nicho ecológico (Hutchinson 1957), onde cada espécie possui um conjunto único de requerimentos que devem ser providos pelo habitat para sua persistência no local (MacKenzie et al. 2006). Desta forma, ecólogos pretendem compreender e identificar as principais variáveis que estão influenciando a distribuição de uma espécie para que, assim, se possam desenvolver modelos preditivos que infiram a abundância ou a ocorrência destas espécies em relação a características ambientais (Verner et al. 1986; MacKenzie et al. 2006), tanto físicas como biológicas. Tais estudos podem auxiliar na conservação e manejo de uma ou várias espécies ao enfocar na preservação das principais características ambientais que as influenciam em um cenário de mudança ambiental - antrópica ou não.

Mamíferos carnívoros são considerados espécies com uma importância chave, apresentando funções e efeitos críticos nos ecossistemas no qual ocorrem (Terborgh et al. 1999; Miller et al. 2001). Estes animais predadores podem desestabilizar toda a cadeia trófica, através da depleção de espécies de presas, caso o ambiente no qual ocorram seja limitado e pequeno (Loreau e Holt 2004; McCann et al. 2005), ou, caso o ambiente seja complexo e aberto, estas espécies podem manter o equilíbrio através do ecossistema, mantendo diferentes espécies de presas em equilíbrio (McCann et al. 2005). Entretanto, este grupo de espécies geralmente está entre os primeiros a desaparecer devido ao aumento da pressão gerada pela atividade humana

\footnotetext{
1 "Ecology is the scientific study of the interactions that determine the distribution and abundance of organisms" - Krebs, 1972.
} 
(Morrison et al. 2007). Neste sentido, é essencial conhecer e definir quais fatores podem afetar estas espécies em diferentes contextos para que seja possível desenvolver quaisquer projetos de conservação, direcionados não apenas para este grupo, mas devido ao seu papel chave nos ambientes no qual ocorrem, para todo o ecossistema onde estão inseridos (Kerr 1997).

Existe um amplo conhecimento sobre espécies de carnívoros ${ }^{2}$ nos trópicos em temas tão diversos como, por exemplo: competição intraguilda (Jacomo et al. 2004; Novack et al. 2005; Haines 2006; Di Bitetti et al. 2009; Romero-Muñoz et al. 2010; Davis et al. 2011; Sollmann et al. 2012), dieta (Chinchilla 1997; Taber et al. 1997; Garla et al. 2001; Wang 2002; Gatti et al. 2006), área de vida (Michalski et al. 2006; Dillon e Kelly 2008), densidade (Silver et al. 2004; Kelly et al. 2008; Silveira et al. 2009), entre outros (Breitenmoser e Breitenmoser 2008; Kolowski e Alonso 2010). Diversos estudos identificaram aspectos que podem afetar a distribuição de espécies de mamíferos carnívoros em contextos distintos. Estes fatores variam entre os diferentes estudos: a forma e as características do ambiente no qual estas espécies de carnívoros estão inseridas (Juarez e Marinho 2002; Di Bitetti et al. 2006; Trovati et al. 2007); a presença de outras espécies, como potenciais competidores (Gehrt e Clark 2003; Davis 2009; Cove et al. 2012); dependência da disponibilidade de recursos, como a presença de presas (Lantschner et al. 2012; Petracca et al. 2013); e, a presença humana, cada vez mais constante e em escala crescente na maioria dos ambientes naturais (Ordeñana et al. 2010; Pia et al. 2013).

Uma visão geral destes estudos indica que fatores bottom-up, ou seja, fatores oriundos dos níveis inferiores da cadeia trófica são os principais responsáveis pela distribuição deste grupo de mamíferos (Carbone e Gittleman 2002; Herfindal et al. 2005; Nilsen et al. 2005). Isto sugere que os efeitos de perda e fragmentação de habitat e a depleção de espécies de presas, resultantes ou não desta fragmentação, são críticos para a persistência destas espécies

\footnotetext{
${ }^{2}$ Neste trabalho, "carnívoros" se relaciona com as espécies de mamíferos da ordem Carnivora.
} 
carnívoras (Schuette et al. 2013). A maior parte destes estudos foi realizada com carnívoros de maior porte. Entretanto, os carnívoros, em sua maioria, não são animais de grande massa corporal, nem mesmo estão situados no topo da cadeia trófica (Roemer et al. 2009).

\section{$\underline{\text { Mesocarnívoros }}$}

Mesocarnívoros, ou mesopredadores, são definidos como espécies de carnívoros que se localizam em uma posição intermediária na rede trófica de uma comunidade (Prugh et al. 2009). Assim, um ponto a ser esclarecido, é que a denominação de "meso" não é derivada do tamanho corporal do animal, e sim, da sua posição trófica (Roemer et al. 2009). Um carnívoro considerado meso em uma comunidade, por exemplo: uma jaguatirica (Leopardus pardalis) em um local onde ela ocorre em simpatria com a Onça-Pintada (Panthera onca), poderia ser considerado o novo carnívoro de topo, no caso da onça seja extinta do local. Este grupo apresenta uma riqueza de espécies muito maior do que os predadores maiores ${ }^{3}$, possuindo comportamentos e ecologia muito mais diversa do que predadores de topo, podendo variar desde espécies altamente sociais a solitárias; frutívoras e onívoras; a hipercarnívoras; especialistas ou generalistas (Roemer et al. 2009).

Este grupo de carnívoros é passível de sofrer uma forte pressão oriunda de predadores localizados no topo da cadeia através da predação intraguilda (Palomares e Caro 1999). Este tipo de interação ocorre quando o mesopredador é atacado e morto pela espécie de carnívoro maior que ocorre em simpatria (Ritchie e Johnson 2009). O efeito que este tipo de interação pode ter sobre as populações de mesocarnívoros tem o potencial de ser mais forte do que interações clássicas entre predador e presa, pois em sua maioria, espécies de carnívoros não são adaptados a vigília e fuga, como o são as espécies de presas dos carnívoros de topo (Ritchie e Johnson 2009). Isto pode ter um efeito negativo, limitando as populações e a distribuição dos

\footnotetext{
${ }^{3}$ Nesta tese, os termos carnívoros e predadores de "topo" ou "maiores" se relacionam com os grandes mamíferos carnívoros localizados no topo da cadeia trófica.
} 
mesopredadores (Elmhagen e Rushton 2007). Quando predadores de topo são extintos em uma comunidade, as espécies de mesocarnívoros, antes possivelmente limitadas pelo carnívoro maior, podem apresentar um grande aumento em suas populações, espectro alimentar e área de vida (Prugh et al. 2009). Este fenômeno, denominado Liberação do Mesopredador ${ }^{4}$, pode causar um distúrbio de curto ou longo prazo nos ambientes em que ocorrem, de maneira mais ampla do que o antigo predador de topo, pois os mesocarnívoros possuem uma maior variabilidade ecológica em suas características, abrangendo assim uma espectro maior de interações nos quais eles possam causar algum efeito (Roemer et al. 2009).

Com poucas exceções, não se sabe o estado das populações, nem os fatores relacionados à distribuição dos mesocarnívoros em diferentes partes do globo, incluindo o Brasil, onde apenas a jaguatirica é uma espécie de mesopredador extensamente descrita e estudada (Crawshaw e Quigley 1989; Abreu et al. 2008; Massara et al. 2015). Assim, em um contexto global no qual os grandes predadores de topo estão com suas populações cada vez mais esparsas e raras, sendo muitas vezes extintas local ou regionalmente (Prugh et al. 2009), os mesocarnívoros podem apresentar um papel ecológico cada vez mais importante nas diversas regiões onde ocorrem. Desta forma, o conhecimento acerca da ecologia e distribuição dos mesopredadores se torna imprescindível para prever e entender como esses predadores podem afetar a biota. Também é relevante saber se os mesocarnívoros estão em algum risco devido a alterações ambientais, causadas pelo homem ou não.

Neste estudo foram selecionadas três espécies de mesocarnívoros, descritas abaixo - a jaguatirica, o Cachorro-do-mato ou lobinho e o gato-do-mato - que ocorrem na região da Caatinga no Brasil. Foram estimados os parâmetros populacionais e os padrões de distribuição

\footnotetext{
${ }^{4}$ Do original Mesopredator release (Ritchie e Johnson 2009)
} 
no tempo e no espaço destas espécies no semiárido, onde sua biologia é praticamente desconhecida.

\section{$\underline{\text { A jaguatirica (Leopardus pardalis, Linnaeus 1758) }}{ }^{5}$}

Esta espécie de felino de médio porte pode atingir de 11 a 16kg (Murray e Gardner 1997) de massa corporal, sendo considerada a maior espécie do gênero Leopardus (Redford e Eisenberg 1992). Esta espécie possui um padrão de marcas e rosetas ao longo de seu corpo, que em conjunto formam padrões característicos (Figura A) que podem ser considerados como únicos para cada indivíduo. Estas marcas podem ser vistas e reconhecidas com certa facilidade através de fotografias provenientes de armadilhas fotográficas tornando a identificação individual dos registros desta espécie relativamente fácil.

A jaguatirica está distribuída por todo o continente americano, podendo ocorrer desde o sul dos Estados Unidos até a região norte da Argentina (Figura B) (Oliveira e Cassaro 2005). Ela possui uma ampla gama de ambientes nos quais pode ocorrer, indo desde ambientes florestais mais densos até regiões campestres e secas (Emmons e Feer 1997). Ocorre por todo o Brasil, com registros em cada um dos estados, geralmente relacionada as formações florestais tropicais e subtropicais (Oliveira e Cassaro 2005). No entanto apesar desta ampla distribuição poder sugerir que a jaguatirica é uma espécie generalista de habitat, sua ocorrência local é relacionada a uma cobertura vegetal mais fechada e densa, aparentemente evitando ambientes muito abertos (Emmons 1988; Sunquist 1992; Murray e Gardner 1997).

\footnotetext{
5 A descrição a seguir retoma parte da discussão já feita em minha dissertação de mestrado, que tratou especificamente da jaguatirica. Para uma descrição mais detalhada da espécie, ver Oliveira, 2012. 


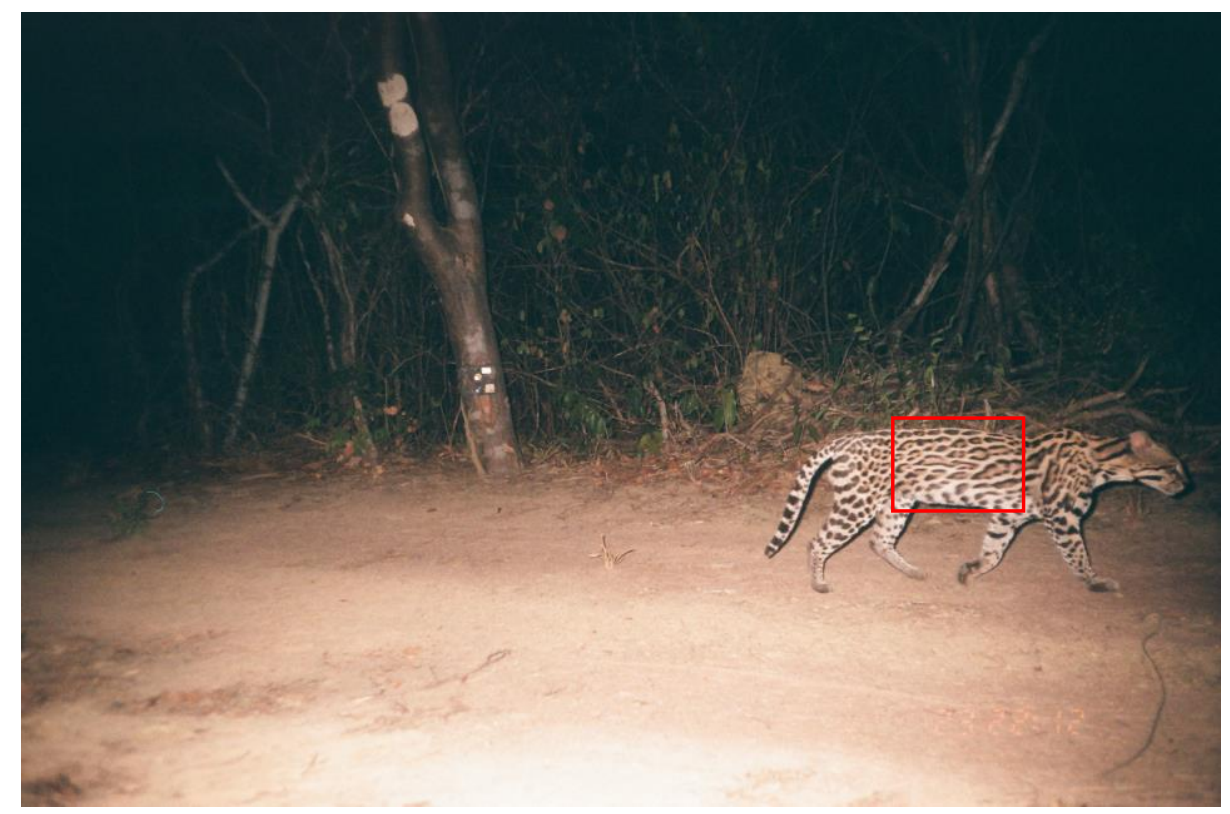

Figura A: Jaguatirica (Leopardus pardalis), em destaque, o padrão característico das rosetas formando faixas longitudinais.

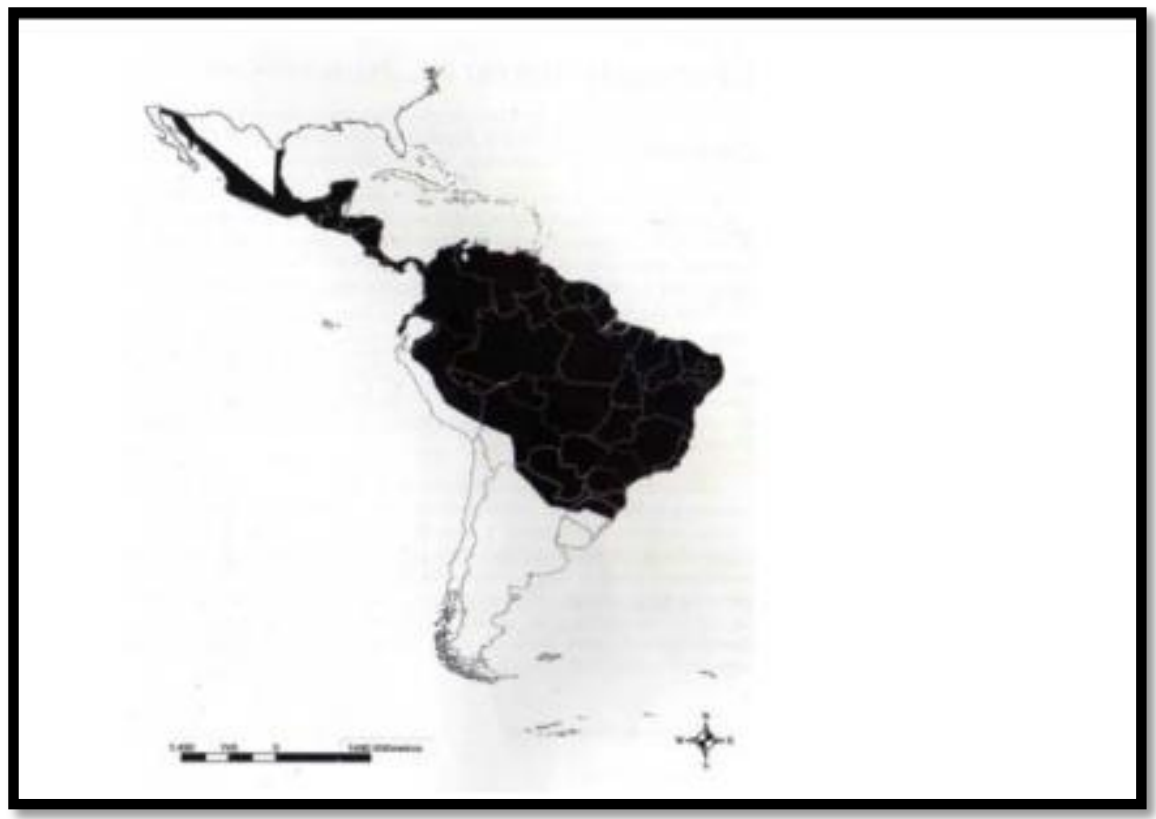

Figura B: Distribuição geográfica da jaguatirica (Leopardus pardalis), que ocorre desde o sul dos Estados Unidos até a porção norte da Argentina (Oliveira e Cassaro, 2005). 


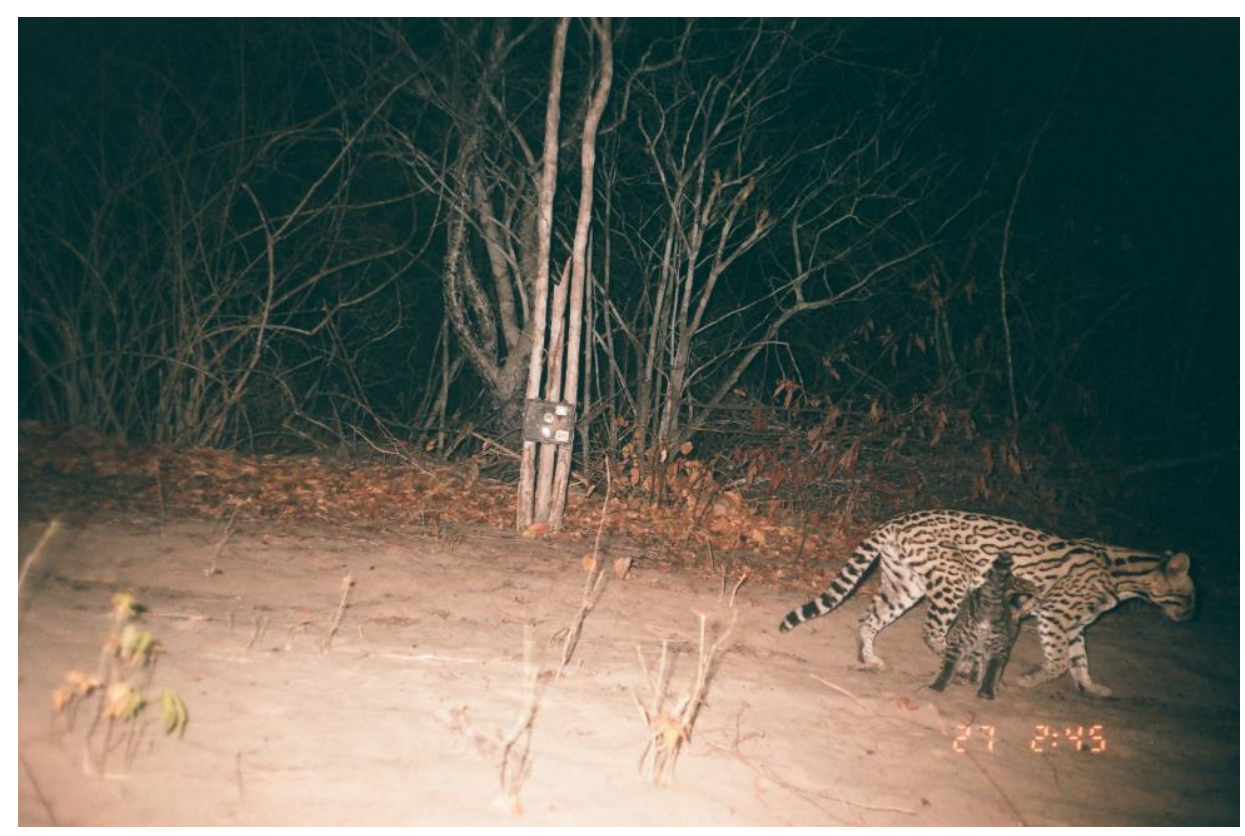

Figura C: Jaguatirica (Leopardus pardalis) com filhote, Parque Nacional da Serra da Capivara, Piauí, Brasil.

A jaguatirica (Figura C) é, dentre as espécies de mesocarnívoros tropicais, a espécie objeto de maior número de estudos. Com efeito, há uma vasta gama de conhecimento sobre seus parâmetros ecológicos, haja vista as pesquisas que levam em consideração: sua dieta (Abreu et al. 2008; Pereira 2009); seus padrões de atividade (Crawshaw e Quigley 1989; Kolowski e Alonso 2010); sua densidade populacional (Trolle e Kéry 2003; Maffei e Noss 2008; Fusco-Costa et al. 2010); e sua área de vida (Ludlow e Sunquist 1987; Haines et al. 2006; Dillon e Kelly 2008). Esses estudos mostram que esta é uma espécie que apresenta muita alteração em suas características ecológicas, dependendo do contexto e do ambiente no qual ela ocorre.

As jaguatiricas, são, normalmente, animais de hábitos crepusculares e noturnos (Laack 1991). Sua atividade diurna parece ser bem dependente do contexto ambiental onde ela se encontra (Di Bitetti et al. 2006), variando em relação ao clima e a precipitação (Murray e 
Gardner 1997). Sua dieta é composta majoritariamente por pequenos mamíferos (Abreu et al. 2008), com a presença, em quantidades muito menores, de aves e répteis e anfíbios.

\section{O gato-do-mato (Leopardus tigrinus, Thomas 1903)}

O gato-do-mato-Pequeno, de agora em diante apenas gato-do-mato, é a menor espécie de felídeo silvestre do Brasil, possuindo proporções corporais similares à do gato-doméstico (Oliveira e Cassaro 2005), com peso médio corporal de 2,4 kg. Possui pelagem com padrão de coloração similar ao da jaguatirica, possuindo, no entanto, rosetas bem mais numerosas (Figura D), com formações abertas e fechadas (Oliveira e Cassaro 2005). Esta espécie é, provavelmente, o felino brasileiro mais desconhecido, principalmente após o reconhecimento de uma espécie nova, Leopardus guttulus, antes uma subespécie de L. tigrinus (Nascimento 2010). A maioria dos estudos conduzidos com o gato-do-mato corresponde às populações atuais de L. guttulus, que ocorrem nas regiões do sul e sudeste brasileiro. A distribuição do gato-do-mato ainda é incerta, e provavelmente compreende a porção norte e nordeste da distribuição anterior (Figura E), antes da separação entre L. tigrinus e L. guttulus. Assim, esta espécie está associada aos ambientes de Cerrado e Caatinga, bem como a algumas regiões da Bacia Amazônica (Nascimento 2010). No entanto, ainda existem poucos registros consistentes desta espécie em algumas regiões do Brasil (Oliveira-Santos et al. 2012), incluindo espécimes identificados como L. tigrinus coletados no sul do país (Nascimento 2010). Isto resulta em inúmeras lacunas no conhecimento sobre a distribuição deste animal.

Muito pouco foi descrito sobre os parâmetros ecológicos dos Gatos-do-Mato ${ }^{6}$, (Oliveira 2006; Michalski et al. 2006). Possui atividade predominantemente noturna, porém a atividade em períodos diurnos não é rara (Oliveira-Santos et al. 2012; Marinho 2015). Sua dieta

\footnotetext{
${ }^{6}$ Os aspectos ecológicos destas duas espécies recém-separadas provavelmente são muito similares nas diversas regiões onde ocorrem. Portanto, o conhecimento da ecologia do L. guttulus, ainda que escasso, será utilizado nesta tese como ponto de partida para as hipóteses do estudo e como medida de comparação e discussão para os resultados aqui obtidos sobre a ecologia de L. tigrinus.
} 
é composta basicamente por pequenos vertebrados, principalmente roedores (Emmons e Feer 1997; Pereira 2009; Tortato 2009). Os poucos estudos que estimaram área de vida desta espécie sugerem valores baixos - de 0,9 a 2,8 $\mathrm{km}^{2}$ para fêmeas e de 4,8 a $17 \mathrm{~km}^{2}$ para indivíduos machos (Oliveira e Cassaro 2005). Este carnívoro está associada a ambientes mais florestados (Trigo et al. 2013) e a presença humana é uma ameaça crítica para esta espécie (Tortato et al. 2013), sendo, em alguns estudos, o animal com maior número de abates por caçadores locais (Mendonça et al. 2011).

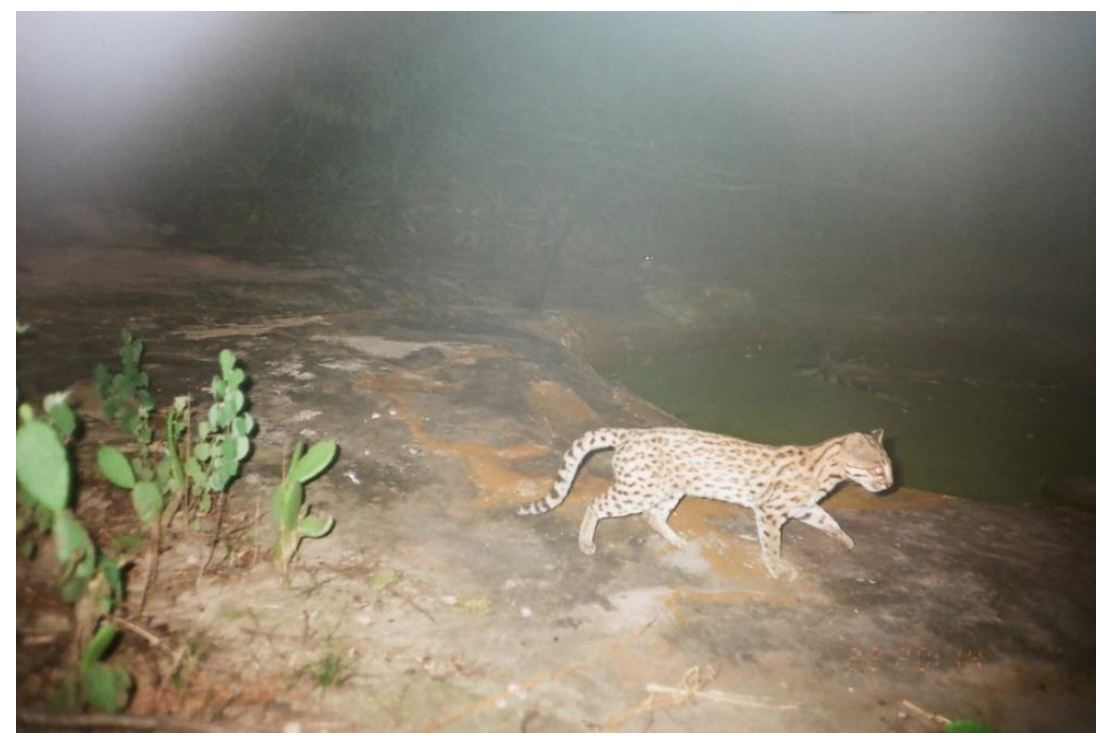

Figura D: O gato-do-mato (Leopardus tigrinus) pode ser encontrado em formações abertas no semiárido da caatinga. 


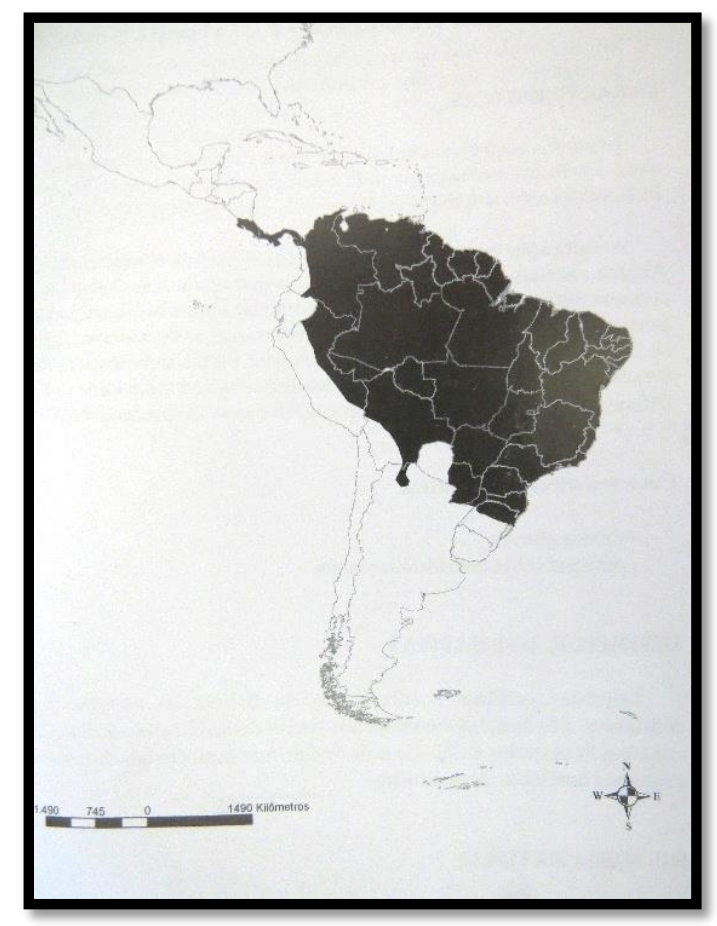

Figura E: Distribuição geográfica das duas espécies de gato-do-mato (Leopardus tigrinus e L. guttulus em conjunto) - (extraído de Oliveira and Cassaro 2005).

\section{O lobinho (Cerdocyon thous, Linnaeus 1766)}

O lobinho, também conhecido como Cachorro-do-Mato, ou Graxaim-do-Campo, é uma espécie de canídeo de médio porte, com peso variando entre 3 a 7 kg. (Emmons e Feer 1997). Possui pelagem cinzenta, com uma faixa mais escura que começa na nuca e termina na ponta da cauda e com o ventre mais claro (Figura F). Não possui dimorfismo sexual aparente (Berta 1982), sendo difícil a definição do sexo desta espécie em fotografias. Sua distribuição vai da Argentina até a Colômbia. No Brasil ocorre no Cerrado, Caatinga, Pantanal, Mata Atlântica e Campos Sulinos (Figura G). Trata-se do canídeo com a distribuição mais ampla da América do Sul (Maffei e Taber 2003).

A maioria dos estudos realizados com o lobinho se concentrou em sua dieta, com poucos trabalhos que focaram em outras características ecológicas (Maffei e Taber 2003). O 
lobinho se alimenta de frutos, pequenos vertebrados, insetos, peixes e qualquer outro item que oportunisticamente possa encontrar (Juarez e Marinho-Filho 2002; Cheida et al. 2003). Esta dieta, muito generalista, pode ser um dos fatores que contribui para que esta espécie ocorra em ambientes impactados (Beisiegel 1999). Apesar de ser um animal de hábitos solitários, não é incomum a presença de pares $($ Figura $\mathrm{H})$ ou pequenos grupos familiares em forrageio conjunto (Cheida et al. 2003). De hábitos principalmente noturnos e crepusculares (Berta 1982; NakanoOliveira 2006; Di Bitetti et al. 2009), esta espécie também pode ser registrada durante o dia (Beisiegel 1999).

Possui uma área de vida entre 2,8 a 4,5 km² (Beisiegel 1999; Nakano-Oliveira 2002), com fêmeas apresentando uma área maior do que a dos machos. Sua densidade foi estimada em 0,78 indivíduos/ $\mathrm{km}^{2}$ no sul do Brasil (Faria-Corrêa et al. 2009). No entanto estes são resultados de estudo pontuais e, tal qual o gato-do-mato, o lobinho ainda é uma espécie relativamente pouco conhecida quanto a sua ecologia e seu comportamento em ambientes naturais.

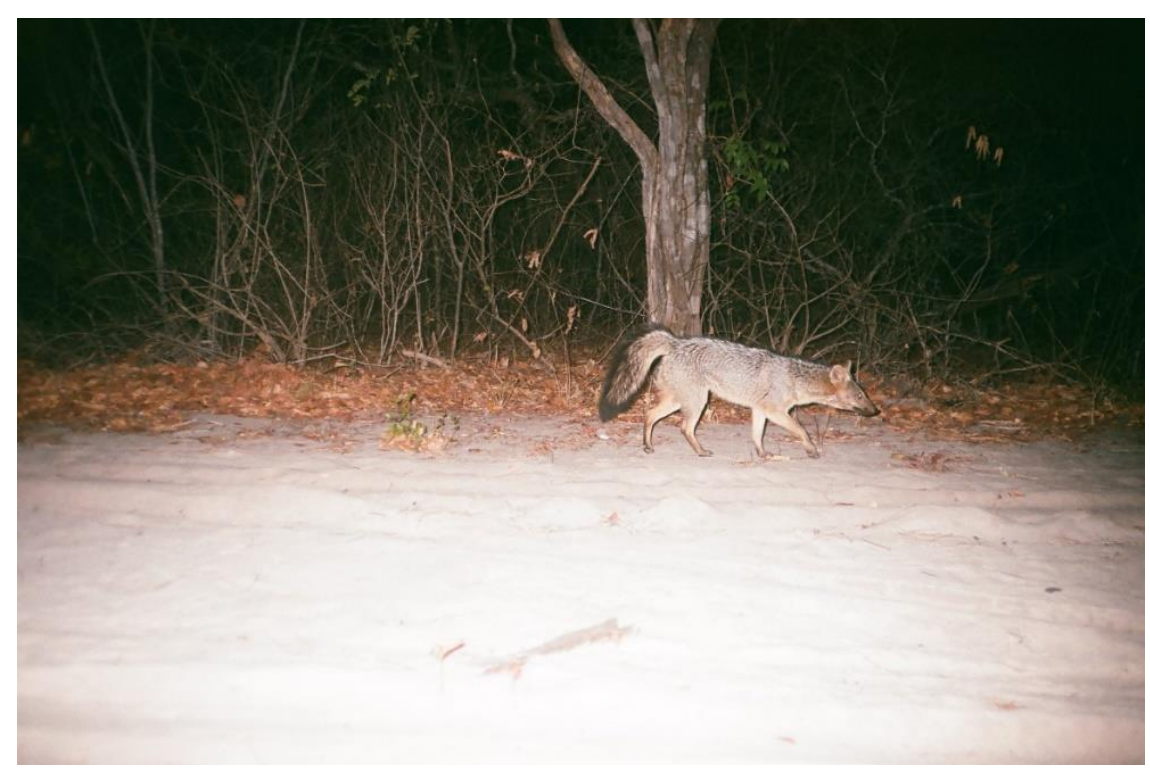

Figura F: O lobinho (Cerdocyon thous) é frequentemente observado nas margens de estradas e trilhas. 


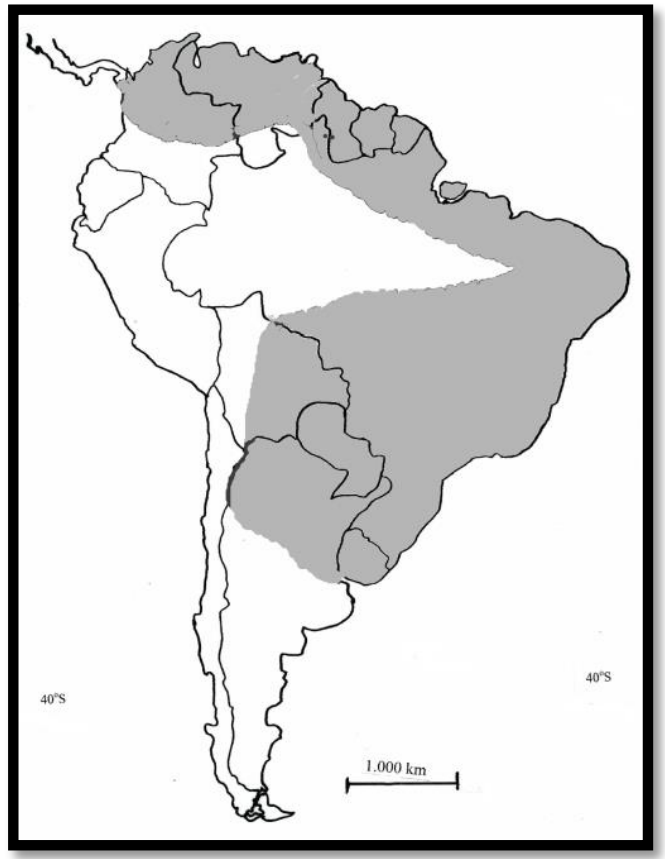

Figura G: Distribuição geográfica do lobinho (Cerdocyon thous) - (Extraído de Beisiegel 1999).

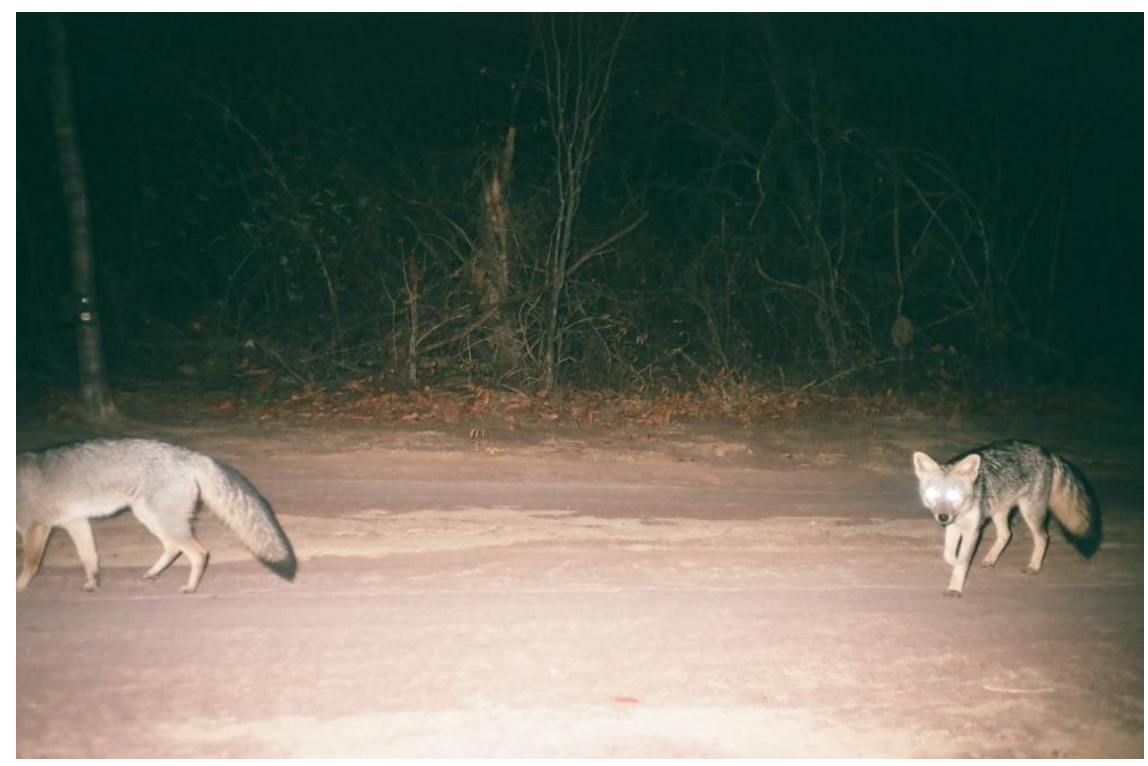

Figura H: O forrageamento de pares ou mesmo grupos maiores de lobinhos (Cerdocyon thous) é frequente em áreas naturais.

Como foi mostrado nesta prévia descrição, estes três mesocarnívoros possuem bases de estudos e conhecimento distintas. A jaguatirica possui inúmeros estudos e trabalhos, enquanto 
que o gato-do-mato e o lobinho têm seus aspectos ecológicos em ambientes naturais praticamente desconhecidos na maior parte de suas distribuições. No entanto, em algumas regiões, até mesmo a ecologia da jaguatirica é desconhecida. Um exemplo disto é o Bioma da Caatinga, no qual praticamente não existem trabalhos publicados em periódicos sobre nenhum mesocarnívoro. As características ambientais únicas desta região podem afetar de modo diverso e particular os padrões ecológicos destas e de outras espécies que ocorrem neste ambiente semiárido.

\section{$\underline{\text { A Caating }^{7}}$}

Um dos biomas menos conhecidos do Brasil, a Caatinga, é também o único bioma cujo limites se encontram todos dentro do território nacional. Ocupando uma área de mais de $800.000 \mathrm{~km}^{2}$, a Caatinga, um ambiente semiárido, apresenta condições climáticas que se localizam nos extremos em relação à outras regiões brasileiras. Sua temperatura média anual está localizada entre os 26 e $28^{\circ} \mathrm{C}$, a mais alta do país, enquanto que a precipitação média anual é a mais baixa do Brasil, com cerca de 300 a 1000mm por ano (Sampaio 1995). A vegetação característica deste ambiente é formada por uma variedade de florestas secas, compreendendo desde vegetações arbustivas a ambientes desérticos, com a presença de regiões localizadas que apresentam uma vegetação florestal úmida. (Tabarelli et al. 2004; Leal et al. 2008).

Este ambiente é historicamente deficiente de estudos, o que faz com que o entendimento acerca de suas espécies e a ecologia que estes organismos apresentam nesta região semiárida seja ainda significativamente desconhecido. No entanto, um volume maior de estudos e pesquisas estão sendo realizados na Caatinga nos últimos anos, indicando uma biota diversa e, muitas vezes, endêmica (Castelletti et al. 2004). O Parque Nacional da Serra da Capivara, uma das poucas unidades de conservação de proteção integral existente neste bioma, possui uma

\footnotetext{
${ }^{7}$ Para uma descrição mais completa da Caatinga e do Parque Nacional da Serra da Capivara ver Oliveira (2012).
} 
importância alta para a preservação da Caatinga (Tabarelli et al. 2004). As três espécies de mesocarnívoros objeto deste atual estudo - A jaguatirica, o lobinho e o gato-do-mato - ocorrem em simpatria neste parque, tornando-o um excelente local para o estudo dos parâmetros ecológicos e das interações destas espécies na Caatinga.

\section{O Parque Nacional da Serra da Capivara}

O Parque Nacional da Serra da Capivara (PNSC), com uma área de 129.953 hectares $\left(1.299,53 \mathrm{~km}^{2}\right)$, está localizado nos municípios de São Raimundo Nonato, São João do Piauí e Canto do Buriti, Sudeste do estado do Piauí. Sua temperatura média anual e de cerca de $28^{\circ} \mathrm{C}$ com os meses outubro e novembro sendo os mais quentes, com temperaturas que podem atingir os $50^{\circ} \mathrm{C}$ (FUMDHAM 1994). Foram descritas oito variações de vegetação no parque, indo desde grandes formações arbóreas, com a presença de um dossel elevado (cerca de 10 metros), até formações arbustivas abertas (Emperaire 1984; Lemos 2004). O parque possui um planalto central com cerca de 600 metros de altura, cortado por vários vales e cânions (Lemos 2004). Apesar de existirem leitos e sulcos de rios no interior do PNSC, estes se encontram secos na maior parte do ano, apenas apresentando algum volume de água durante o período das chuvas. Por esta razão, a Fundação Museu do Homem Americano, a gestora do Parque, estabeleceu um manejo de água artificial, no qual foram construídos e estabelecidos centenas de poços de água, distribuídos por toda a extensão do Parque. Esta criação de pontos de água artificiais foi indicada no Plano de Manejo do Parque, realizada com o objetivo de prover água para a fauna presente no Parque.

\section{$\underline{\text { Justificativa }}$}

Recentemente, foram conduzidos estudos sobre as populações de carnívoros de topo (Onça-pintada e Onça-parda) e de suas presas em potencial na Serra da Capivara (Silveira et 
al. 2009; Foster et al. 2013), bem como minha dissertação de mestrado que estimou a densidade da jaguatirica neste Parque. Os resultados encontrados mostram que esta é uma região onde o ambiente árido é capaz de afetar de forma particular estas espécies. No entanto, como mencionado anteriormente, estudos e dados sobre mesocarnívoros, tanto na Serra da Capivara, quanto na Caatinga como um todo, são extremamente escassos (Dias e Bocchiglieri 2015; Marinho 2015). Isso prejudica o conhecimento sobre o estado de preservação destas espécies no semiárido brasileiro. Com o propósito de contribuir para a redução da lacuna de conhecimento em relação aos mesocarnívoros no semiárido, e avançando em relação aos achados de minha pesquisa de mestrado, este estudo pode ajudar a entender melhor como estas diferentes espécies são capazes de adaptar-se a diferentes contextos ambientais, tanto na Caatinga como em outras regiões nos quais ocorrem.

\section{Objetivos e delineamento}

O objetivo principal deste estudo é procurar entender como os três mesocarnívoros estudados (jaguatirica, lobinho e gato-do-mato) se distribuem neste ambiente árido. O primeiro capítulo apresenta uma estimativa da variação da abundância de indivíduos, averiguando se as populações de cada uma das três espécies estiveram estáveis durante os dois anos de amostragem. À diferença da estimativa de abundância da jaguatirica feita no mestrado, este capítulo estima a abundância de duas novas espécies (lobinho e gato do mato) e utiliza modelos mais atuais e precisos, o que permite averiguar em que medida diferentes modelos podem levar a resultados diferentes. O segundo capítulo examina os padrões de atividade diários destes três carnívoros no PNSC, e sua relação com a presença de outras espécies. Por fim, o terceiro capítulo apresenta os padrões de ocupação dos mesocarnívoros do PNSC e o efeito de variáveis ambientais sobre sua distribuição, como a presença de outras espécies e de atividade humana. 
Este estudo é, portanto, composto de três trabalhos que, em conjunto, apresentam um quadro da população e da distribuição, tanto no tempo quanto no espaço, de três espécies de mesocarnívoros em um ambiente semiárido. 


\section{Referências Bibliográficas}

Abreu KC, Moro-Rios RF, Silva-Pereira JE, Miranda JMD, Jablonski EF e Passos FC (2008) Feeding habits of ocelot (Leopardus Pardalis) in Southern Brazil. Mammalian Biology 73:407-411.

Andrade-Lima D (1981) The Caatingas Dominium. Revista Brasileira de Botânica 4:149-453.

Beisiegel BM (1999) Contribuição ao estudo da história natural do Cachorro do mato,

Cerdocyon thous, e do cachorro vinagre, Speothos venaticus. Beatriz de Mello Beisiegel. Etologia. Tese de Doutorado. Universidade de São Paulo.

Berta A (1982). Cerdocyon thous. Mammalian Species 186:1-4.

Di Bitetti MS, Di Blanco YE, Pereira JA, Paviolo A e Pérez IJ (2009). Time partitioning favors the coexistence of sympatric Crab-eating Foxes (Cerdocyon thous) and Pampas foxes (Lycalopex gymnocercus). Journal of Mammalogy 90:479-490.

Di Bitetti MS, Paviolo A e De Angelo C (2006) Density, habitat use and activity patterns of Ocelots (Leopardus pardalis) in the Atlantic Forest of Misiones, Argentina. Journal of Zoology 270:153-163.

Breitenmoser C e Breitenmoser U (2008) The Jaguar in Brazil. Cat News Special Issue 4.

Carbone CJ e Gittleman L (2002) A common rule for the scaling of carnivore density. Science 295:2273-2276.

Castelletti C, Silva JMC, Tabarelli M e Santos AMM (2004) Quanto ainda resta da Caatinga? Uma estimativa preliminar. Pp. 91-100 In: Biodiversidade da Caatinga: áreas e ações prioritárias para a conservação.

Cheida C, Nakano-Oliveira E, Fusco-Costa R, Rocha-Mendes F e Quadros J (2003) Ordem Carnivora. Mamíferos do Brasil.(Reis NR, Peracchi AL, Pedro WA e Lima IP, Eds.). Londrina:242-275.

Chinchilla F (1997) La dieta del Jaguar (Panthera onca), el Puma (Felis concolor) y el Manigordo (Felis pardalis) (Carnivora: Felidae) en el Parque Nacional Corcovado, Costa Rica. Revista De Biologia Tropical 45:1223-1229.

Collier BA, Groce J, Morrison M, Newnam J, Campomizzi A, Farrel S, Mathewson H, 
Snelgrove R, Carrol R e Wilkins R (2012) Predicting patch occupancy in fragmented landscapes at the rangewide scale for an endangered species: an example of an american warbler. Diversity \& Distributions 18:158-167.

Cove M, Jones B, Bossert EA (2012). Use Of Camera Traps To Examine The Mesopredator Release Hypothesis In A Fragmented Midwestern Landscape. The American Midland Naturalist 168:456-465.

Crawshaw PG (1995) comparative ecology of ocelot (felis pardalis) and jaguar (panthera onca) in a protected subtropical forest in brazil and argentina.

Crawshaw, P. e Quigley HB (1989) Notes on ocelot movement and activity in the Pantanal region, Brazil. Biotropica 21:377-379.

Davis ML (2009). Densities, habitat-use, and mesopredator release of the ocelot in Belize. Tese de Doutorado.Virginia Polytechnic Institute and State University.

Davis ML, Kelly MJ e Stauffer DF (2011). Carnivore co-existence and habitat use in the mountain pine ridge forest reserve, Belize. Animal conservation 14:56-65.

Dias DM e Bocchiglieri A (2015). Trophic and spatio-temporal niche of the crab-eating fox, Cerdocyon thous (linnaeus, 1766) (Carnivora: Canidae), in a remnant of the Caatinga in northeastern Brazil. Mammalia 80:281-291.

Dillon A e Kelly MJ (2008). Ocelot home range, overlap and density: comparing radio telemetry with camera trapping. Journal of Zoology 275:391-398.

Elmhagen B e Rushton SP (2007). Trophic control of mesopredators in terrestrial ecosystems: top-down or bottom-up? Ecology Letters 10:197-206.

Emmons L (1988) A field study of ocelots (Felis pardalis) in Peru. Revue d'Ecologie (Terre Vie) 43:133-158.

Emmons L e Feer F (1997) Neotropical rainforest mammals: a field guide. University of Chicago Press.

Emperaire L (1984) A região da Serra da Capivara (sudeste do Piaui) e sua vegetação. Brasil Florestal 60:5-21.

Faria-Corrêa M, Balbueno RA, Vieira EM e Freitas TRO (2009) Activity, habitat use, density, and reproductive biology of the crab-eating fox (Cerdocyon thous) and 
comparison with the pampas fox (Lycalopex gymnocercus) in a restinga area in the southern brazilian Atlantic Forest. Mammalian Biology 74:220-229.

Foster VC, Sarmento P, Sollmann R, Torres N, Jacomo ATA, Negrões N, Fosneca C e Silveira L (2013) Jaguar and puma activity patterns and predator-prey interactions in four brazilian biomes. Biotropica 45:373-379.

FUMDHAM (Fundação Museu do Homem Americano) (1994) Parque Nacional da Serra da Capivara. Alinea publicações editora, Teresina, Piauí.

Fusco-Costa R, Ingberman B, Couto HTZ, Nakano-oliveira E e Monteiro-Filho ELA (2010) Population density of a coastal island population of the ocelot in Atlantic Forest, southeastern Brazil. Mammalian Biology 75:358-362.

Garda EC (1996) Atlas do meio ambiente do Brasil. Editora Terra Viva, Brasília.

Garla RC, Setz EZF e Gobbi N (2001) Jaguar (Panthera onca) food habits in atlantic rain forest of southeastern Brazil. Biotropica 33:691-696.

Gatti A, Bianchi R, Rosa CRX e Mendes SL (2006). Diet of two sympatric carnivores, Cerdocyon thous and Procyon cancrivorus, in a restinga area of espirito santo state, Brazil. Journal of tropical ecology 22:227-230

Gehrt S e Clark WR (2003) Raccoons, coyotes, and reflections on the mesopredator release hypothesis. Wildlife Society Bulletin 31:836-842.

Haines A (2006) Is there competition between sympatric jaguar Panthera onca and puma Puma concolor. Acta Zoologica Sinica 52:1142-1147

Haines A, Janecka JE, Tewes ME, Grassman Jr. LI e Morton P (2006) The importance of private lands for ocelot Leopardus pardalis conservation in the united states. Oryx 40:90.

Herfindal I, Linnell JDC, Odden J, Nilsen EB e Andersen R (2005) Prey density, environmental productivity and home-range size in the eurasian lynx (Lynx lynx). Journal of Zoology 265:63-71.

Hutchinson G (1957) Cold Spring Harbor Symposium on Quantitative Biology. Concluding Remarks 22:415-427.

Jacomo ATA, Silveira L e Diniz-filho JAF (2004). Niche separation between the maned wolf 
(Chrysocyon brachyurus), the crab-eating fox (Dusicyon thous) and the hoary fox (Dusicyon vetulus) in central Brazil. Journal of Zoology 262:99-106.

Juarez KM e Marinho-filho J (2002) Diet, habitat use, and home ranges of sympatric canids in central Brazil. Journal of Mammalogy 83:925-933.

Kelly MJ, Noss AJ, Di Bitetti MS, Maffei L, Arispe RL, Paviolo A, De Angelo C e Di Blanco YE (2008) Estimating puma densities from camera trapping across three study sites: Bolivia, Argentina, and Belize. Journal of Mammalogy 89:408-418.

Kerr JT (1997) Species richness, endemism, and the choice of areas for conservation. Conservation Biology 11:1094-1100.

Kéry M (2011) Towards the modelling of true species distributions. Journal of Biogeography 38:617-618.

Kolowski J e Alonso A (2010) Density and activity patterns of ocelots (Leopardus pardalis) in northern Peru and the impact of oil exploration activities. Biological Conservation 143:917-925.

Krebs CJ (1972) Ecology. New Harper Press, New York.

Laack L (1991) Ecology of the ocelot (Felis pardalis) in south Texas. Tese de Doutorado. Texas University.

Lantschner MV, Rusch V e Hayes JP (2012) Habitat use by carnivores at different spatial scales in a plantation forest landscape in Patagonia, Argentina. Forest Ecology and Management 269:271-278.

Leal IR, Tabarelli M e Silva JMC (2008) Ecologia e conservação da Caatinga. 3 Ed. Universidade Federal de Pernambuco.

Lemos J (2004) Composição florística do Parque Nacional da Serra da Capivara, Piauí, Brasil. Rodriguesia:55-66.

Loreau M, e Holt RD (2004) Spatial flows and the regulation of ecosystems. The american naturalist 163:606-615.

Ludlow M e Sunquist M (1987) Ecology and behavior of ocelots in Venezuela. National Geographic Research 3:447-461.

Mackenzie DJ, Nichols D, Royle JA, Pollock KH, Bailey L e Hines JE (2006) Occupancy 
estimation and modeling: inferring patterns and dynamics of species occurrence. Academic press.

Maffei L e Noss AJ (2008) How small is too small? Camera trap survey areas and density estimates for ocelots in the bolivian Chaco. Biotropica 40:71-75.

Maffei L e Taber A (2003) Área de acción, actividad y uso de hábitat del zorro patas negras, Cerdocyon thous, en un bosque seco. Mastozoología Neotropical 10:154-160.

Marinho PHD (2015) Gato-do-mato-pequeno (Leopardus tigrinus) na Caatinga: ocupação e padrão de atividade de um felídeo ameaçado e pouco conhecido na floresta tropical seca do nordeste do brasil. Dissertação de Mestrado. Universidade Federal do Rio Grande do Norte.

Massara RL, Paschoal AM, Doherty PF, Hirsch A e Chiarello AG (2015) Ocelot population status in protected brazilian Atlantic Forest. Plos One 10: e0141333

Mccann KS, Rasmussen JB e Umbanhowar J (2005) The dynamics of spatially coupled food webs. Ecology Letters 8:513-523.

Mendonça LET, Souto CM, Andrelino LL, Souto WMS, Vieira WLS e Alves RNN (2011) Conflitos entre pessoas e animais silvestres no semiárido paraibano e suas implicações para conservação. Sitientibus série ciências biológicas 11:185-199.

Michalski F, Crawshaw PG, Oliveira TG e Fabián ME (2006) Notes on home range and habitat use of three small carnivore species in a disturbed vegetation mosaic of southeastern. Mammalia 70:52-57.

Morrison JC, Sechrest W, Dinerstein E, Wilcove DS e Lamoreux JF (2007) Persistence of large mammal faunas as indicators of global human impacts. Journal of Mammalogy 88:1363-1380.

Murray JL e Gardner GL (1997) Leopardus pardalis. Mammalian Species:1-10.

Nakano-oliveira E. 2002. Ecologia alimentar e área de vida de carnívoros da Floresta Nacional de Ipanema, Iperó, SP (Carnivora: Mammalia). Dissertação de Mestrado. Unicamp.

Nakano-Oliveira E (2006) Ecologia e conservação de mamíferos carnívoros de Mata Atlântica na região do complexo estuarino lagunar de Cananéia, estado de São Paulo. 
Tese de Doutorado. Unicamp.

Nascimento F (2010). Revisao taxonomica do gênero Leopardus gray, 1842 (Carnivora, Felidae. Tese de Doutorado. USP.

Nilsen EB, Herfindal I e Linnell JDC (2005) Can intra-specific variation in carnivore homerange size be explained using remote-sensing estimates of environmental productivity? Ecoscience 12:68-75.

Nimer E (1972) Climatologia da região nordeste do Brasil. Revista Brasileira de Geografia $34: 3-51$.

Novack AJ, Main MB, Sunquist ME e Labisky RF (2005) Foraging ecology of jaguar (Panthera onca) and puma (Puma concolor) in hunted and non-hunted sites within the Maya Biosphere Reserve, Guatemala. Journal of Zoology 267:167.

Oliveira GP. (2012) Ecologia da jaguatirica Leopardus pardalis (Linnaeus, 1758), na Caatinga do Piauí. Dissertação de Mestrado. Universidade de Brasília.

Oliveira TG e Cassaro K (2005) Guia de campo dos felinos do Brasil. Instituto Prócarnívoros.

Oliveira TG (2006) Research in terrestrial carnivora from Brazil: current knowledge and priorities for the new millennium. In Manejo e conservação de carnívoros tropicais (Morato RG, Rodrigues FHG, Eizirik E, Mangini PR, Azevedo FCC e Marinho Filho J, orgs.). Ibama, Brasilia.

Oliveira-santos LGR, Graipel ME, Tortato MA, Zucco CA, Cáceres NC e Goulart FVB (2012) Abundance changes and activity flexibility of the oncilla, Leopardus tigrinus (Carnivora: Felidae), appear to reflect avoidance of conflict. Zoologia (Curitiba) 29:115-120.

Ordeñana MA, Crroks KR, Boydston EE, Fisher RN, Lyren LM, Siudyla S, Haas CD, Harris S, Hathaway SA, Turshak GM, Miles AK e Vuren DHV (2010) Effects of urbanization on carnivore species distribution and richness effects of urbanization on carnivore species distribution and richness. Journal of Mammalogy 91:1322-1331.

Palomares F e Caro TM (1999) Interspecific killing among mammalian carnivores. American Naturalist 153:492-508. 
Pellerin J (1991) Aspectos físicos (in: Plano de manejo: Parque Nacional da Serra da Capivara). Ibama, Brasília.

Pereira JES (2009) Dieta de tres especies simpatricas de felideos - Leopardus pardalis, Leopardus tigrinus e Puma yagouaroundi (Carnivora: Felidae) - em floresta ombrofila mista e campos gerais, Paraná, sul do Brasil. Dissertação de Mestrado. UFPR.

Petracca LS, Ramirez-Bravo OE e Hernandez-Santin L (2013) Occupancy estimation of jaguar Panthera onca to assess the value of east-central Mexico as a jaguar corridor. Oryx 48:1-8.

Pia M, Renison VD, Mangeaud A, De Angelo C e Haro JG (2013) Occurrence of top carnivores in relation to land protection status, human settlements and rock outcrops in the high mountains of central Argentina. Journal of Arid Environments 91:31-37.

Prado DE (2008) As Caatingas da America do Sul. (in: Ecologia e conservação da Caatinga (Leal IR, Tabarelli M e Silva JMC - Orgs.). Ed. Universitária da UFPE, recife.

Prugh LR, Stoner CJ, Epps CW, Bean WT, Ripple WJ, Laliberte AS e Brashares JS (2009) The rise of the mesopredator. Bioscience 59:779-791.

Redford KH e Eisenberg JF (1992) Mammals of the Neotropics, volume 2: the southern cone: Chile, Argentina, Uruguay, Paraguay. University of Chicago Press.

Rio CM, Dugelby B, Foreman D, Miller B, Noss R e Phillips M (2001) The importance of large carnivores to healthy ecosystems. Endangered Species Update 18:202.

Ritchie EG e Johnson CN (2009) Predator interactions, mesopredator release and biodiversity conservation. Ecology Letters 12:982-98.

Roemer GW, Gompper ME e Valkenburgh BV (2009) The ecological role of the mammalian mesocarnivore. Bioscience 59:165-173.

Romero-Muñoz A, Maffei L, Cuéllar E e Noss AJ (2010) Temporal separation between jaguar and puma in the dry forests of southern Bolivia. Journal of Tropical Ecology 26:303.

Sampaio EVSB (1995) Overview of the brazilian Caatinga (in: Seasonally dry tropical forests (Bullock SH, Mooney HH e Medina E - Orgs.). Cambridge University Press, Cambridge. 
Schuette P, Wagner AP, Wagner ME e Creel S (2013) Occupancy patterns and niche partitioning within a diverse carnivore community exposed to anthropogenic pressures. Biological Conservation 158:301-312.

Silveira L, Jacomo ATA, Astete S, Sollmann R, Torres NM, Furtado MM e Marinho Filho J (2009) Density of the near threatened jaguar Panthera onca in the Caatinga of northeastern Brazil. Oryx 44:104.

Silver SC, Ostro LET, Marsh LK, Maffei L, Noss AJ, Kelly MJ, Wallace RB, Gomez H e Ayala G (2004). The use of camera traps for estimating jaguar Panthera onca abundance and density using capture/recapture analysis. Oryx 38:148-154.

Sollmann R, Furtado MM, Hofer H, Jácomo ATA, Tôrres NM e Silveira L (2012) Using occupancy models to investigate space partitioning between two sympatric large predators, the jaguar and puma in central brazil. Mammalian Biology 77:41-46.

Sunquist M (1992) The ecology of the ocelot: the importance of incorporating life history traits into conservation plans. Memorias del Simposio Organizado por FUDECI. Caracas.

Tabarelli M, Silva JMC, Leal I e Silva J (2004) Áreas e ações prioritárias para a conservação da biodiversidade da Caatinga (in: Ecologia e conservação da Caatinga (Leal IR, Tabarelli M e Silva JMC - Orgs.). Ed. Universitária da UFPE, recife.

Taber A, Novaro A, Neris N e Colman F (1997) The food habits of sympatric jaguar and puma in the paraguayan Chaco. Biotropica 29:204-213.

Terborgh J, Estes JA, Paquet P, Ralls K, Boyd-Herger D, Miller BJ, Noss RF (1999) The role of top carnivores in regulating terrestrial ecosystems. Wild earth 9:42-56.

Tortato FR, Tortato MA e Koehler E (2013) Poultry predation by Leopardus wiedii and Leopardus tigrinus (Carnivora: Felidae ) in southern Brazil. Revista Latinoamericana de Conservacíon 3:51-53.

Tortato MA (2009) Disponibilidade e uso de presas na dieta do gato-do-mato-pequeno, Leopardus tigrinus (schreber, 1775) em área de restinga no sul do Brasil. Dissertação de Mestrado. UFPR.

Trigo TC, Tirelli FP, Machado LF, Peters FB, Indrusiak CB, Mazim FD, Sana D, Eizirik E, de Freitas TR (2013) Geographic distribution and food habits of Leopardus tigrinus and 
L. Geoffroyi (Carnivora: Felidae) at their geographic contact zone in southern Brazil. Studies on Neotropical Fauna and Environment 48:56-67.

Trolle M e Kéry M (2003) Estimation of ocelot density in the pantanal using capturerecapture analysis of camera-trapping data. Journal of Mammalogy 84:607-614.

Trovati RG, Brito BA e Duarte JMB (2007) Área de uso e utilizaçao de habitat de cachorrodo-mato (Cerdocyon thous Linnaeus, 1766) no cerrado da região central do tocantins, brasil. Mastozoología Neotropical 14:61-68.

Verner J, Morrison M e Ralph C (1986). Wildlife 2000. Modeling habitat relationships of terrestrial vertebrates. University of Wisconsin Press.

de Villa Meza, Meyer EM e González CAL (2002) Ocelot (Leopardus pardalis) food habits in a tropical deciduous forest of Jalisco, Mexico. The american midland naturalist 148:146-154.

Wang E. 2002. Diets of ocelots (Leopardus pardalis), margays (L. Wiedii), and oncillas (L. Tigrinus) in the Atlantic Rainforest in southeast Brazil. Studies on Neotropical Fauna and Environment 37:207-212. 


\section{Capítulo 1 - VARIAÇÃO POPULACIONAL DE TRÊS ESPÉCIES DE MESOCARNÍVOROS NA CAATINGA DO PIAUÍ, BRASIL.}

\section{Introdução}

A identificação da variação populacional de uma espécie é de grande importância para entender as diferentes dinâmicas que uma população pode apresentar em determinada região (Chandler e Andrew Royle 2011). Com esta identificação é possível inferir se as populações estão estáveis ou em alteração, seja em declínio ou em aumento, ajudando a prever e a entender como alterações ambientais podem afetar as diferentes espécies nos ambientes em que elas ocorrem (Dénes et al 2015). Desta forma, a estimativa populacional consiste na ferramenta primária, capaz de auxiliar nas definições de planos de manejo para populações em ambientes naturais (Mourão e Magnusson 1997)

Entretanto, em populações naturais, a realização de um censo (i.e. a contagem de todos os indivíduos) é quase sempre impossível (Dénes et al 2015). Esta dificuldade é mais acentuada em estudos que amostram espécies de mamíferos carnívoros. Estas espécies geralmente possuem comportamento ilusivo e críptico, além de uma atividade concentrada em períodos crepusculares e/ou noturnos (Karanth et al 2006; Reppucci et al 2011). Como resultado, vários pesquisadores utilizaram de medidas e índices que poderiam ser consideradas análogas ao tamanho populacional da espécie estudada (Dénes et al 2015). Entre estas medidas, o índice de abundância relativa - RAI (do inglês Relative Abundance Index), que considera, por exemplo, o número de indivíduos detectados por unidade amostral (Buckland et al 2008; O’Brien e Kinnaird 2011) - foi amplamente empregado. Estes índices de abundância relativa, no entanto, apresentam resultados controversos. Sua maior falha é considerar que nossa habilidade de detectar os animais no espaço ou no tempo se mantém constante (Sollmann et al 2013), ou seja, estes índices ignoram a probabilidade de detecção imperfeita que temos ao registrar espécies 
em ambientes naturais (Dorazio 2014). O problema que surge com a utilização destes índices para realizar comparações entre locais ou períodos, por exemplo, é não existir maneira de verificar, inequivocamente, se as diferenças observadas são oriundas de variações reais na abundância populacional, ou se são resultado de diferenças na probabilidade de detecção (Archaux et al 2012; Sollmann et al 2013). Em alguns casos, todavia, as características do estudo e/ou espécie alvo permitem a utilização de métodos mais precisos para se estimar a abundância populacional de uma espécie.

A condução de estudos que ativamente capturam o animal, para que seja marcado e posteriormente solto, tornam possível a aplicação de análises de captura-recaptura (CR) que conseguem estimar a probabilidade de um indivíduo ser capturado de acordo com o número de recapturas no total da amostragem (Chao e Huggins 2005). A partir desta premissa básica, modelos de captura-recaptura foram expandidos, passando a incluir não apenas uma estimativa da probabilidade de captura, mas também, variações desta (Otis et al 1978). Porém, mesmo com o desenvolvimento e aperfeiçoamento destas ferramentas de análises, a exigência de efetivamente capturar o animal estudado limitou - em razão de logística, dinheiro e características dos animais - as espécies que poderiam ser estudadas. Felizmente, o advento de armadilhas fotográficas avançou consideravelmente a capacidade de estudar um maior espectro de espécies (Kays e Slauson 2008).

Armadilhas fotográficas são ferramentas de coleta de dados não invasivas e podem ser aplicadas em uma área extensa com um esforço relativamente baixo (Silveira et al 2003). Além de poderem ser aplicadas em uma ampla gama de estudos sobre variados aspectos da vida selvagem, tais como o comportamento e distribuição, as armadilhas fotográficas podem ser combinadas com as análises de captura-recaptura para produzir resultados satisfatórios de abundância e densidade populacional em espécies que possuem padrões característicos de 
pelagem ou alguma outra distinção marcante que permita a individualização dos registros (Karanth 1995). Esta metodologia foi utilizada em diversos contextos e diferentes espécies, como, por exemplo, hienas (Singh et al 2010), leopardos-da-neve (Jackson et al 2006) e onçaspardas (Kelly et al 2008). E foi aplicada, principalmente, em estudos com tigres (Karanth e Nichols 1998; Karanth et al 2006; Sharma et al 2010) e onças-pintadas (Silver et al 2004; Soisalo e Cavalcanti 2006; Silveira et al 2009).

Muitos estudos têm se voltado para estimativa dos parâmetros populacionais de mesocarnívoros como seu objetivo principal (Cuellar et al 2006; Reppucci et al 2011; Mohamed et al 2013). Nestes trabalhos a jaguatirica foi a espécie mais estudada (Trolle e Kéry 2003; Dillon 2005; Di Bitetti et al 2006; Martínez-Hernández et al 2015), devido a sua distribuição simpátrica com a onça-pintada, sendo assim frequentemente registrada com este carnívoro maior (Maffei et al 2005). Nestes estudos, esta espécie apresenta ampla variação em sua abundância e densidade, dependendo dos métodos aplicados e da região estudada (Dillon e Kelly 2007; Kolowski e Alonso 2010; Fusco-Costa et al 2010). No entanto, é possível inferir alguns padrões sobre a variação em sua abundância em relação ao local de estudo, tanto em escala local como regional (Di Bitetti et al 2008). Localmente, as populações desta espécie parecem responder principalmente à influência humana, possuindo uma população menor em locais com maiores pressões antrópicas, como caça, corte de árvores e presença de animais domésticos (Di Bitetti et al 2008). Porém, não foram separados os efeitos distintos da presença antrópica na abundância da jaguatirica, ou seja, não foi possível afirmar qual efeito (por exemplo, a caça ou a presença de cães) possui maior importância local para as populações da jaguatirica. Em uma escala regional, a jaguatirica apresenta populações maiores em ambientes com cobertura vegetal densa (Emmons et al 1989; Sunquist e Sunquist 2002) e também segue os padrões de precipitação, possuindo maior abundância em regiões com maior abundância de chuva (Maffei et al 2005; Di Bitetti et al 2008). Esta tendência também foi detectada em 
estudos com outras espécies de felinos de médio porte em outras regiões (Herfindal et al 2005; Nilsen et al 2005).

Estimativas de abundância de outras espécies de mesocarnívoros como o lobinho são raras, e necessitavam de um real evento de captura-marcação-recaptura para poder produzir resultados precisos (Faria-Corrêa et al. 2009), o que limita consideravelmente a realização de estudos com estas espécies, gerando assim uma enorme lacuna no conhecimento deste grupo de animais. Entretanto, recentes desenvolvimentos em análises de captura-recaptura conseguem estimar, de forma relativamente precisa, a abundância de espécies com a utilização de dados de presença-ausência, ou seja, dados que não necessitam de identificação individual de cada registro, sendo aplicados em distintos estudos com diferentes espécies, como aves e mamíferos (Royle e Nichols 2003; Chandler e Andrew Royle 2013; Ramsey et al 2015). Estes métodos podem ser dividos em dois grupos, dependendo do delineamento da amostragem. Se os pontos de coleta forem afastados o suficiente uns dos outros, evitando a autocorrelação espacial entre os repetidos registros, modelos hieráquicos conhecidos como Modelos $R N$ (Royle e Nichols 2003) apresentam resultados satisfatórios de abundância. Por outro lado, se a disposição das estações de coletas de dados forem muito próximas, foram desenvolvidos recentemente modelos que se utilizam desta correlação para estimar valores de abundância (Chandler e Andrew Royle 2013). Desta forma, é possível ampliar o espectro de espécies que podem ter sua abundância auferida utilizando estas ferramentas de análise, de forma pratica e com baixo custo, através da utilização de armadilhas fotográficas.

Tendo em vista esse breve histórico sobre estimativas de abundância, o presente estudo possui o objetivo de verificar a variação populacional de três espécies de mesocarnívoros no Parque Nacional da Serra da Capivara, localizado na Caatinga do Piauí: a jaguatirica, o lobinho e o gato-do-mato. Para tanto, será feita uma estimativa, através de modelos que não necessitam 
da individualização de cada registro, em dois anos de amostragem consecutivos. Com a exceção da jaguatirica (Oliveira 2012), não existem dados sobre as populações de mesocarnívoros na Caatinga, sendo esta uma deficiência no conhecimento destas espécies em uma área limítrofe de suas distribuições. De tal modo, a amostragem das populações destas espécies em períodos distintos poderá indicar o estado das populações destes predadores estável, em aumento ou em declínio - no Parque Nacional da Serra da Capivara e em regiões similares na Caatinga. Conjuntamente, será realizada a análise da população da jaguatirica em 2009 através de modelos de captura e recaptura espacialmente explícitos (SECR), o que requerer a identificação de cada registro. Esta estimativa da densidade da jaguatirica foi realizada anteriormente, em minha pesquisa de mestrado. Contudo, os métodos analíticos utilizados na época foram superados, devido aos resultados subjetivos que produziam. Desta forma, a análise da densidade da jaguatirica em 2009 será refeita com o primeiro objetivo de estimar valores mais próximos da realidade. Em seguida, este valor de densidade estimado a partir de métodos mais recentes será utilizado como medida de comparação e referência para as análises realizadas através de métodos analíticos que não necessitam a identificação individual, aplicados às três espécies aqui amostradas nos dois anos de coleta. Ao final do capítulo discuto algumas implicações da utilização dos diferentes métodos para auferir a densidade estimada, apontando para os avanços em precisão e refinamento dos métodos mais recentes, quando contrastados com os anteriores.

\section{Material e métodos}




\section{$\underline{\text { Coleta de dados }}{ }^{8}$}

Entre os meses de setembro de 2009 e janeiro de 2010, foram instaladas 58 estações de captura em trilhas e estradas do Parque Nacional da Serra da Capivara (Figura 1-1), espaçadas por uma distância que variou de 2 a $3 \mathrm{~km}$ uma das outras. A amostragem foi repetida nos mesmos meses do ano seguinte, ou seja, entre setembro de 2010 e janeiro de 2011 , com as câmeras instaladas nos mesmos locais. As câmeras foram dispostas nestes locais específicos devido a necessidade de se aumentar a detecção das espécies alvo (O’Brien e Kinnaird 2011), visto que espécies de carnívoros, incluindo os mesocarnívoros, possuem mais registros em estradas do que em áreas florestais mais fechadas (Trolle e Kéry 2003; Silver et al 2004). Esta disposição, portanto, maximizou a chance de se obter registros destes animais. Em adição a esta necessidade de se aumentar a probabilidade registros destas espécies de mesocarnívoros, as características da região amostrada, com vegetação fechada e repleta de espinhos, bem como a presença de inúmeras formações rochosas, impossibilitaram que as armadilhas fossem instaladas em locais que não fossem as estradas (Oliveira 2012).

\footnotetext{
${ }^{8}$ Os dados coletados em 2009 são os mesmos utilizados em minha pesquisa de mestrado. Embora as análises realizadas aqui incorporem uma nova gama de métodos, além de incluir duas novas espécies de mesocarnívoros e a adição de uma amostragem adicional em 2010, a forma de coleta de dados foi essencialmente a mesma. Portanto, a descrição de material e métodos realizada aqui retoma e amplia a discussão já feita na dissertação (Oliveira, 2012).
} 


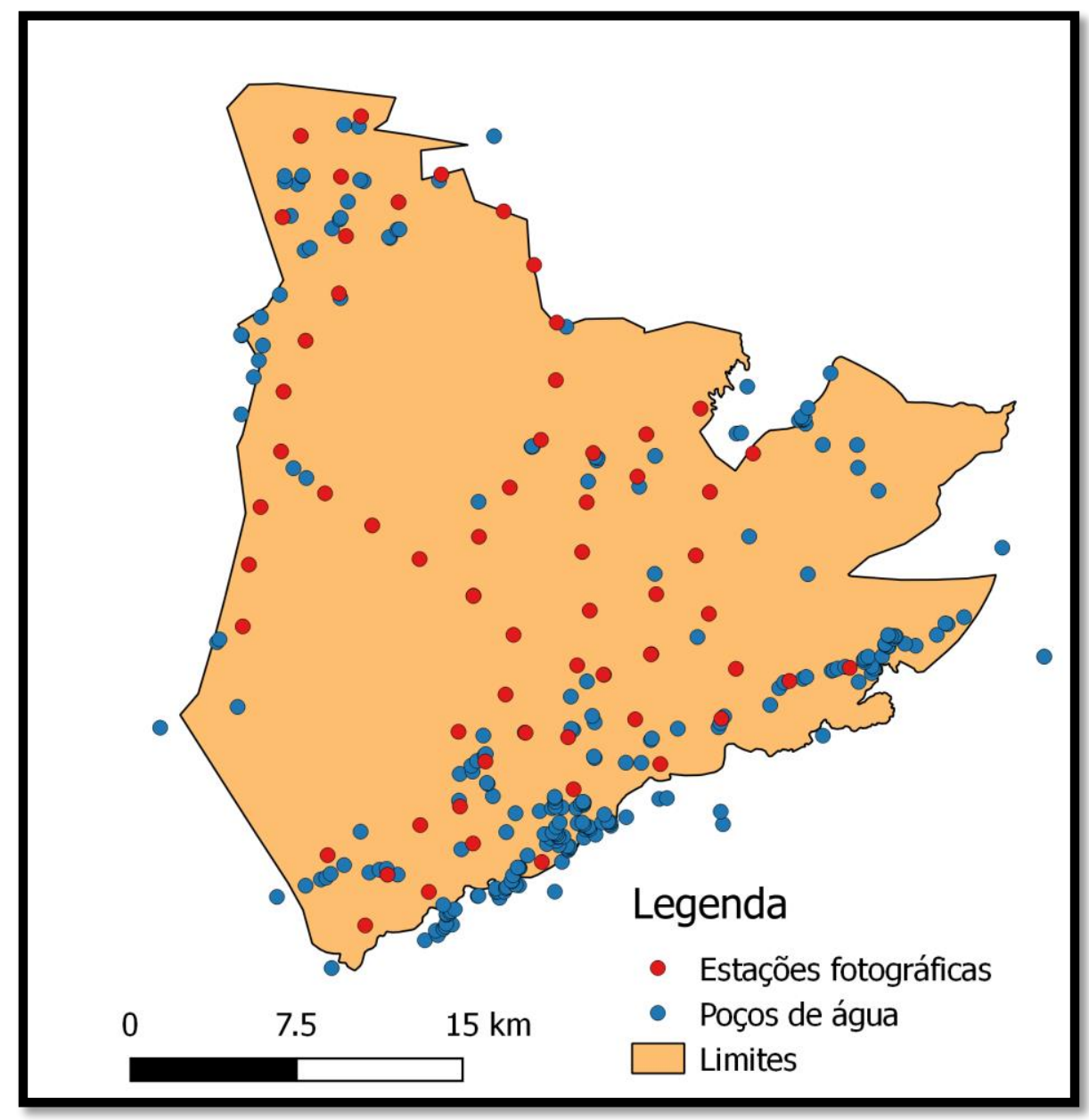

Figura 1-1: Parque Nacional da Serra da Capivara, com a localização das armadilhas fotográficas.

Cada estação de captura é constituída de duas armadilhas fotográficas instaladas uma em frente à outra (Figura 1-2). Esta disposição é realizada com o intuito de se obter a fotografia de ambos os lados de um mesmo animal, facilitando, assim a sua posterior identificação através de subsequentes registros (Oliveira 2012). As armadilhas fotográficas utilizadas foram da marca CamTrakker (CamTrack South Inc., Watkinsville, USA), armadilhas passivas, acionadas por calor e movimento. Devido às informações obtidas em uma amostragem prévia, realizada em 2007, no qual foi constatado que as espécies de carnívoros que ocorrem no PNSC são extremamente noturnas, as armadilhas foram programadas para operar entre as $1700 \mathrm{~h}$ e 0600h, com um período mínimo de 5 minutos entre fotografias consecutivas para evitar que o mesmo animal fosse fotografado repetidamente no mesmo horário, poupando filmes e bateria. 


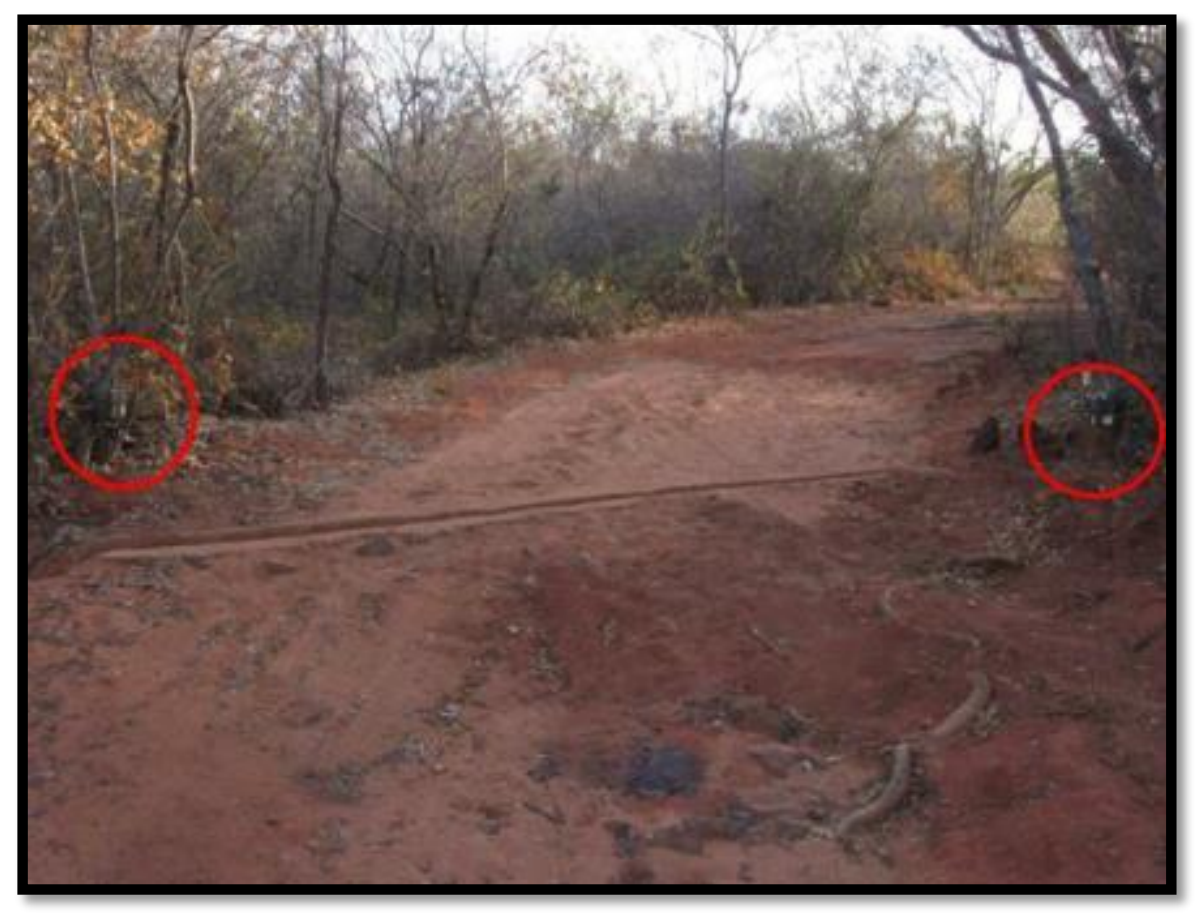

Figura 1-2: Estação de captura, composta por duas armadilhas fotográficas, em destaque (extraído de Oliveira 2012)

\section{$\underline{\text { Análise dos dados }}$}

A análise dos dados foi dividida em duas seções. Primeiramente foram implementados modelos analíticos, que não necessitam da identificação dos indivíduos, para a estimativa de abundância das três espécies: A jaguatirica, o lobinho e o gato-do-mato nos dois anos de amostragem. Essa técnica utiliza modelos hierárquicos desenvolvidos para estudos com múltiplas visitas, também conhecidos como modelos $R N$ (Royle e Nichols 2003; Royle 2004). O modelo aplicado para a estimativa de abundância parte do pressuposto que cada estação de registro possui uma probabilidade de detecção $\pi^{9}$, isto é, a probabilidade de detectar ao menos um indivíduo no local $i$. Se assumirmos que a abundância de uma espécie varia entre os diferentes pontos de amostragem, podemos esperar que a variação na detecção $\pi$ seja resultado

\footnotetext{
${ }^{9}$ Esta probabilidade de detecção ao nível de local é diferente da probabilidade $p$ de detecção ao nível de indivíduo. Isto é, a probabilidade $\pi$ é a probabilidade de, em algum local específico, ser detectado uma espécie, enquanto que a probabilidade $p$ é a probabilidade de um indivíduo ser detectada.
} 
da variação desta abundância, pois locais com maior abundância também apresentariam mais detecções (Dénes et al 2015). A existência desta variação na probabilidade de se detectar uma espécie em um determinado local levou ao desenvolvimento de modelos que estimam a abundância através de observações binárias de detecção e não-detecção - os modelos RN (Royle e Nichols 2003). Estes modelos assumem que a detecção específica de cada local é dependente da abundância no mesmo local, ou seja, o modelo deriva a distribuição da abundância local através da heterogeneidade da probabilidade $\pi$ entre os pontos amostrados.

Como visto, os modelos $R N$ estimam abundância específica de cada local amostrado. $\mathrm{Na}$ utilização de armadilhas fotográficas, no entanto, é complicado definir este local de amostragem, ou seja, definir qual é a área de abrangência de cada estação de captura. Assim, não é possível extrapolar os valores estimados em cada estação de captura para todo o parque, ou mesmo realizar alguma estimativa de densidade real. Assim sendo, os valores estimados de abundância com estes modelos devem ser considerados como um tipo de abundância relativa ou, no caso de animais cuja área de vida seja compatível com a distribuição dos pontos de coleta, uma abundância mínima. No entanto, ao contrário de índices simples de RAI, a estimativa aqui empregada considera a probabilidade de detecção, produzindo resultados mais confiáveis. Assim, com a verificação da diferença nas estimativas entre os dois anos amostrados, será possível identificar a variação populacional destas espécies durante o estudo. Estes modelos foram aplicados no software R 3.0.1, através do pacote "unmarked" (Fiske e Chandler 2011).

Em segundo lugar foi realizada a estimativa da abundância da jaguatirica no primeiro ano da amostragem (2009) através de métodos SECR - Spatially-explicit capture-recapture (Borchers and Efford 2008), que necessitam a identificação individual de cada registro. Estes modelos estimam a abundância $(\widehat{N})$ assumindo que existe uma relação da probabilidade de 
detecção de um animal com a distância $(d)$ do centro de atividade de cada indivíduo. Este modelo segue uma função com dois parâmetros: $g(d)$, no qual $g_{0}$ significa a probabilidade de detecção quando $d=0$, e a escala espacial $\sigma$, que está relacionada com o tamanho da área de vida da espécie (O’Brien e Kinnaird 2011). Nesta análise foram realizados seis modelos que consideram diferentes fontes de variação na probabilidade de detecção: (1) nenhuma variação na detecção $[g O(.) \sigma()],.(2)$ variação na detecção após o primeiro registro $[g O(b) \sigma()$.$] , (3)$ variação com o tempo $[g O(T) \sigma()],.(4)$ diferenças entre animais machos e fêmeas $[g O(\operatorname{sex}) \sigma()$.$] ,$ (5) o efeito conjunto entre tempo e sexo $[g O(\operatorname{sex}+T) \sigma()$.$] e (6) entre o comportamento e tempo$ $[g O(b+T) \sigma()$.

Para isso, todos os registros de jaguatirica obtidos foram individualizados, sendo considerados apenas os animais que apresentaram registros de ambos os lados, para evitar que um mesmo animal fosse considerado como mais de um indivíduo. Após esta identificação, foi construída uma matriz de capturas fotográficas por indivíduo. Esta matriz consiste em uma sequência de " $0 \mathrm{~s}$ " e " $1 \mathrm{~s}$ ", no qual $\mathrm{y}_{i j k}=1$, significa que o indivíduo $i$ foi registrado no ponto de captura $j$ durante o evento $k$, e $\mathrm{y}_{i j k}=0$, que ele não foi. Esta análise foi implementada no programa R 3.0.1 através do pacote "secr" (Efford 2011). Os modelos foram selecionados através do Critério de Informação de Akaike, ajustado para amostras pequenas (AICc). Esta análise, que considera o fator espacial na distribuição dos pontos de coleta, efetivamente estima a densidade real da espécie alvo, e não um índice, como foi realizado na análise anterior. Desta forma, esta análise servirá como parâmetro para verificar a precisão das análises através dos modelos $R N$ realizados na verificação da variação populacional entre os dois anos de amostragem.

\section{Resultados}


Foram obtidos 328 registros de jaguatirica, 1012 de lobinho e 112 de gato-do-mato na primeira amostragem. No segundo ano de amostragem, as jaguatiricas apresentaram 363 registros, os lobinhos 452 e o gato-do-mato 109. As duas espécies de felinos apresentaram um número de registros similar entre os anos, porém, o lobinho apresentou uma diminuição de quase a metade no número de registros. Na amostragem da jaguatirica de 2009 alguns indivíduos não apresentaram registros em ambos os lados do animal, o que não permitiu a construção de uma matriz de captura confiável. Assim, dos 328 registros de jaguatirica nesta amostragem, foram utilizados 316 , nos quais foram identificados 51 indivíduos distintos. Para as análises através dos modelos $R N$, todos os registros foram considerados.

A análise SECR da jaguatirica em 2009, e a posterior seleção de modelos através do AICc, selecionou o modelo [ $g O(\operatorname{sex}) \sigma()$.$] , variação da probabilidade de detecção entre os sexos$ do animal (Tabela 01). Este modelo resultou em uma densidade de indivíduos de $5.65 \pm$ 0.46/100 $\mathrm{km}^{2}$, se considerarmos a área da Serra da Capivara, $1.291 \mathrm{~km}^{2}$. Através deste valor podemos estabelecer uma abundância relativa de 73 indivíduos de jaguatirica no Parque, durante a amostragem de 2009. Como medida de comparação interna entre os diferentes métodos, a análise da abundância relativa da jaguatirica em 2009, através dos modelos RN, resultou em um padrão de abundância muito similar. $\mathrm{O}$ valor obtido de abundância pontual $(R N)$ foi de 1.36 indivíduos por estação de captura. Se multiplicado pelo número de armadilhas, gera um índice de abundância de 78 jaguatiricas. Este número, relacionado com a área do Parque, sugere uma densidade de 6,04 indivíduos $/ 100 \mathrm{~km}^{2}$ (Tabela 02). É importante notar, mais uma vez, que não se deve confundir estes valores obtidos de abundância e densidade relativa como valores reais desta espécie no Parque. Estas estimativas são um índice, que consideram a detectabilidade imperfeita, no qual é possível realizar a comparação entre diferentes amostragens para a mesma espécie no mesmo local. 
Tabela 1-1: Resultado da seleção de modelos para a estimativa de abundância da Jaguatirica atravéz do método SECR.

\begin{tabular}{lccc}
\hline Model & AICc & $\Delta$ AICc & AIC weight \\
\hline$[\mathrm{g}(\operatorname{sex}) \sigma()]$. & 1998.5 & 0 & 0.67 \\
{$[\mathrm{~g}(\operatorname{sex}+\mathrm{T}) \sigma()]$.} & 2000.1 & 1.56 & 0.3 \\
{$[\mathrm{~g}(\mathrm{~b}) \sigma()]$.} & 2005.7 & 7.24 & 0.01 \\
{$[\mathrm{~g}(\mathrm{~b}+\mathrm{T}) \sigma()]$.} & 2008.5 & 10.06 & 0 \\
{$[\mathrm{~g}(.) \sigma()]$.} & 2012.1 & 13.64 & 0 \\
\hline
\end{tabular}

Assim sendo, foi seguida a análise através dos modelos $R N$ para a jaguatirica em 2010 e para as outras duas espécies de mesocarnívoros. Durante a segunda amostragem, a jaguatirica apresentou a abundância relativa de 52,78 indivíduos, o que sugere uma densidade de 4,06 indivíduos $/ 100 \mathrm{~km}^{2}$. O lobinho apresentou uma abundância de 90.48 indivíduos no primeiro ano de amostragem e de 96,28 no segundo ano. Estes valores se traduzem em uma densidade de 6,96 e de 7,40 indivíduos $/ 100 \mathrm{~km}^{2}$, respectivamente (Tabela 02). Já o gato-do-mato apresentou valores mais baixos do que ambas as espécies maiores: Abundância de 42,34 indivíduos em 2009, e de 33,06 em 2010. Valores estes que significam uma densidade de 3,25 e de 2,54 indivíduos $/ 100 \mathrm{~km}^{2}$ na primeira e na segunda amostragem (Tabela 02).

Tabela 02: Resultados da estimativa de abundância obtida através dos modelos $R N$, para as três espécies nos dois anos de amostragem

\begin{tabular}{lccc}
\hline \multicolumn{4}{c}{ Amostragem 2009} \\
Espécie & Abundância $(\mathrm{sd})$ & $\mathrm{IC}(95 \%)$ & Densidade $/ 100 \mathrm{~km}^{2}(\mathrm{sd})$ \\
\hline Jaguatirica & $78.88(9.28)$ & $69-88$ & $6.07(0.71)$ \\
Lobinho & $90.48(7.54)$ & $82-98$ & $6.96(0.58)$ \\
Gato-do-Mato & $42.34(15.66)$ & $25-58$ & $3.26(1.2)$ \\
& \multicolumn{4}{c}{ Amostragem 2010} \\
Espécie & Abundância & IC (95\%) & Densidade $/ 100 \mathrm{~km}^{2}(\mathrm{sd})$ \\
\hline Jaguatirica & $52.78(9.86)$ & $43-62$ & $4.06(0.76)$ \\
Lobinho & $96.28(8.69)$ & $88-107$ & $7.41(0.66)$ \\
Gato-do-Mato & $33.06(11.6)$ & $22-44$ & $2.54(0.89)$ \\
\hline
\end{tabular}




\section{Discussão}

O presente trabalho é o primeiro estudo, do qual temos conhecimento, que verificou parâmetros populacionais do lobinho através de armadilhas fotográficas. Da mesma forma, é o primeiro estudo que estimou estes parâmetros para do gato-do-mato na Caatinga e o segundo estudo sobre a população desta espécie em qualquer hábitat (Oliveira-Santos et al 2012). É também a primeira vez que se verifica a variação nas estimativas populacionais em dois anos, para estas três espécies, no Brasil. A escassez de estudos sobre este tema era esperada devido à dificuldade de identificação individual do lobinho, e devido à dificuldade de se registrar o gato-do-mato com probabilidade de detecção e qualidade de registros fotográficos em número suficiente para permitir análises. O surgimento e o desenvolvimento de novas ferramentas analíticas podem alterar esse panorama, com o provável aumento de estudos com este, e subsequente ampliação do conhecimento das populações, não apenas destas três espécies, mas dos mesocarnívoros em geral.

Com isso em mente, o primeiro ponto a ser discutido é a efetividade do método aplicado para a estimativa da variação populacional. Os modelos aplicados partem de dois pressupostos iniciais. Primeiro, o de que a população é fechada em cada amostragem, isto é, pondera que durante a amostragem total, deve-se considerar que não houve alterações na abundância da espécie alvo devido a processos demográficos e de movimento. Devido ao curto período de tempo amostrado em cada ano, quatro meses, é plausível concluir que as populações destas espécies funcionaram como populações fechadas durante os períodos de amostragem, atendendo ao primeiro pressuposto.

Em segundo lugar, deve-se considerar a correlação entre a localização espacial dos pontos de captura. Se muitos animais se movem entre os diferentes pontos, os valores da estimativa de abundância podem ser inflados, devido à contagem consistentemente repetitiva 
do mesmo animal em diferentes locais, fazendo com que indivíduos particulares afetem de maneira desproporcional o valor de $\pi$. Em relação à distância entre as estações de captura, houve alguns movimentos de jaguatiricas entre diferentes estações durante a amostragem de 2009, sendo que mais da metade dos indivíduos foram registrados em mais de uma armadilha, e 30\% foram registrados em três ou mais estações de captura. Não é possível afirmar se isto também ocorreu para o lobinho e gato-do-mato. Porém, considerando que suas áreas de vida conhecidas são menores do que a da jaguatirica (Juarez e Marinho-Filho 2002; Maffei e Taber 2003; Oliveira e Cassaro 2005) e condizente com espaçamento existente entre as armadilhas dispostas na Serra da Capivara, podemos supor que se houve movimento, este pode não ter sido uma forte fonte de inflação nas estimativas. No entanto, a estimativa populacional da jaguatirica poderia ter sido afetada por seus movimentos entre as diferentes estações, inflando os valores de abundância obtidos. Contudo a utilização dos modelos $R N$ neste estudo não foi feita com o objetivo de atingir valores populacionais absolutos, e sim, um índice para averiguar a variação entre anos destas populações. Portanto, caso tenha havido algum viés na estimativa populacional da jaguatirica, este seria similar para os dois anos amostrados, e consequentemente, a variação encontrada é coerente devido ao mesmo método utilizado.

A partir da verificação de que, pelo menos internamente, os resultados são coesos, podemos explorar o que os valores estimados de abundância e sua alteração em dois anos podem significar. Ambas as espécies de felinos apresentaram valores mais baixos em relação à abundância do lobinho. Enquanto a abundância do lobinho permaneceu similar nos dois anos, a população das duas espécies de gatos diminuiu. Podemos inferir algumas razões para estas diferenças e variações nos valores estimados na abundância destas espécies. Em um estudo realizado neste mesmo local e período, foi estimado que a densidade da Onça-Pintada (Panthera onca) aumentou no segundo ano (2010) em relação ao primeiro ano (2009) de amostragem (Astete 2012). Esta espécie de carnívoro de topo apresentou um efeito negativo 
sobre as populações de jaguatiricas em outros locais (Moreno et al 2006; Davis 2009) -. Assim, se a Onça-Pintada estiver afetando negativamente a jaguatirica na Serra da Capivara (ver capítulos 2 e 3), o aumento da densidade deste carnívoro de topo pode estar relacionado à diminuição da população da jaguatirica neste estudo.

Além do efeito mencionado acima, as condições climáticas presentes na região durante a execução do estudo podem ter tido alguma influência no menor valor de abundância registrado no segundo ano. Durante a amostragem de 2010, a temperatura do ar apresentou valores médios bem mais altos e precipitação menor do que os anos anteriores (INPE). Uma vez que a abundância da jaguatirica foi anteriormente relacionada com estes dois fatores ambientais, apresentando menores densidades em regiões mais quentes e mais secas (Di Bitetti et al 2008), estas condições climáticas também podem ter tido efeito na amostragem de 2010. Apesar de não existirem estudos que conectem fatores ambientais à abundância de Gatos-doMato, a mesma relação pode ser verdadeira para o felino menor, devido às similaridades existentes entre a biologia e ecologia deles, como dieta e o comportamento. Assim, a menor população do gato-do-mato no segundo ano pode ser um reflexo do ambiente e não estar relacionado à densidade da Onça-Pintada. Isto porque estas duas espécies de carnívoros possuem uma enorme diferença no tamanho corporal. O efeito negativo de predadores de topo sobre mesocarnívoros é considerado como mais forte quando a razão de massa corporal entre as duas espécies se situa entre 2 a 5,4 (Donadio e Buskirk 2006). No entanto, deve-se levar em conta que as estimativas da abundância deste pequeno felino apresentaram um alto desvio padrão, com uma sobreposição dos valores entre os dois anos. Como o número de registros dessa espécie foi pequeno, é plausível que a diferença encontrada na estimativa de abundância não reflita alterações reais na abundância entre os anos, e sim, representem valores similares nos dois anos, incluídos dentro do intervalo de confiança da análise. 
O lobinho, por sua vez, é uma espécie de canídeo que comumente forma grupos familiares e que possui hábito generalista (Berta 1982). Mudanças ambientais talvez não sejam tão fortes para esta espécie, que pode consumir uma ampla variedade de recursos (Juarez e Marinho-Filho 2002; Gatti et al 2006) e utilizar diferentes habitats de maneira generalizada (Macdonald e Courtenay 1996; Juarez e Marinho-Filho 2002). Assim, esta espécie pode ser menos suscetível a alterações populacionais em um curto período de tempo, possuindo maior resiliência em ambientes no qual ela ocorre. Os valores entre os dois anos, apesar de indicarem um pequeno aumento, foram muito parecidos, com as estimativas sobrepostas no intervalo de confiança, da mesma forma que as estimativas do gato-do-mato. No entanto, ao contrário desta espécie de pequeno felino, a estimativa da população do lobinho apresentou valores de desvio pequenos, indicando maior precisão na estimativa.

Outra questão que poderia surgir com a análise destes resultados é a definição da densidade populacional. Este parâmetro sempre está presente em estudos de abundância populacional de várias espécies (Carbone e Gittleman 2002; Silver et al 2004; Di Bitetti et al 2006), no entanto a definição do significado de densidade é controversa (Dillon e Kelly 2007). O problema surge na delimitação da área na qual a abundância populacional estimada é dividida. Por exemplo, anteriormente, a maioria dos estudos utilizava um método arbitrário de definição da área efetivamente amostrada conhecido como a "média distância máxima movida" - Maximum mean distance moved. Estes estudos consideravam o valor de movimentação médio dos diferentes indivíduos entre as armadilhas fotográficas e utilizavam a média deste valores, obtidas através da movimentação de todos os indivíduos, como um valor de buffer, aplicado em cada armadilha fotográfica, estimando assim a área amostrada por cada armadilha para cada espécie. Este método foi utilizado na estimativa da densidade da jaguatirica em minha dissertação de mestrado (Oliveira, 2012). No entanto, desenvolvimentos recentes colocam em cheque a efetividade destas estimativas devido à arbitrariedade da definição da área amostrada. 
Assim, os valores aqui apresentados da densidade da jaguatirica podem ser considerados valores mais precisos e mais próximos da realidade, em comparação com a densidade apresentada anteriormente. Houve uma variação de 4.49 indivíduos a cada $100 \mathrm{~km}^{2}$, obtida no mestrado, para os valores atuais de $5.65 \pm 0.46 / 100 \mathrm{~km}^{2}$. A diferença entre os resultados indica como os modelos analíticos anteriores podem subestimar a área efetivamente amostrada, realizando uma estimativa de densidade populacional menor.

Todavia, mesmo modelos espacialmente explícitos - SECR - precisam considerar algum valor máximo de área para que seja calculada a densidade populacional. Quanto maior este valor, ou seja, quanto maior a área em que o estudo considera que a abundância estimada seja importante, menor será a densidade. Modelos SECR são formulados de forma que exista um certo amortecimento nas diferenças no resultado final em relação ao aumento da área (Efford 2011). Assim se for considerado uma área grande o suficiente, aumentos neste valor não irão mais gerar aumentos na estimativa de densidade. No entanto, ainda assim, esses valores são abstratos. Apenas a definição de uma área grande o suficiente, para que não sejam criados vieses nos resultados das estimativas de densidade, não necessariamente corresponde à realidade física e biológica do local amostrado. A existência de rios, montanhas, e outras áreas em que o animal não pode ocorrer dentro da área total de estudo irá fazer com que a estimativa de densidade seja subestimada, pois foi considerada uma área maior do que ela realmente é em relação à biologia do animal estudado. Poucos estudos levam isso em consideração ao estimar a densidade, criando máscaras de habitat na região amostrada (Rayan et al 2012). O presente estudo, apesar de apresentar valores de densidade, teve como foco a variação na abundância. Portanto, qualquer comparação entre a densidade estimada aqui e estimativas com qualquer outro trabalho, devem ser interpretadas com ressalvas. Isto, na verdade, deve ser feito entre quaisquer trabalhos que utilizem métodos diferentes, tanto de desenho amostral (local de instalação de pontos de coleta), quanto de análises. 
A amostragem de apenas dois anos não permite afirmar, com certeza, que as alterações na abundância, ou a falta delas, seja uma tendência em longo prazo ou apenas parte do ciclo populacional normal destas espécies na Serra da Capivara. Para espécies com história de vida longa, como estes carnívoros, a amostragem de vários anos em sequência é necessária para responder perguntas sobre tendências populacionais e sobrevivência destas espécies na região no futuro. No entanto, este estudo apresentou valores inéditos que podem servir como base para futuros estudos na Caatinga ou mesmo em outras regiões áridas, além de sugerir prováveis efeitos de variáveis externas (clima e presença de carnívoros maiores) na regulação populacional de mesocarnívoros neste ambiente semiárido. Posteriores estudos devem levar em consideração estes fatores quando realizarem estimativas populacionais de mesocarnívoros em ambientes áridos. 


\section{Referências Bibliográficas}

Archaux F, Henry PY, Gimenez O (2012) When can we ignore the problem of imperfect detection in comparative studies? Methods in Ecology and Evolution 3:188-194.

Astete S (2012) Ecologia e conservação da onça-pintada e da onça parda no parque nacional serra da capivara, Piauí. Tese de Doutorado. Universidade De Brasília

Berta A (1982) Cerdocyon Thous. Mammalian Species 186:1-4.

Borchers DL, Efford MG (2008) Spatially-explicit maximum likelihood methods for capturerecapture studies. Biometrics 64:377-85.

Buckland ST, Marsden SJ, Green RE (2008) Estimating bird abundance: making methods work. Bird Conservation International 18:91-108.

Carbone C, Gittleman JL (2002) A common rule for the scaling of carnivore density. Science 295:2273-6.

Chandler RB, Royle JA (2013) Spatially-explicit models for inference about density in unmarked or partially marked populations. Annals of Applied Statistics 7:936-954.

Cuellar E, Maffei L, Arispe R, Noss A (2006) Geoffroy's cats at the northern limit of their range: activity patterns and density estimates from camera trapping in bolivian dry forests. Studies on Neotroprical Fauna and Environment 41:169-177.

Davis ML (2009) Densities, habitat-use, and mesopredator release of the ocelot in Belize. Tese de Doutorado. Virginia Polytechnic Institute And State University.

Dénes F V., Silveira LF, Beissinger SR (2015) Estimating abundance of unmarked animal populations: accounting for imperfect detection and other sources of zero inflation. Methods in Ecology and Evolution 6:543-556.

Di Bitetti MS, Paviolo A, De Angelo C (2006) density, habitat use and activity patterns of ocelots (Leopardus Pardalis) in the Atlantic Forest of Misiones, Argentina. Journal of Zoology 270:153-163.

Di Bitetti MS, Paviolo A, De Angelo CD, Di Blanco YE (2008) Local And Continental Correlates Of The Abundance Of A Neotropical Cat, The Ocelot (Leopardus Pardalis). Journal of Tropical Ecology 24:189-200.

Dillon A (2005) Ocelot Density And Home Range In Belize, Central America: Camera- 
Trapping And Radio Telemetry. Tese de Doutorado. Virginia Polytechnic Institute And State University.

Dillon A, Kelly MJ (2007) Ocelot Leopardus Pardalis In Belize: The Impact Of Trap Spacing And Distance Moved On Density Estimates. Oryx 41:469-477.

Donadio E, Buskirk SW (2006) Diet, Morphology, And Interspecific Killing In Carnivora. American Naturalist 167:524-536.

Efford MG (2011) Estimation Of Population Density By Spatially Explicit Capture-Recapture Analysis Of Data From Area Searches. Ecology 92:2202-7.

Emmons LH, Sherman P, Bolster D, Et Al (1989) Ocelot Behavior In Moonlight. Adv Neotrop Mammal 1989:233-242.

Faria-Corrêa M, Balbueno R A., Vieira EM, De Freitas TRO (2009) Activity, Habitat Use, Density, And Reproductive Biology Of The Crab-Eating Fox (Cerdocyon Thous) And Comparison With The Pampas Fox (Lycalopex Gymnocercus) In A Restinga Area In The Southern Brazilian Atlantic Forest. Mammalian Biology 74:220-229.

Fusco-Costa R, Ingberman B, Do Couto HTZ, Et Al (2010) Population Density Of A Coastal Island Population Of The Ocelot In Atlantic Forest, Southeastern Brazil. Mammalian Biology 75:358-362.

Gatti A, Bianchi R, Rosa CRX, Mendes SL (2006) Diet Of Two Sympatric Carnivores, Cerdocyon Thous And Procyon Cancrivorus, In A Restinga Area Of Espirito Santo State, Brazil. Journal of Tropical Ecology 22:227-230.

Herfindal I, Linnell JDC, Odden J, Et Al (2005) Prey Density, Environmental Productivity And Home-Range Size In The Eurasian Lynx (Lynx Lynx). Journal of Zoology 265:63-71.

Jackson RM, Roe JD, Wangchuk R, Hunter DO (2006) Estimating Snow Leopard Population Abundance Using Photography And Capture-Recapture Techniques. Wildlife Society Bulletin 34:772-781.

Juarez K, Marinho-Filho J (2002) Diet, Habitat Use, And Home Ranges Of Sympatric Canids In Central Brazil. Journal of Mammalogy 83:925-933.

Karanth K (1995) Estimating Tiger Panthera Tigris Populations From Camera-Trap Data Using Capture--Recapture Models. Biological Conservation 71:333-338. 
Karanth KU, Nichols JD (1998) Estimation of tiger densities in india using photographic captures and recaptures. Ecology 79:2852-2862.

Karanth KU, Nichols JD, Kumar NS, Hines JE (2006) Assessing Tiger Population Dynamics Using Photographic Capture-Recapture Sampling. Ecology 87:2925-37.

Kelly MJ, Noss AJ, Di Bitetti MS, Et Al (2008) Estimating Puma Densities From Camera Trapping Across Three Study Sites: Bolivia, Argentina, And Belize. Journal of Mammalogy 89:408-418.

Kolowski J, Alonso A (2010) Density And Activity Patterns Of Ocelots (Leopardus pardalis) In Northern Peru And The Impact Of Oil Exploration Activities. Biological Conservation 143:917-925.

Macdonald DW, Courtenay O (1996) Enduring Social Relationships In A Population Of CrabEating Zorros, Cerdocyon thous, In Amazonian Brazil (Carnivora, Canidae). Journal of Zoology 239:329-355.

Maffei L, Noss AJ, Cuéllar E, Rumiz DI (2005) Ocelot (Felis Pardalis) Population Densities, Activity, And Ranging Behaviour In The Dry Forests Of Eastern Bolivia: Data From Camera Trapping. Journal of Tropical Ecology 21:349-353.

Martínez-Hernández A, Rosas-Rosas OC, Clemente-Sánchez F, Tarango-Arámbula LA, Palacio-Nunez J, Bender LC, Herrera-Haro JG (2014) Density of threatened ocelot Leopardus pardalis in the Sierra Abra-Tanchipa Biosphere Reserve, San Luis Potosi, Mexico. Oryx 49:619-625

Mohamed A, Sollmann R, Bernard H, Et Al (2013) Density And Habitat Use Of The Leopard Cat (Prionailurus Bengalensis) In Three Commercial Forest Reserves In Sabah, Malaysian Borneo. Journal of Mammalogy 94:82-89.

Moreno RS, Kays RW, Samudio Jr R (2006) Competitive Release In Diets Of Ocelot (Leopardus Pardalis) And Puma (Puma Concolor) After Jaguar (Panthera Onca) Decline. Journal of Mammalogy 87:808-816.

Mourao G, Magnusson W (1997) Uso de levantamentos aéreos para o manejo de populações silvestres. Manejo E Conservação da Vida Silvestre No Brasil. CNPQ/Sociedade Civil Mamiraua, Brasilia/Belém.

Nilsen EB, Herfindal I, Linnell JDC (2005) Can Intra-Specific Variation In Carnivore Home- 
Range Size Be Explained Using Remote-Sensing Estimates Of Environmental Productivity? Ecoscience 12:68-75.

O’Brien TG (2011) Abundance, Density And Relative Abundance: A Conceptual Framework. Camera Traps in Animal Ecology. Springer Japan.

O’Brien TG, Kinnaird MF (2011) Density Estimation Of Sympatric Carnivores Using Spatially Explicit Capture - Recapture Methods And Standard Trapping Grid. Ecological Applications 21:2908-2916.

Oliveira-Santos LGR, Graipel ME, Tortato M A., Et Al (2012) Abundance Changes And Activity Flexibility Of The Oncilla, Leopardus Tigrinus (Carnivora: Felidae), Appear To Reflect Avoidance Of Conflict. Zool 29:115-120.

Otis DL, Burnham KP, White GC, Anderson DR (1978) Statistical Inference From Capture Data On Closed Animal Populations. Wildlife Monographs 3-135.

Oliveira GP. (2012) Ecologia da jaguatirica Leopardus pardalis (Linnaeus, 1758), na Caatinga do Piauí. Dissertação de Mestrado. Universidade de Brasília.

Ramsey DSL, Caley P A., Robley A (2015) Estimating Population Density From PresenceAbsence Data Using A Spatially Explicit Model. The Journal Of Wildlife Management 79, 491-499.

Rayan DM, Mohamad SW, Dorward L, Et Al (2012) Estimating The Population Density Of The Asian Tapir (Tapirus Indicus) In A Selectively Logged Forest In Peninsular Malaysia. Integrative Zoology 7:373-380.

Reppucci J, Gardner B, Lucherini M (2011) Estimating Detection And Density Of The Andean Cat In The High Andes. Journal of Mammalogy 92:140-147.

Royle JA (2004) N-Mixture Models For Estimating Population Size From Spatially Replicated Counts. Biometrics 60:108-115.

Sharma RK, Jhala Y, Qureshi Q, Et Al (2010) Evaluating Capture-Recapture Population And Density Estimation Of Tigers In A Population With Known Parameters. Animal Conservation 13:94-103.

Silveira L, Jácomo ATA, Astete S, Et Al. (2009) Density Of The Near Threatened Jaguar Panthera Onca In The Caatinga Of North-Eastern Brazil. Oryx 44:104. 
Silveira L, Jácomo ATA, Diniz-Filho JAF (2003) Camera Trap, Line Transect Census And Track Surveys: A Comparative Evaluation. Biological Conservation 114:351-355.

Silver SCSC, Ostro LETLET, Marsh LKLK, Et Al (2004) The Use Of Camera Traps For Estimating Jaguar Panthera Onca Abundance And Density Using Capture/Recapture Analysis. Oryx 38:148-154.

Singh P, Gopalaswamy AM, Karanth KU (2010) Factors Influencing Densities Of Striped Hyenas (Hyaena Hyaena) In Arid Regions Of India. Journal of Mammalogy 91:11521159.

Soisalo M, Cavalcanti S (2006) Estimating The Density Of A Jaguar Population In The Brazilian Pantanal Using Camera-Traps And Capture-Recapture Sampling In Combination With GPS Radio-Telemetry. Biological Conservation 129:487-496.

Sollmann R, Mohamed A, Samejima H, Wilting A (2013) Risky Business Or Simple Solution - Relative Abundance Indices From Camera-Trapping. Biological Conservation 159:405412.

Sunquist ME, Sunquist F (2002) Wild Cats Of The World. University Of Chicago Press, 2002.

Trolle M, Kéry M (2003) Estimation Of Ocelot Density In The Pantanal Using CaptureRecapture Analysis Of Camera-Trapping Data. Journal of Mammalogy 84:607-614.

Trolle M, Kéry M (2005) Camera-Trap Study Of Ocelot And Other Secretive Mammals In The Northern Pantanal. Mammalia 69:409-416. 


\section{Capítulo 2 - PADRÕES DE ATIVIDADE DE MESOCARNÍVOROS NO SEMIÁRIDO DA CAATINGA, BRASIL.}

\section{Introdução}

Existem diferentes fatores capazes de regular e/ou alterar os padrões de atividade de um animal. O risco de predação, por exemplo, pode fortemente afetar a atividade de espécies que sofram predação de espécies maiores (Farías et al 2012). Da mesma forma, animais carnívoros podem ajustar sua atividade diária àquela de suas espécies de presas, aumentando assim, seu sucesso de predação (Emmons et al 1989; Hayward e Slotow 2009). Para espécies de mesocarnívoros, a presença de espécies predadoras maiores, ocorrendo em simpatria, pode levar à segregação temporal (Azlan e Sharma 2006), onde o carnívoro menor irá evitar os mesmos horários em que o predador de topo está mais ativo, diminuindo assim a probabilidade de encontros antagônicos com carnívoros maiores (Hayward e Slotow 2009; Lesmeister e Nielsen 2015). Diferentes espécies também podem ajustar seu comportamento em relação a alterações do ambiente, como, por exemplo, às mudanças na quantidade de luz disponível durante a noite - seja pela lua ou outra fonte artificial (Emmons et al 1989; Cozzi et al 2012), ou mesmo em diferentes estações ou temperaturas (Zielinski et al 2014). No entanto, estes fatores não são mutuamente exclusivos, e em ambientes naturais provavelmente ocorrem ao mesmo tempo, moldando padrões de atividade das espécies em diferentes contextos e ambientes.

Neste estudo foram estimados, através de modernos métodos de estatística circular, os padrões de atividade de três espécies de mesocarnívoros: Leopardus pardalis, a jaguatirica; Cerdocyon thous, o lobinho; e L. tigrinus, o gato-do-mato, na caatinga do estado do Piauí. A jaguatirica possui hábitos normalmente crepusculares e noturnos (Laack 1991; Weller e Bennett 2001; Di Bitetti et al 2006; Pérez-irineo e Santos-moreno 2014), com algum grau de 
atividade diurna que varia entre diferentes regiões e contextos ambientais em que ela ocorre (Di Bitetti et al 2006). O lobinho também é uma espécie com hábitos preferentemente noturnos (Berta 1982; Courtenay e Maffei 2004; Vieira e Port 2007; Di Bitetti et al 2009; Faria-Corrêa et al 2009a). Apesar de ter sido considerado como uma espécie estritamente noturna (Macdonald e Courtenay 1996), o lobinho pode apresentar atividade durante todo o dia em alguns casos (Maffei e Taber 2003). Ao contrário das duas espécies anteriormente citadas, o gato-do-mato não possui um número de estudos que permita uma definição segura de seu padrão de atividade. Os poucos trabalhos publicados divergem sobre este parâmetro, considerando esta espécie como ativa o dia inteiro ou mesmo noturna, com a diminuição de atividade nos horários mais quentes do dia (Di Bitetti et al 2010; Oliveira-Santos et al 2012; Resende et al 2014).

Não existem dados sobre a atividade dos dois mesocarnívoros menores na Caatinga, contudo, em minha dissertação de mestrado (Oliveira 2012) foi realizada uma descrição dos padrões de atividade jaguatirica na Serra da Capivara em 2007. Durante esta amostragem foi encontrado que os registros da jaguatirica foram noturnos. No entanto, este foi um estudo simples, que não incluiu nenhuma análise estatística para a estimativa de um padrão de atividade. Assim, neste capítulo, a estimativa do padrão de atividade da jaguatirica, e adicionalmente dos dois mesocarnívoros menores, será efetivamente realizada para os dados coletados em 2007, através de análises circulares, gerando resultados precisos que indiquem a real probabilidade de cada uma destas espécies estar ativas em qualquer período do dia. Em conjunto a esta análise, foi estimado também a atividade noturna dos mesocarnívoros, e de outras espécies que possuem o potencial de interagir com eles, em uma amostragem mais ampla, compreendendo 2 anos realizada em 2009 e 2010, para verificar as divergências entre os picos de atividade destes animais. 
Desta forma, este estudo parte da hipótese de que as elevadas temperaturas predominantes na região afetem a atividade destas espécies, que portanto, devem evitar horários diurnos, quando a temperatura é maior. Assim, estes carnívoros podem ter que se manter ativos nos mesmos horários, não apenas uns dos outros, mas também no horário de atividade de predadores maiores que ocorrem no mesmo local (a Onça-Pintada e a OnçaParda), que estariam sujeitos às mesmas condições que limitam a atividade nos períodos mais quentes do dia. Estando a atividade destas espécies, na região, restritas à noite, é criada a segunda hipótese, de que existe diferenças claras entre os seus picos de atividade, caso a competição e/ou a predação intraguilda seja um fator forte (Carothers e Jaksic 1984; Di Bitetti et al 2009; Hayward e Slotow 2009). No entanto, caso a pressão de outras espécies de carnívoros não influencie a atividade diária destas espécies, é verificado a hipótese final de que os mesocarnívoros aqui amostrados devam ajustar seus picos de atividade àqueles de suas espécies de presas (Halle 2000; Hayward e Slotow 2009). Portanto, neste estudo a atividade diária das três espécies de mesocarnívoros será sobreposta e comparada à atividade de outros grupos de espécies que ocorrem em simpatria na Caatinga do Piauí.

\section{Material e Métodos}

\section{Coleta de dados}

Este estudo apresenta duas amostragens distintas, realizadas em períodos e locais diferentes. A primeira amostragem foi realizada em 2007, quando foram instaladas 26 estações de captura (compostas da mesma forma descrita no capítulo 1) na região sul do Parque Nacional da Serra da Capivara (Figura 2.1). Esta amostragem foi realizada como um estudo piloto prévio da amostragem maior realizada nos anos seguintes, 2009 e 2010. As câmeras desta amostragem foram configuradas de modo a funcionar 24 horas por dia. 


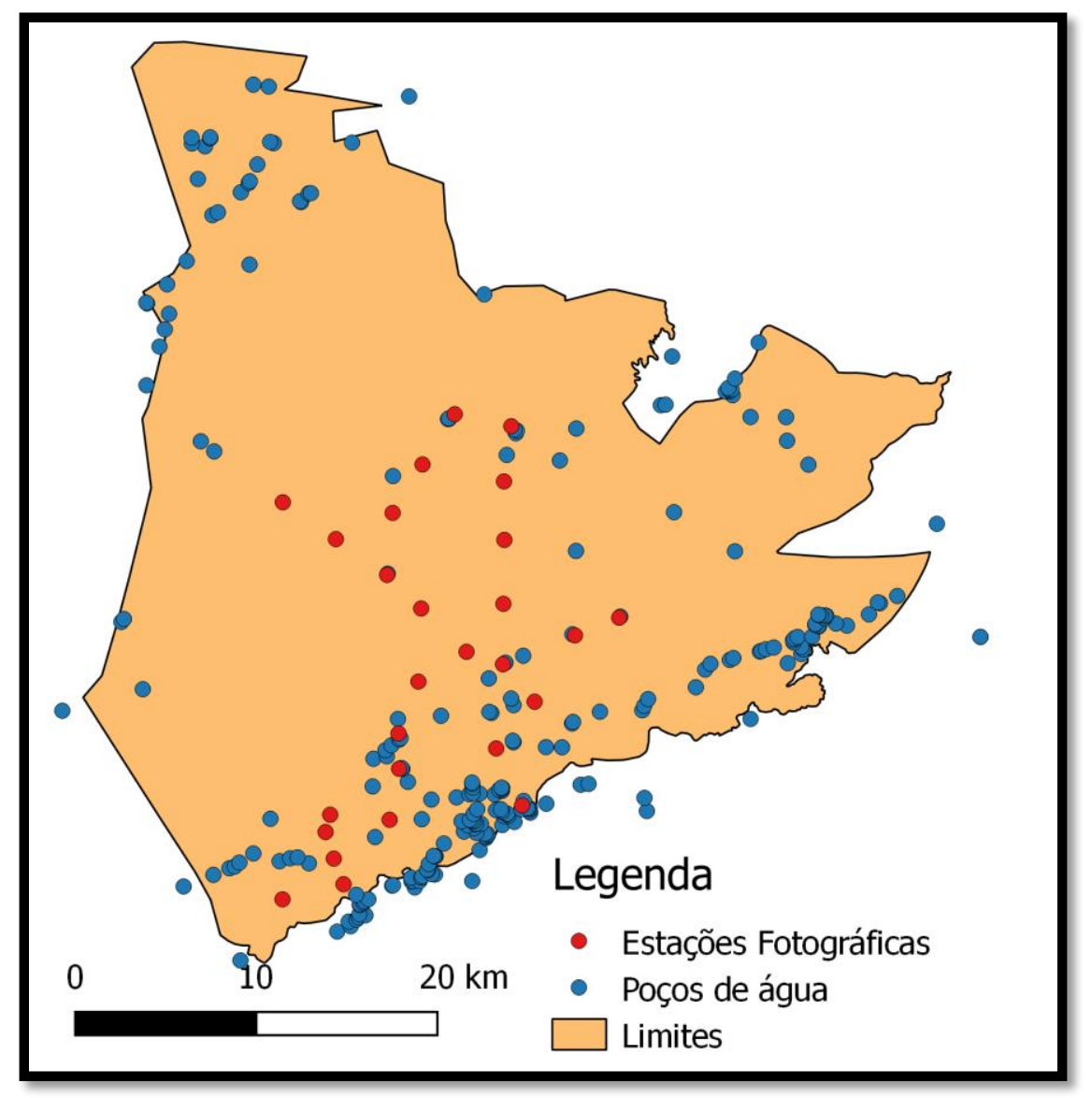

Figura 2-1: Parque Nacional da Serra da Capivara, com a localização das armadilhas instaladas durante a amostragem de 2007

Com esta primeira amostragem foi percebido que os carnívoros do Parque Nacional da Serra da Capivara são essencialmente noturnos (ver resultados, abaixo). Portanto, no segundo circuito de amostragem (as duas amostragens consecutivas de 2009 e 2010), que abrangeram a totalidade do Parque, as câmeras foram configuradas de modo a estarem ativas entre o período contido entre as 18 e 06 horas (ver capítulo 1). Esta configuração evitou o desperdício de filme e de bateria, além de evitar que as câmeras apresentassem algum defeito devido ao extremo calor na região de estudo - alguns defeitos atribuíveis ao calor ocorreram durante o estudo piloto de 2007 com as armadilhas fotográficas. Assim, a primeira amostragem, realizada em 2007, será utilizada para a definição dos padrões de atividade total e para o cálculo de sobreposição de atividade entre as diferentes espécies amostradas neste estudo, visto que funcionaram 24h por dia. As amostragens mais amplas de 2009 e 2010 serão utilizadas para a 
comparação da atividade noturna destas mesmas espécies, procurando diferenças e semelhanças entre os picos de atividade no período da noite entre estes animais.

\section{$\underline{\text { Análise dos dados }}$}

Foram analisados os dados de atividade das três espécies de mesocarnívoros alvo deste estudo (jaguatirica, o lobinho e o gato-do-mato), junto aos padrões das duas espécies de carnívoros de topo que ocorrem no Parque Nacional da Serra da Capivara (Onça-pintada e Onça-parda). Para a análise de 2009 e 2010 foi incluído também o registro de roedores nas análises. Como a identificação de espécies de pequeno porte, como roedores, que apresentam proporções e padrões corporais semelhantes, é muito difícil a partir de fotografias, não foi realizada a análise levando em conta diferentes espécies de roedores, e sim o grupo como um todo. Vários registros de espécies de tatus também foram obtidas, no entanto, devido ao mal funcionamento do câmeras, que falhou em marcar o horário de registro de grande parte das fotografias de tatus, este grupo de espécies não foi considerado para a análise temporal (No entanto, os tatus foram considerados na análise espacial realizada no capítulo 3)

Para a estimativa dos padrões de atividade e cálculo da sobreposição existente entre a atividade de diferentes pares de espécies foi utilizado o método descrito por Ridout e Linkie (2009), que emprega um amplo conjunto de ferramentas estatísticas para análises de dados circulares. A aplicação de análises circulares em estudos de padrão de atividade solucionou diversos problemas que métodos anteriores criavam na interpretação dos resultados. Por exemplo, se um animal apresenta um padrão diurno, sua atividade poderia ser considerada como unimodal, com apenas um pico na curva concentrado perto do meio dia. No entanto, se este mesmo padrão for alterado por $12 \mathrm{~h}$, por exemplo, a curva apresentaria um formato de $\mathrm{U}$, com dois picos no início e fim do dia. Da mesma forma, as análises devem considerar que o tempo transcorrido entre 23:59 e 00:01 é o mesmo tempo que existe entre 11:59 e 12:01, por 
exemplo. Estas peculiaridades nos padrões de dados temporais fazem com que análises estatísticas convencionais, como estimativas de média e variância, ou mesmo regressões, não sejam apropriadas, gerando resultados errados e de difícil interpretação. Consequentemente, análises análogas, desenvolvidas especialmente para dados circulares, foram criadas (SenGupta 2001).

Para a presente análise, os registros de horários obtidos pelas armadilhas fotográficas foram considerados como amostras aleatórias de uma distribuição contínua. A partir disto, o padrão de atividade é estimado através da densidade Kernel, que calcula as curvas de densidades, neste caso, a atividade da espécie em todo o espectro temporal do dia. Desta forma, pode-se estimar a probabilidade de registro do animal em qualquer período de tempo, e não apenas em blocos (número de registros entre $01 \mathrm{~h}$ e $02 \mathrm{~h}$, por exemplo), como realizado anteriormente por inúmeros estudos (Vieira e Port 2007, Oliveira 2012), o que limitava em muito o entendimento dos padrões de atividade das espécies. Desta forma, é possível realizar a comparação da sobreposição entre duas curvas, ou padrões de atividade, verificando o quanto estas curvas são similares ou distintas. Seguindo a recomendação de Ridout e Linkie (2009) foi escolhido o parâmetro de concentração Kernel de $k=3$, e parâmetro de suavização de $c=1$. $\mathrm{O}$ estimador selecionado foi o $\Delta_{1}$, que segundo os autores, representa melhor a realidade para dados ecológicos que apresentam amostragens pequenas, como é o caso do presente estudo. Este estimador apresenta um coeficiente de sobreposição, que varia entre 0 (nenhuma sobreposição entre as duas curvas de densidade) e 1 (sobreposição total, ou seja, duas curvas idênticas). As análises foram realizadas no programa R 3.0.1 através dos pacotes: "circular" e “overlap".

\section{Resultados}


$\mathrm{Na}$ amostragem de 2007 foram obtidos 58 registros de jaguatirica, 78 registros para o lobinho, e 15 para o gato-do-mato. Em relação às outras espécies amostradas, a Onça-pintada apresentou 282 registros, seguido da Onça-parda, com 186 fotos. Não houve fotos de espécies de roedores nesta amostragem. Portanto em 2007 foi verificado o padrão de atividade dos mesocarnívoros e a sobreposição destes com as outras espécies de predadores apenas.

Todas as espécies de mesocarnívoros foram extremamente noturnas (Figura 2.2), com a jaguatirica apresentando apenas $1(1,7 \%)$ registro durante o dia, o lobinho com $10(12 \%)$ e o gato-do-mato com 3 (20\%). O lobinho apresentou dois picos de atividade, o primeiro ocorrendo próximo às 1900 h e o segundo as $0300 \mathrm{~h}$. A jaguatirica apresentou apenas um pico de atividade próximo à meia noite. Ambas as espécies iniciaram sua atividade perto das $18 \mathrm{~h}$ e terminaram entre as $06 \mathrm{~h}$ e $07 \mathrm{~h}$, indicando um comportamento noturno, porém mais crepuscular para o lobinho. $\mathrm{O}$ gato-do-mato apresentou uma atividade inicialmente crescente a partir da metade do dia, atingindo um primeiro pico logo antes da meia noite e um segundo pico antes do amanhecer. Ambos predadores menores tiveram uma atividade mais baixa no horário em que a jaguatirica apresentou sua maior atividade (Figura 2.2).

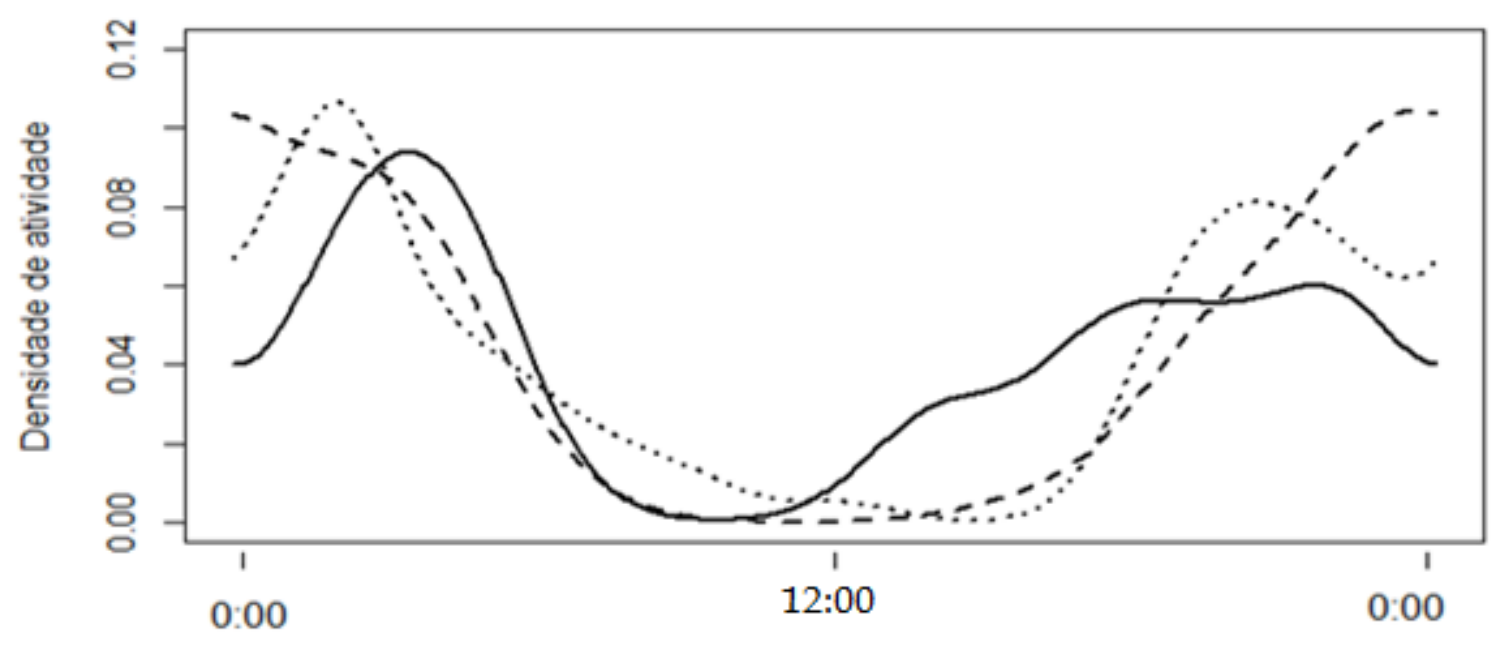

Jaguatirica (Tracejado), Gato-do-Mato (Linha), Lobinho (Pontilhado)

Figura 2-2: Padrões de atividade dos três mesocarnívoros obtidas durante a amostragem de 2007. 
Os coeficientes de sobreposição estimados entre estas espécies foram muito altos (Tabela 2.1). Mesmo na espécie que apresentou os menores valores de sobreposição com os outros carnívoros, o gato-do-mato, o coeficiente ainda assim foi alto $\left(\Delta_{1}>0.7\right)$. Em relação à sobreposição da atividade com carnívoros de topo (a Onça-pintada e a Onça-parda), todos os mesocarnívoros também apresentaram valores altos de sobreposição (Tabela 2.1), pois estes dois predadores de topo também possuem um comportamento principalmente noturno nesta região (Foster et al 2013). A inspeção visual dos padrões de atividade dos mesocarnívoros em relação aos predadores de topo (Figura 2.3) mostra que o pico de atividade da jaguatirica coincide com a diminuição da atividade da Onça-parda (Figura 2.3d), enquanto se assemelha à atividade da Onça-pintada (Figura $2.3 a$ ), apenas com uma pequena diferença no horário do pico noturno. O lobinho apresentou o padrão inverso, com sua atividade sendo similar à da Onça-parda (Figura 2.3 e), com alguma diminuição nos horários em que a Onça-pintada esteve mais ativa (Figura 2.3 b). Já o padrão do gato-do-mato pareceu não estar relacionado a nenhuma espécie de predador de topo (Figura $2.3 c$ e $f$ ).

Tabela 2-1: Coeficiente de sobreposição temporal $(\Delta 1(95 \% \mathrm{CI}))$ entre as diferentes espécies de carnívoros amostradas no Parque Nacional da Serra da Capivara em 2007.

\begin{tabular}{|c|c|c|c|c|c|}
\hline & \multicolumn{3}{|c|}{ Mesocarnívoros } & \multicolumn{2}{|c|}{ Predadores de topo } \\
\hline & L. pardalis & L. tigrinus & C. thous & P. onca & P. concolor \\
\hline L. pardalis & - & $0.76(0.46-0.86)$ & $0.86(0.70-0.89)$ & $0.90(0.75-0.93)$ & $0.80(0.65-0.88)$ \\
\hline L. tigrinus & $0.76(0.46-0.86)$ & - & $0.77(0.45-0.82)$ & $0.74(0.44-0.86)$ & $0.79(0.47-0.84)$ \\
\hline C. thous & $0.86(0.70-0.89)$ & $0.77(0.45-0.82)$ & - & $0.85(0.73-0.90)$ & $0.89(0.74-0.91)$ \\
\hline
\end{tabular}




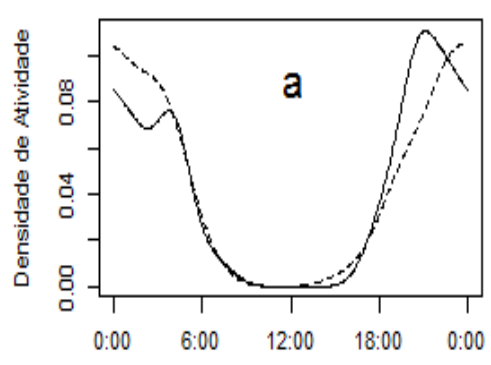

Jaguatirica (Tracejado), Onça-Pintada (Linha)

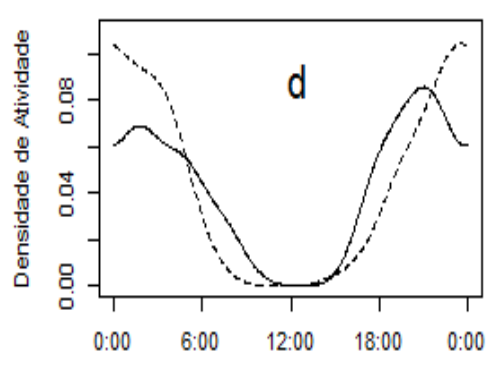

Jaguatirica (Tracejado), Onça-Parda (Linha)

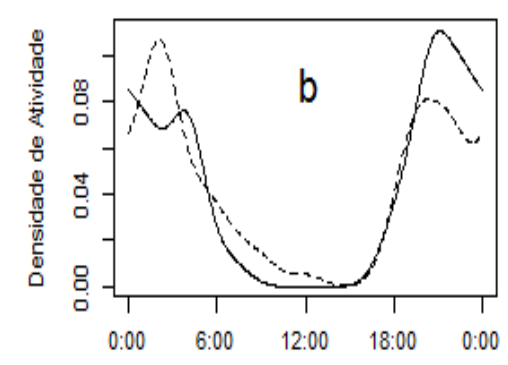

Lobinho (Tracejado), Onça-Pintada (Linha)

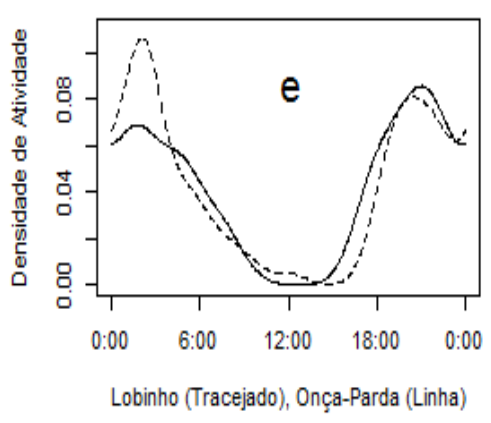

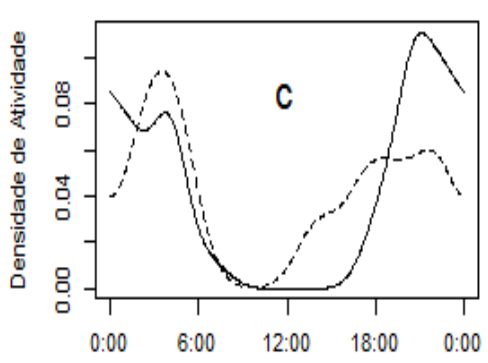

Gato-do-Mato (Tracejado), Onça-Pintada (Linha)

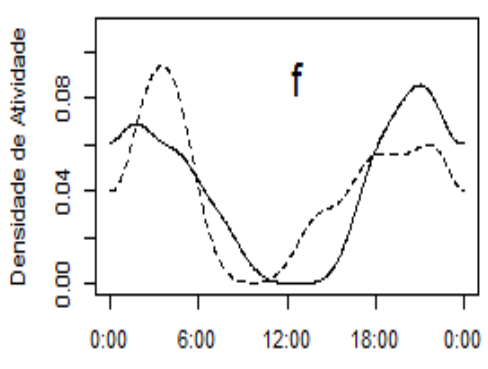

Gato-do-Mato (Tracejado), Onça-Parda (Linha)

Figura 2-3: Padrões de atividade dos três mesocarnívoros em relação à atividade dos dois predadores de topo na amostragem de 2007.

$\mathrm{Na}$ amostragem maior de 2009 e 2010, foram obtidos 516 registros noturnos para a jaguatirica, 1015 para o lobinho e 171 para o gato-do-mato. A Onça-pintada obteve 318 fotos, seguida pela Onça-parda com 186. As espécies de roedores apresentaram um total de 1445 registros; apesar de não ser possível a identificação específica dos roedores com acurácia, foi notado que a maioria dos registros aparentam ser do Mocó - Kerodon rupestris. Isto também foi observado pessoalmente no próprio campo, onde a presença desta espécie de roedor foi muito comum nas trilhas e estradas do Parque, durante as amostragens. Nesta amostragem também foi registrado a presença do Jaguarundi (Puma yagouaroundi) em algumas fotos, no entanto o volume de dados obtidos para esta espécie foi muito baixo, apenas 9 registros, o que impossibilitou quaisquer análises com este mesopredador. 
Os dois mesocarnívoros maiores (a jaguatirica e o lobinho) tiveram sua atividade noturna assemelhada, com um pico de atividade no início da noite e uma atividade menor à meia-noite, com algum aumento na madrugada posterior (Figura 2.4). A jaguatirica apresentou um pico de atividade noturna perto das $2000 \mathrm{~h}$, diminuindo a atividade até seu menor valor, perto da meia-noite. Após isso esta espécie apresentou dois picos menores à 0100h e às $0300 \mathrm{~h}$ (Figura 2.4). O lobinho, também teve seu maior pico às $2000 \mathrm{~h}$, apresentando uma atividade menor e constante no decorrer da noite, com um segundo pico perto das 0400h. De forma diferente, o gato-do-mato apresentou três picos bem definidos, com o primeiro em horário similar aos dois mesocarnívoros maiores, entre as $1900 \mathrm{~h}$ e 2000h, o segundo à meia-noite, e o terceiro e último antes do amanhecer, às $0400 \mathrm{~h}$. O pico de atividade à meia-noite do gato-domato foi coincidente com a menor atividade noturna da jaguatirica (Figura 2.4).

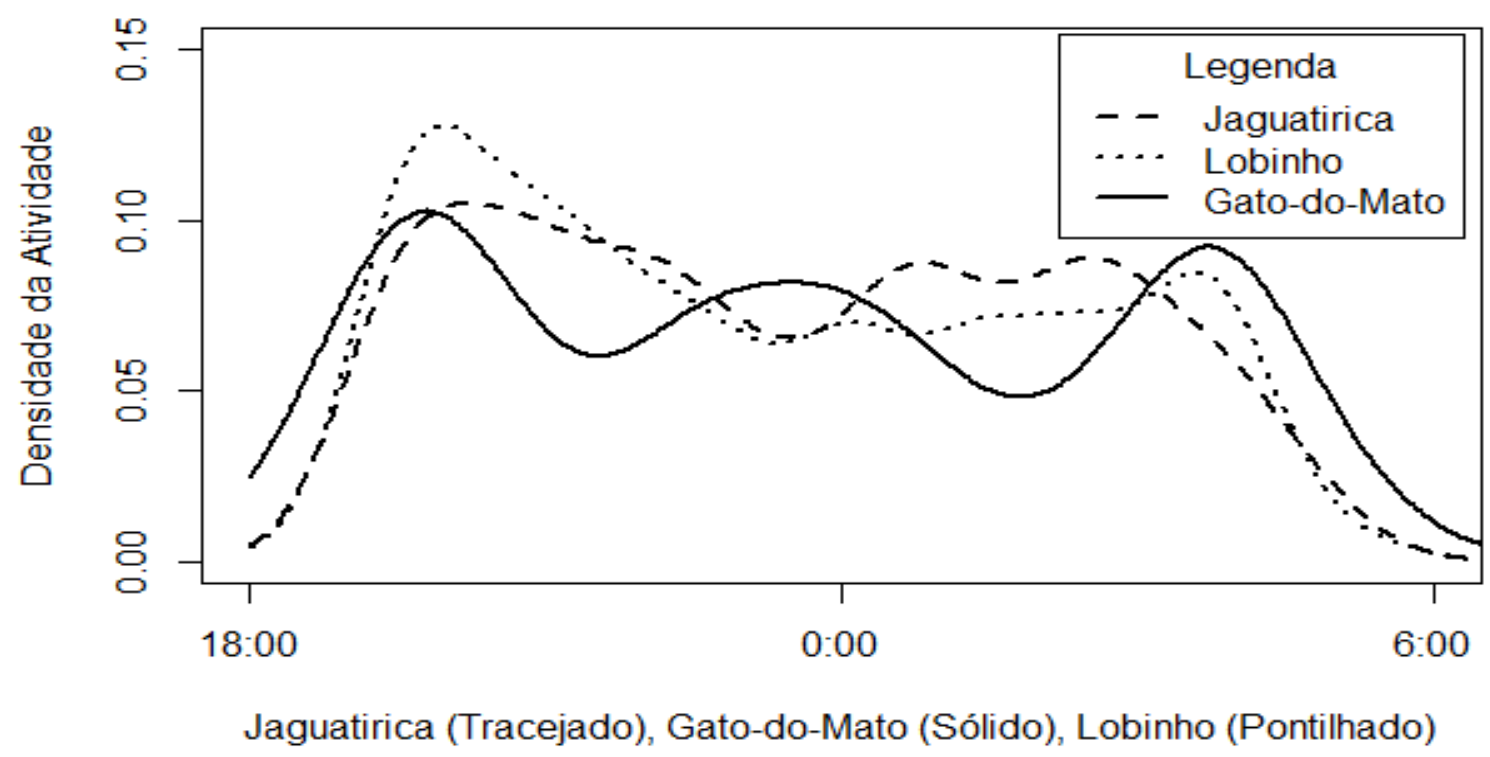

Figura 2-4: Padrões de atividade dos três mesocarnívoros obtidas durante as amostragens de 2009 e 2010.

Tanto a jaguatirica como o lobinho não apresentaram indicação forte de que sua atividade noturna foi ajustada para evitar a presença da Onça-pintada. A jaguatirica, por 
exemplo, possui seus períodos de maior atividade nos mesmos horários deste carnívoro de topo, inclusive apresentando a mesma baixa de atividade à meia-noite (Figura $2.5 a$ ). No entanto, no maior pico de atividade da Onça-pintada, próximo às 0200h, a jaguatirica teve uma pequena diminuição em sua atividade. A atividade do lobinho, por sua vez não apresentou nenhum indício de relação com a atividade da Onça-pintada (Figura 2.5 b). A atividade do gato-domato parece estar relacionada negativamente com a atividade da Onça-pintada, apresentando seus picos de atividade nos momentos em que o predador de topo possui seus menores valores (Figura $2.5 c$ ). A atividade noturna da Onça-parda foi diferente de todas as outras espécies de carnívoros amostradas neste estudo, com a presença de apenas um pico entre a meia-noite e a 0100h da manhã. Devido a este padrão, esta espécie parece não influenciar a atividade de nenhum mesocarnívoro aqui amostrado (Figura $2.6 a-c$ ).
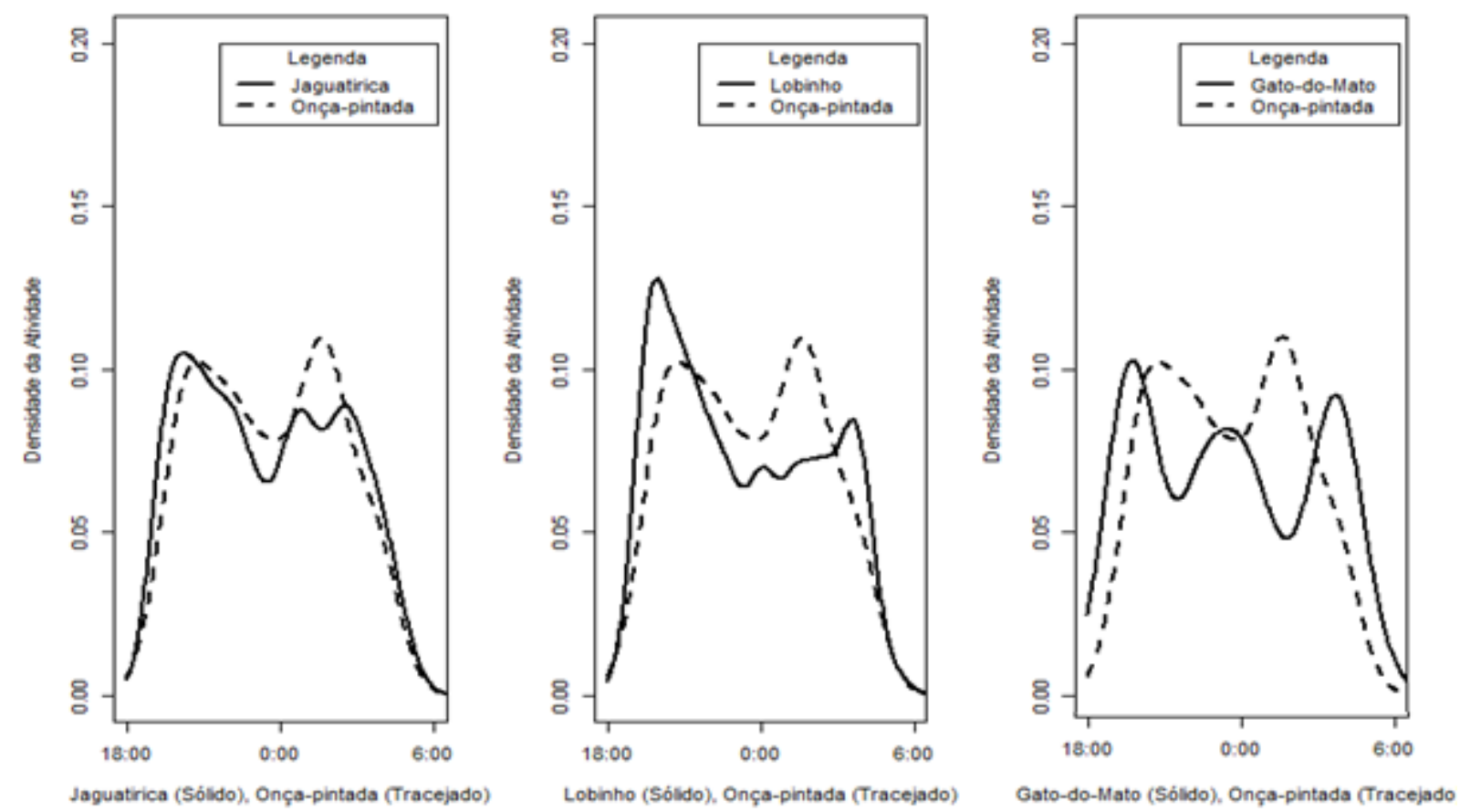

Figura 2-5: Padrões de atividade dos três mesocarnívoros em relação à atividade da Onçapintada nas amostragens de 2009 e 2010. 

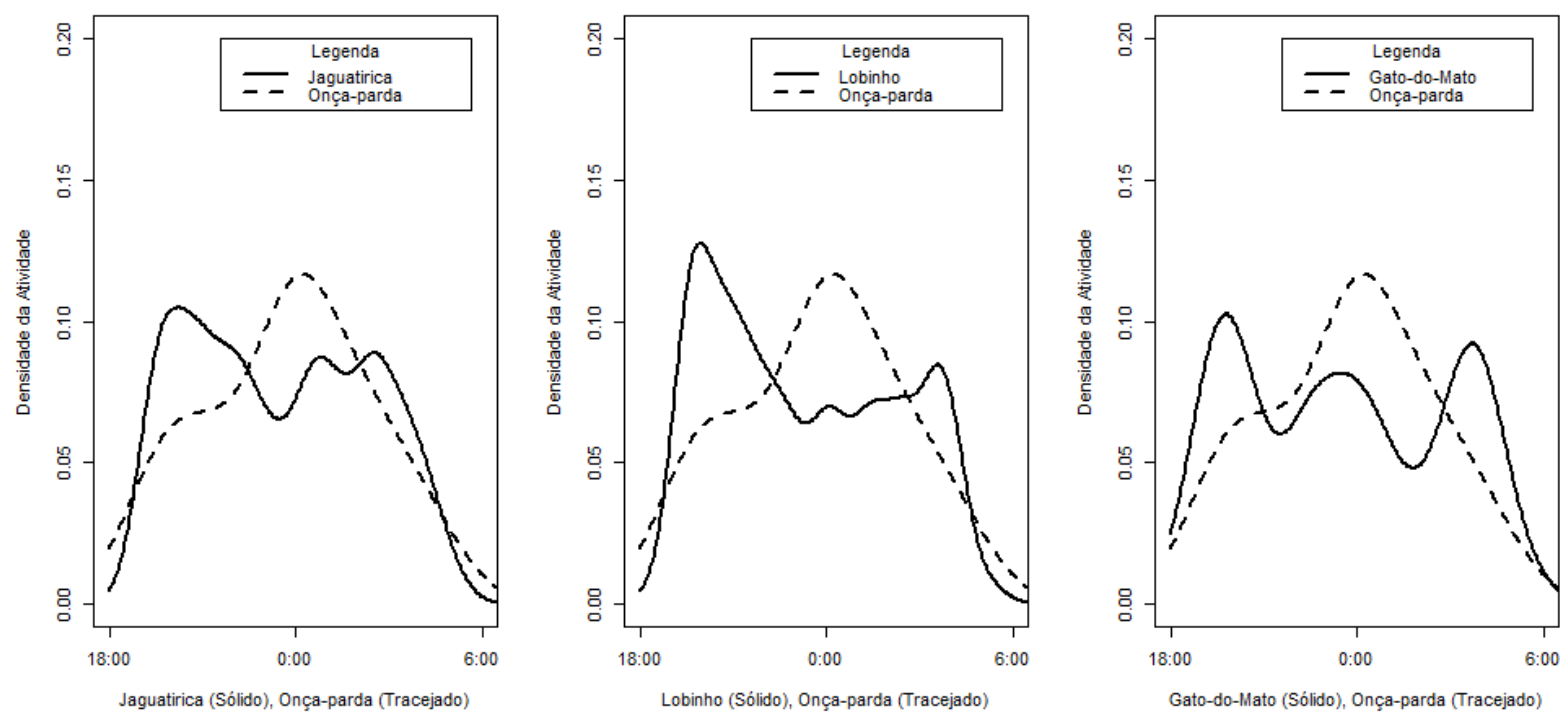

Figura 2-6: Padrões de atividade dos três mesocarnívoros em relação à atividade da Onçaparda nas amostragens de 2009 e 2010.

A atividade dos roedores, por outro lado, apresenta um padrão que se encaixa de maneira visível com os padrões de atividade da jaguatirica e lobinho (Figura $2.7 a$ e $b$ ). O maior pico da atividade dos roedores se encontra às $1800 \mathrm{~h}$, seguido de uma abrupta queda, com seu valor mais baixo à meia-noite. Por fim, os roedores apresentam um crescimento na atividade durante a parte final da noite, apresentando um segundo pico logo antes do amanhecer. Este padrão se assemelha muito aos padrões da jaguatirica e do lobinho, sendo que estes mesocarnívoros apresentaram uma variação em suas densidades de atividade noturna que aparentam ser um reflexo da atividade dos roedores, com picos e quedas em aparente sincronia. O primeiro e último pico de atividade do Gato-do-mato também ocorreram nos mesmos horários dos picos de atividade dos roedores. No entanto, o pico de atividade à meia-noite deste carnívoro não se assemelha à atividade destas potenciais espécies de presas (Figura 2.7 c). 

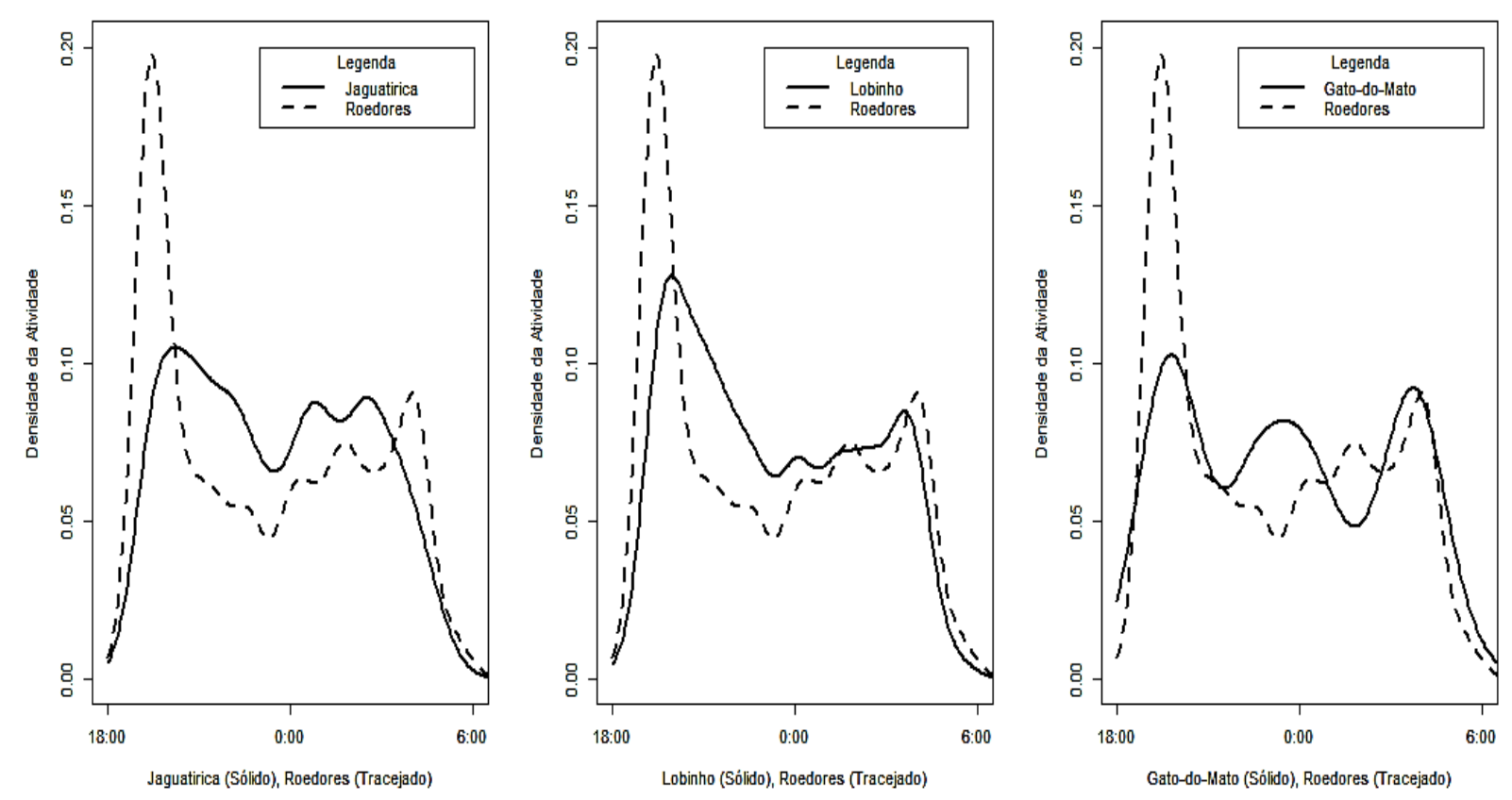

Figura 2-7: Padrões de atividade dos três mesocarnívoros em relação à atividade das espécies de roedores nas amostragens de 2009 e 2010.

\section{Discussão}

O padrão de atividade encontrado, durante a amostragem de 2007, para as três espécies de mesocarnívoros amostradas neste estudo - principalmente o noturno - era esperada devido ao conhecimento prévio sobre estes animais encontrados em estudos anteriores (Berta 1982; Crawshaw e Quigley 1989; Maffei et al 2007; Oliveira-Santos et al 2012; Pérez-irineo e Santosmoreno 2014; Resende et al 2014). No entanto, existem algumas diferenças entre os padrões aqui encontrados em relação a estas mesmas espécies em outros locais, provavelmente devido ao contexto ambiental de forte seca e de altas temperaturas existente na Caatinga deste Parque Nacional.

A jaguatirica, cujo padrão de atividade diário é bem descrito na literatura (Maffei et al 2005; Di Bitetti et al 2006), é considerada uma espécie noturna e crepuscular. Isto é um padrão 
esperado para esta espécie, pois suas presas são, em sua maioria, espécies noturnas (Ludlow e Sunquist 1987; Konecny 1989). No entanto, a atividade desta espécie durante o período diurno é observada em outros trabalhos, ainda que em menor frequência do que a atividade noturna (Weller e Bennett 2001; Goulart et al 2009). Esta atividade diurna apresenta variação em sua intensidade de acordo com os estudos e locais nos quais a espécie foi amostrada, podendo ser apenas um reflexo das condições locais (Di Bitetti et al 2006). Neste estudo, a jaguatirica seguiu o padrão noturno previamente descrito para a espécie em toda sua ocorrência, no entanto, ao contrário da maioria dos estudos conduzidos com este mesocarnívoro, a atividade diurna foi praticamente inexistente. Isto pode sugerir que o contexto climático local, com temperaturas muito elevadas e a seca pronunciada, características do semiárido, pode ser um fator limitante da sua atividade durante o período diurno neste local.

É interessante notar a diferença da atividade estimada através destes modelos estatísticos em relação a simples apresentação dos horários de registros. Durante minha dissertação, cujo foi apresentado apenas os horários de registros da amostragem de 2007, a jaguatirica apresentou dois picos noturnos, um as $23 \mathrm{~h}$ e outro as $3 \mathrm{~h}$ (Oliveira 2012). No entanto, com a análise de densidade de atividade apresentada aqui, estes picos somem e são amortizados para uma atividade maior perto da meia noite, mostrando ser esse o horário no qual a jaguatirica apresentou a maior probabilidade de estar ativa, o que nos dá um entendimento melhor do comportamento temporal deste animal. Isto mostra a vantagem de se aplicar análises refinadas, que nos levam a interpretação mais direta dos resultados. Portanto, a análise dos dados coletados em 2009 e 2010, a amostragem noturna, nos mostra estes valores de probabilidade de atividade, o que permitiu a comparação mais clara e precisa entre os picos de atividade das diferentes espécies amostradas nesta tese. 
O lobinho, como a jaguatirica, também é considerado uma espécie noturna (FariaCorrêa et al 2009b), mas quase sempre apresenta atividade durante o dia (Maffei e Taber 2003), principalmente pela manhã (Maffei et al 2007; Dias e Bocchiglieri 2015). Canídeos podem lidar com temperaturas altas de melhor forma que espécies de felinos, por possuirem numerosos mecanismos para lidar com o calor, como, por exemplo, narinas úmidas que ajudam a dissipar o calor, ausente em gatos (West 2005). Desta forma, os registros desta espécie durante o período da manhã, ainda que poucos em relação ao registro noturno, podem sugerir que ela consiga suportar o ambiente seco e a temperatura alta, pelo menos na primeira metade do dia, de forma melhor do que a jaguatirica. Outro fator que ajuda a entender melhor sua atividade durante as primeiras horas do dia, horário em que as temperaturas são, geralmente, mais amenas do que no meio do dia, é a dieta onívora e oportunista deste animal (Gatti et al 2006). Apesar de consumir muitas espécies de pequenos mamíferos, em sua maioria animais noturnos, o lobinho também se alimenta de insetos, sementes, frutas e outros vertebrados (Juarez e Marinho-Filho 2002; Dias e Bocchiglieri 2015). Assim, esta espécie, ao contrário da jaguatirica, uma espécie de dieta relativamente especializada (Abreu et al 2008), tem a possibilidade de encontrar alimento em diferentes horas do dia, não sendo tão fortemente restrita a determinado horário devido a sua alimentação. Ainda assim, registros diurnos do lobinho foram escassos neste estudo, sugerindo uma preferência e/ou limitação de sua atividade durante os horários mais quentes do dia.

Por fim, o gato-do-mato é uma espécie que possui um padrão de atividade muito variável conforme observado nos diferentes estudos (Oliveira-Santos et al 2012), sendo considerada uma espécie com um comportamento que varia desde o catemeral, no qual não existe uma preferência por um período específico do dia (Di Bitetti et al 2010), até principalmente noturna ou noturna com pouca atividade diurna (Resende et al 2014). Da mesma forma que o lobinho, ainda que em menor grau, o Gato-do-mato apresenta um espectro 
mais amplo de dieta do que a jaguatirica, incluindo desde pequenos mamíferos até insetos e lagartos (Wang 2002; Tortato 2009). Consequentemente, esta espécie também é capaz de encontrar alimentos em diferentes horários do dia, o que provavelmente resulta nesta variação da atividade em diferentes regiões. Esta variação também é tida como uma resposta à presença de outras espécies de carnívoros que possam afetá-lo negativamente (Oliveira-Santos et al 2012). Assim ela seria uma espécie preferencialmente noturna, devido principalmente à maior atividade de roedores neste horário, porém agindo durante o período diurno se ocorrer em simpatria com outros predadores, como foi o caso deste estudo.

O comportamento temporal de uma espécie de mesocarnívoro também pode ser influenciado pela presença de predadores maiores (Hayward e Slotow 2009; Romero-muñoz et al 2014; Lesmeister e Nielsen 2015). Se a competição ou ataques intraguilda forem fatores seletivos fortes em determinada comunidade, a segregação temporal pode ser o melhor mecanismo para evitar esta competição (Carothers e Jaksic 1984; Di Bitetti et al 2010). Como também será discutido no capítulo 3, predadores maiores podem inibir a ação de carnívoros menores, que evitarão os mesmos horários no qual o carnívoro de topo está mais ativo, diminuindo assim, a chance de encontros agonísticos (Sergio e Hiraldo 2008; Cozzi et al 2012). Porém, como visto nos resultados, os coeficientes de sobreposição de atividade se mostraram elevados, pois todas as três espécies se encontraram com sua atividade quase restrita ao mesmo período. Assim, se estas espécies (mesocarnívoros e predadores de topo) estão afetando umas às outras no contexto do atual estudo, a segregação temporal não parece ser um dos principais fatores a permitir a coexistência (ver capítulo 3 sobre segregação espacial). No entanto, a amostragem noturna, com maior esforço amostral em 2009 e 2010, indica que durante o período da noite o Gato-do-mato apresenta uma menor atividade justamente no horário de maior atividade da Onça-pintada e, em menor grau, à da jaguatirica e lobinho, que possuíram padrões de atividade noturna semelhantes à Onça-Pintada. Portanto, apesar do comportamento 
noturno estimado para estas espécies, pelo menos no caso do Gato-do-mato, a presença de predadores maiores pode ter algum efeito em sua distribuição temporal. Isto também é sugerido pela seu padrão de atividade estimado aqui, apresentando uma maior atividade diurna em relação aos outros carnívoros amostrados (Oliveira-Santos et al 2012).

Apesar do efeito que potenciais predadores/competidores podem ter sobre o comportamento de espécies de mesocarnívoros menores, o padrão de atividade de uma espécie predadora é tido como ajustado ao padrão de suas espécies de presas (Foster et al 2013), o que maximizaria sua obtenção de energia e, consequentemente, sua aptidão (Romero-Muñoz et al 2010). Os padrões de atividade noturnos amostrados em 2009 e 2010 mostram um provável ajuste do padrão de atividade da jaguatirica e lobinho ao de suas presas potenciais. Estas duas espécies apresentam um reflexo ao padrão de atividade de espécies de roedores. No momento em que a atividade dos pequenos mamíferos aumentou ou diminuiu, a atividade do carnívoro a seguiu imediatamente. Apesar de ser impossível afirmar com certeza que as espécies de roedores amostradas são, de fato, as presas destes mesocarnívoros, o conhecimento prévio de suas dietas sugere que estes roedores provavelmente compõem a maior parte dos itens alimentares dos mesocarnívoros estudados aqui (Juarez e Marinho 2002; Gatti et al 2006; Abreu et al 2008). Isto indica que a atividade destas espécies está provavelmente mais associada à atividade de suas presas do que à presença de predadores maiores.

O gato-do-mato, apesar de ter apresentado seu primeiro pico de atividade coincidente com o pico das espécies de roedores, não pareceu ter sua atividade sincronizada - como os dois mesocarnívoros maiores - com a atividade destes pequenos mamíferos. Não é possível afirmar que esta falta de sincronia se deve ao fato destes roedores não serem itens importantes da dieta do gato-do-mato, ou se deve à presença dos carnívoros maiores, afetando a atividade deste pequeno predador. A continuidade dos estudos na área pode ajudar a esclarecer esta questão. 
De forma geral, este estudo indicou que no ambiente seco e de altas temperaturas da Caatinga do Parque Nacional da Serra da Capivara, as espécies de mesocarnívoros são mais noturnas, com o caso extremo da jaguatirica. Também indicou que durante o período da noite estas espécies parecem ajustar sua atividade de acordo com a atividade de suas presas, maximizando assim sua capacidade de encontrar alimento. No entanto, o Gato-do-mato, menor espécie de carnívoro que ocorre nesta região, pode estar sendo afetado também pela presença de carnívoros maiores. Isto demonstra que inúmeros fatores podem agir em conjunto na definição dos padrões de atividades das espécies em ambientes naturais. Desta forma, no que concerne a distribuição temporal de espécies de mesocarnívoros, este estudo apresenta uma base para posteriores trabalhos, na Caatinga ou em outros ambientes áridos. 


\section{Referências Bibliográficas.}

Abreu KC, Moro-Rios RF, Silva-Pereira JE, Et Al (2008) Feeding Habits Of Ocelot (Leopardus Pardalis) In Southern Brazil. Mammalian Biology 73:407-411.

Azlan JM, Sharma DSK (2006) The Diversity And Activity Patterns Of Wild Felids In A Secondary Forest In Peninsular Malaysia. Oryx 40:36.

Bartness TJ, Albers HE (2000) Activity Patterns And The Biological Clock In Mammals. In: Halle S, Stenseth NC (Orgs) Activity Patterns In Small Mammals. Springer Berlin Heidelberg, Berlin, Heidelberg, P 23-47

Beltrán J., Delibes M (1994) Environmental Determinants Of Circadian Activity Of FreeRanging Iberian Lynxes. Journal Of Mammalogy

Berta A (1982) Cerdocyon Thous. Mammalian Species 186:1-4.

Carothers J, Jaksic F (1984) Time As A Niche Difference: The Role Of Interference Competition. Oikos 42:403-406.

Courtenay O, Maffei L (2004) Cerdocyon Thous (Linnaeus, 1766). Canid Action Plan

Cozzi G, Broekhuis F, Mcnutt JW, Et Al (2012) Fear Of The Dark Or Dinner By Moonlight? Reduced Temporal Partitioning Among Africa’s Large Carnivores. Ecology 93:25902599.

Crawshaw P, Quigley HB (1989) Notes On Ocelot Movement And Activity In The Pantanal Region, Brazil. Biotropica 21:377-379.

Di Bitetti MS, De Angelo CD, Di Blanco YE, Paviolo A (2010) Niche Partitioning And Species Coexistence In A Neotropical Felid Assemblage. Acta Oecologica 36:403-412.

Di Bitetti MS, Di Blanco YE, Pereira JA, Et Al (2009) Time Partitioning Favors The Coexistence Of Sympatric Crab-Eating Foxes (Cerdocyon Thous) And Pampas Foxes (Lycalopex Gymnocercus). Journal Of Mammalogy 90:479-490.

Di Bitetti MS, Paviolo A, De Angelo C (2006) Density, Habitat Use And Activity Patterns Of Ocelots (Leopardus Pardalis) In The Atlantic Forest Of Misiones, Argentina. Journal Of Zoology 270:153-163.

Dias DDM, Bocchiglieri A (2015) Trophic And Spatio-Temporal Niche Of The Crab- Eating 
Fox, Cerdocyon Thous (Linnaeus, 1766) (Carnivora: Canidae), In A Remnant Of The Caatinga In Northeastern Brazil. Mammalia.

Emmons LH, Sherman P, Bolster D, Et Al (1989) Ocelot Behavior In Moonlight. Advances In Neotropical Mammalogy 1989:233-242.

Faria-Corrêa M, Balbueno R, Vieira EM, De Freitas TRO (2009) Activity, Habitat Use, Density, And Reproductive Biology Of The Crab-Eating Fox (Cerdocyon Thous) And Comparison With The Pampas Fox (Lycalopex Gymnocercus) In A Restinga Area In The Southern Brazilian Atlantic Forest. Mammalian Biology - Zeitschrift Für Säugetierkunde 74:220-229.

Farías V, Fuller T, Sauvajot R (2012) Activity And Distribution Of Gray Foxes (Urocyon Cinereoargenteus) In Southern California. The Southwestern Naturalist 57:176-181.

Foster VC, Sarmento P, Sollmann R, Et Al (2013) Jaguar And Puma Activity Patterns And Predator-Prey Interactions In Four Brazilian Biomes. Biotropica 45:373-379.

Gatti A, Bianchi R, Rosa CRX, Mendes SL (2006) Diet Of Two Sympatric Carnivores, Cerdocyon Thous And Procyon Cancrivorus, In A Restinga Area Of Espirito Santo State, Brazil. Journal Of Tropical Ecology.

Goulart F, Graipel ME, Tortato M, Et Al (2009) Ecology Of The Ocelot (Leopardus Pardalis) In The Atlantic Forest Of Southern Brazil. Neotropical Biology And Conservation 4:137-143.

Halle S (2000) Ecological Relevance Of Daily Activity Patterns. In: Halle S, Stenseth NC (Orgs) Activity Patterns In Small Mammals. Springer Berlin Heidelberg, Berlin.

Hayward MW, Slotow R (2009) Temporal Partitioning Of Activity In Large African Carnivores: Tests Of Multiple Hypotheses. South African Journal Of Wildlife Research 39:109-125.

Juarez K, Marinho-Filho J (2002) Diet, Habitat Use, And Home Ranges Of Sympatric Canids In Central Brazil. Journal Of Mammalogy 83:925-933.

Konecny MJ (1989) Movement Patterns And Food Habits Of Four Sympatric Carnivore Species In Belize, Central America. Advances In Neotropical Mammalogy 1989:243264. 
Laack LL (1991) Ecology Of The Ocelot (Felis Pardalis) In South Texas. Texas A \& I University

Lesmeister DB, Nielsen CK (2015) Spatial And Temporal Structure Of A Mesocarnivore Guild In Midwestern North America. 191:1-61.

Ludlow M, Sunquist M (1987) Ecology And Behavior Of Ocelots In Venezuela. National Geographic Research 3:447-461.

Macdonald DW, Courtenay O (1996) Enduring Social Relationships In A Population Of Crab-Eating Zorros, Cerdocyon Thous, In Amazonian Brazil (Carnivora, Canidae). Journal Of Zoology 239:329-355.

Maffei L, Noss AJ, Cuéllar E, Rumiz DI (2005) Ocelot (Felis Pardalis) Population Densities, Activity, And Ranging Behaviour In The Dry Forests Of Eastern Bolivia: Data From Camera Trapping. Journal Of Tropical Ecology 21:349-353.

Maffei L, Paredes R, Segundo A, Noss A (2007) Home Range And Activity Of Two Sympatric Fox Species In The Bolivian. Canid News 10:1-7.

Maffei L, Taber A (2003) Área De Acción, Actividad Y Uso De Hábitat Del Zorro Patas Negras, Cerdocyon Thous, En Un Bosque Seco. Mastozoología Neotropical 10:154160.

Oliveira GP. (2012) Ecologia da jaguatirica Leopardus pardalis (Linnaeus, 1758), na Caatinga do Piauí. Dissertação de Mestrado. Universidade de Brasília.

Oliveira-Santos LGR, Graipel ME, Tortato M A., Et Al (2012) Abundance Changes And Activity Flexibility Of The Oncilla, Leopardus Tigrinus (Carnivora: Felidae), Appear To Reflect Avoidance Of Conflict. Zoologia (Curitiba) 29:115-120.

Pérez-Irineo G, Santos-Moreno A (2014) Density, Distribution, And Activity Of The Ocelot Leopardus Pardalis (Carnivora: Felidae) In Southeast Mexican Rainforests. 62:14211432.

Resende LDS, Neto GLE, Carvalho PGD, Et Al (2014) Time Budget And Activity Patterns Of Oncilla Cats (Leopardus Tigrinus) In Captivity. Journal Of Applied Animal Welfare Science: $17: 73-81$.

Ridout MS, Linkie M (2009) Estimating Overlap Of Daily Activity Patterns From Camera 
Trap Data. Journal Of Agricultural, Biological, And Environmental Statistics 14:322337.

Romero-Muñoz A, Maffei L, Cuéllar E, Et Al (2014) Of Tropical Ecology : Temporal Separation Between Jaguar And Puma In The Dry Forests Of Southern Bolivia Temporal Separation Between Jaguar And Puma In The Dry Forests Of Southern Bolivia. 303-311.

Romero-Muñoz A, Maffei L, Cuéllar E, Noss AJ (2010) Temporal Separation Between Jaguar And Puma In The Dry Forests Of Southern Bolivia. Journal Of Tropical Ecology 26:303.

Sergio F, Hiraldo F (2008) Intraguild Predation In Raptor Assemblages: A Review. Ibis 150:132-145.

Tortato MA (2009) Disponibilidade E Uso De Presas Na Dieta Do Gato-Do-Mato-Pequeno, Leopardus Tigrinus (SCHREBER, 1775) Em Área De Restinga No Sul Do Brasil.

Vieira EM, Port D (2007) Niche Overlap And Resource Partitioning Between Two Sympatric Fox Species In Southern Brazil. Journal Of Zoology 272:57-63.

Wang E (2002) Diets Of Ocelots (Leopardus Pardalis), Margays (L. Wiedii), And Oncillas (L. Tigrinus) In The Atlantic Rainforest In Southeast Brazil. Studies On Neotropical Fauna And Environment 37:207-212.

Weller SH, Bennett CL (2001) Twenty-Four Hour Activity Budgets And Patterns Of Behavior In Captive Ocelots (Leopardus Pardalis). Applied Animal Behaviour Science 71:67-79.

West P (2005) The Lion's Mane: Neither A Token Of Royalty Nor A Shield For Fighting, The Mane Is A Signal Of Quality To Mates And Rivals, But One That Comes With Consequences. American Scientist 93:226-235.

Zielinski WJ, Spencer WD, Barrett RH (2014) Relationship Between Food Habits And Activity Patterns Of Pine Martens. 64:387-396. 


\section{Capítulo 3 - OCUPAÇÃO DE TRÊS MESOCARNÍVOROS NO SEMIÁRIDO BRASILEIRO: EFEITOS DE FATORES AMBIENTAIS E BIOLÓGICOS.}

\section{Introdução}

A distribuição de diferentes espécies, e os padrões associados a ela, é um conceito central da Ecologia (Collier et al., 2012). Mamíferos carnívoros são considerados espécies chave, apresentando efeitos e papéis críticos no ecossistema em que ocorrem (Miller et al., 2001; Terborgh et al., 2001). Dependendo do contexto, estes predadores podem desestabilizar ou mesmo estabilizar toda a cadeia trófica, devido à forte supressão de espécies de presas em ambientes pequenos e/ou limitados (Loreau e Holt, 2004; McCann et al., 2005), ou devido à sua capacidade de responder prontamente a flutuações na abundância de presas entre diferentes locais, em ambientes abertos e complexos (McCann et al., 2005). Estas espécies, entretanto, estão entre as primeiras a desaparecer com o aumento das alterações ambientais provocadas pelo efeito da presença humana (Morrison et al., 2007). Neste sentido, o conhecimento acerca dos fatores responsáveis por afetar e regular a distribuição destas espécies de predadores é essencial para o desenvolvimento e definição de quaisquer programas de preservação e conservação direcionados ao ecossistema no qual estas espécies estejam inseridas (Kerr, 1997).

Diversos estudos identificaram aspectos que podem afetar a distribuição de espécies de mamíferos carnívoros em contextos distintos. Estes fatores variam entre os diferentes estudos, indo desde: (1) a forma e as características do ambiente no qual estas espécies de carnívoros estão inseridas (Di Bitetti et al., 2006; Juarez e Marinho, 2002; Trovati et al., 2007); (2) serem afetados pela presença de outras espécies, como potenciais competidores (Cove et al., 2012; Davis, 2009; Gehrt e Clark, 2003); (3) serem dependentes da disponibilidade de recursos, como a presença de presas (Lantschner et al., 2012; Petracca et al., 2013); e ainda (4) a presença humana, cada vez mais constante e em escala crescente na maioria dos ambientes naturais 
(Ordeñana et al., 2010; Pia et al., 2013). Uma visão geral destes estudos indica que fatores bottom-up, ou seja, fatores oriundos dos níveis inferiores da cadeia trófica, são os principais responsáveis pela distribuição de carnívoros em contextos regionais e/ou locais (Carbone e Gittleman, 2002; Herfindal et al., 2005; Nilsen et al., 2005). Isto sugere que os efeitos de perda e fragmentação de habitat e a depleção de espécies de presas, resultantes ou não desta fragmentação, sejam críticas para a persistência destas espécies carnívoras (Schuette et al., 2013). Assim, é razoável inferir que espécies carnívoras devam ocorrer em habitats que maximizem a obtenção da energia necessária para sua sobrevivência, ao passo que, em ambientes alterados, no qual o volume de presas não seja suficiente, os carnívoros podem estar ameaçados (Chamberlain e Leopold, 2002).

No entanto, carnívoros localizados em um nível intermediário da cadeia trófica, os mesopredadores (Prugh et al., 2009), além de terem sua distribuição potencialmente regulada por aspectos oriundos de níveis inferiores da cadeia trófica, podem também ser afetados pela presença de predadores maiores (Ritchie e Johnson, 2009). A predação intraguilda em carnívoros (Palomares e Caro, 1999) ocorre quando o mesopredador, ou seja, a espécie de carnívoro que ocorre em um nível intermediário da cadeia trófica (Prugh et al., 2009), é atacado e morto por outra espécie carnívora de maior porte (Ritchie e Johnson, 2009). O efeito que este tipo de interação pode ter sobre as populações de mesocarnívoros tem potencial de ser ainda mais forte do que interações clássicas entre predador e presa, pois em sua maioria, espécies de carnívoros não são adaptados a vigília e fuga, como o são as espécies de presas dos carnívoros de topo (Ritchie e Johnson, 2009). Assim, se a predação intraguilda for um fator que esteja ocorrendo em uma comunidade natural, é esperado que a espécie de mesocarnívoro que sofre os efeitos negativos desta interação apresente mecanismos para evitar possíveis encontros antagônicos com o predador de topo, como por exemplo, através da segregação espacial (Palomares e Ferreras, 1996; Sergio e Hiraldo, 2008). Por outro lado, em um contexto 
ambiental árido, a disponibilidade de água pode ter um efeito chave na distribuição de espécies de mamíferos (James et al., 1999; O’Brien e Waddell, 2006), incluindo espécies de carnívoros (de Boer et al., 2010; Valeix et al., 2008) que se concentrariam em regiões próximas a ela. A razão para esta ocorrência próxima a fontes de água é discutida, tendo como pontos principais a necessidade de água livre para o consumo (Destefano et al., 2000) ou a maior presença de espécies de presas próximas à água (James et al., 1999; Valeix, 2011).

Este estudo tem o objetivo de estimar a probabilidade de ocorrência, através de modelos de ocupação, de três espécies de mesocarnívoros: a jaguatirica (Leopardus pardalis), o lobinho (Cerdocyon thous) e o gato-do-mato-pequeno (Leopardus tigrinus), em um contexto semiárido na Caatinga do Piauí. Através destas análises, o estudo procurou identificar quais variáveis foram mais importantes na definição dos padrões de distribuição destas espécies, e o efeito que tiveram sobre a probabilidade de ocupação. A hipótese principal é que devido às condições xéricas encontradas no local de estudo, as três espécies de mesocarnívoros amostradas irão ocorrer preferencialmente em locais com maior disponibilidade de água. No entanto, se existir alguma pressão intraguilda forte, a presença de espécies de carnívoros maiores, neste caso a Onça-Pintada e Onça-Parda, irá afetar a distribuição dos mesocarnívoros. Concomitantemente, também consideramos a hipótese de a distribuição dos mesocarnívoros neste ambiente ser ditada, principalmente, por fatores ambientais e pela distribuição de presas - efeitos bottom-up discutidos anteriormente.

\section{Material e Métodos}




\section{Coleta de dados}

Os dados coletados neste estudo de ocupação foram obtidos entre os meses de setembro de 2009 e janeiro de 2010, quando 58 estações de captura, compostas por duas câmeras cada, posicionadas de frente uma a outra, foram dispostas nas trilhas e estradas do Parque Nacional da Serra da Capivara (Figura 3.1), sendo a mesma amostragem já descrita nos dois capítulos anteriores. A disposição das câmeras nestes locais foi feita de maneira a aumentar a probabilidade de registros destas espécies de carnívoros (O’Brien, 2011), utilizando-se estradas, trilhas e caminhos, haja vista que a vegetação de caatinga, densa e repleta de espinhos, impossibilitava a instalação das armadilhas fotográficas em outros locais.

As armadilhas fotográficas utilizadas foram da marca CamTrakker (CamTrack South Inc., Watkinsville, USA), ativadas por calor e movimento. Estas câmeras foram configuradas para operar entre as $1700 \mathrm{~h}$ e $0600 \mathrm{~h}$, possuindo um atraso de cinco minutos entre fotos consecutivas. Este atraso é configurado com o intuito de evitar o desperdício de filme resultante do registro consecutivo do mesmo animal nas estações de captura. Como mencionado nos capítulos anteriores, as câmeras foram programadas para o funcionamento noturno devido tanto ao forte calor durante do período diurno no Parque Nacional da Serra da Capivara - o que pode levar as câmeras a disparar fotos indiscriminadamente ou provocar mal funcionamento das armadilhas -, quanto devido à constatação de que as espécies alvo são extremamente noturnas nessa região. Assim, poupava-se o filme fotográfico com fotografias de nenhuma espécie ou de espécies fora do interesse do estudo. 


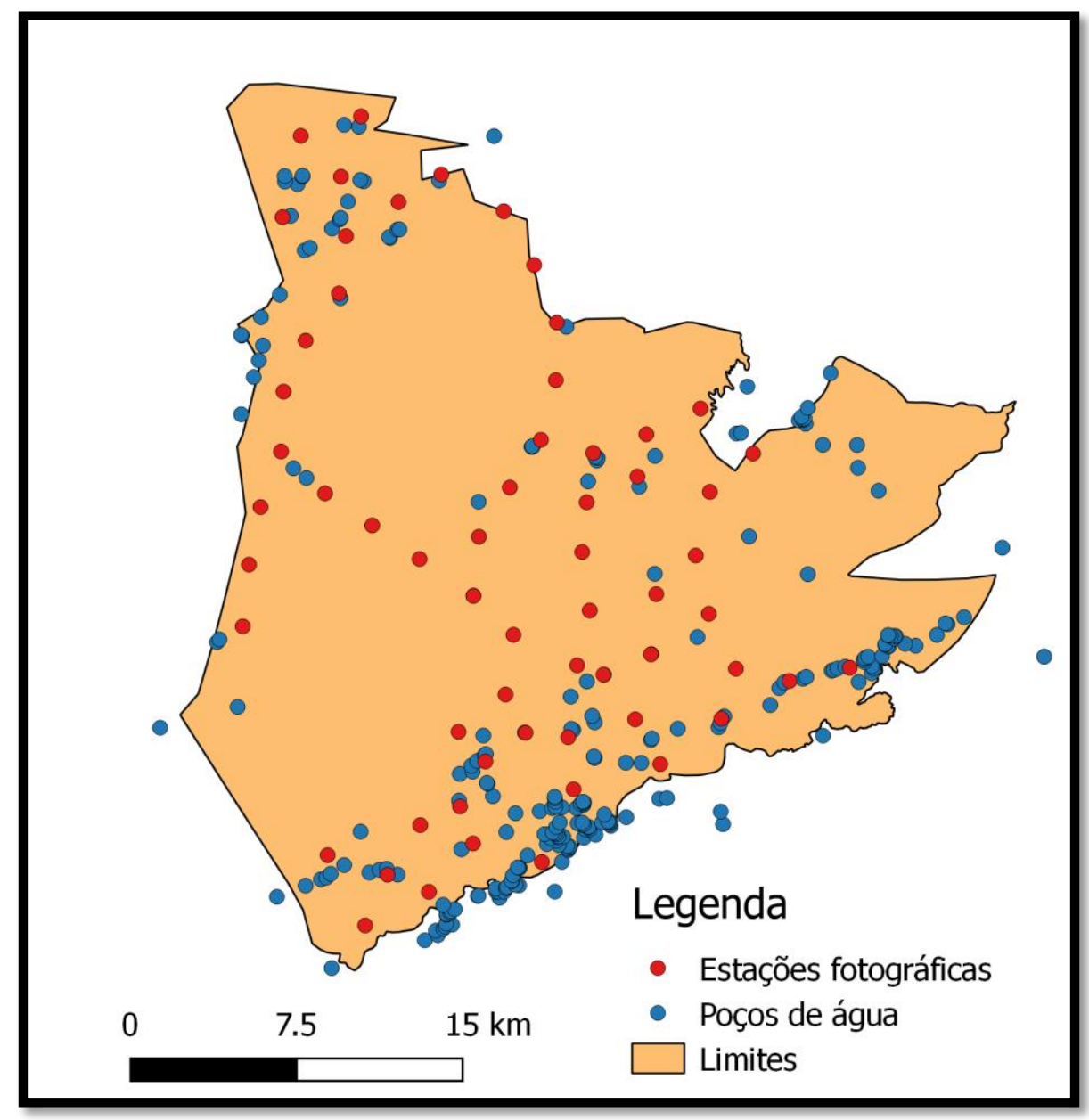

Figura 3-1: Parque Nacional da Serra da Capivara, com a localização das armadilhas fotográficas utilizadas no estudo de ocupação durante as amostragens de 2009-2011.

\section{Estruturação dos dados}

Para o estudo de ocupação foram selecionadas diferentes variáveis que pudessem exercer algum efeito na distribuição dos mesocarnívoros estudados. Estas variáveis foram divididas em quatro grupos distintos, não exclusivos, sendo que diferentes tipos de pressões podem afetar concomitantemente a ocupação destes três mesocarnívoros. Em primeiro lugar foram considerados os fatores ambientais. Três variáveis se encaixam neste grupo: distância do ponto de água mais próximo, número de pontos de água próximos a cada estação de armadilhamento e a altitude. O efeito da proximidade e da abundância de pontos de água sob a presença dos mesocarnívoros pode parecer redundante, no entanto, alguns pontos podem 
possuir uma fonte de água próxima, mas com poucos pontos de água livre próximos, enquanto que outras regiões podem ter maior densidade de pontos de água disponíveis, mesmo que um pouco mais longe da estação de captura. A altitude foi considerada como um índice para número de abrigos e heterogeneidade do terreno: nas altitudes mais baixas da Serra da Capivara estão localizados a maior parte das formações rochosas e cânions. Estes locais apresentam maior número de cavernas, grutas e fendas, que os animais podem utilizar tanto como refúgio do calor do dia, ou para evitar o encontro com predadores maiores. Estas variáveis foram calculadas através do programa ArcGis 10.1.

O segundo grupo de variáveis considerado foi a presença de carnívoros maiores que potencialmente afetam a ocupação das espécies menores, a Onça-pintada e Onça-parda para todas as três espécies de mesocarnívoros; com a inclusão da jaguatirica, em relação ao lobinho e o Gato-do-mato; e inclusão do lobinho para o pequeno Gato-do-mato. O terceiro grupo de variáveis foi a presença de espécies de presas em potencial para os três carnívoros estudados: roedores e tatus. Diversas espécies de roedores foram registrados nas armadilhas fotográficas. Infelizmente não foi possível realizar a identificação precisa das espécies de roedores amostradas, no entanto o mocó (Kerodon rupestris) provavelmente foi a espécie com o maior número de registros. Os tatus foram incluídos nesta análise e não na análise temporal do capítulo anterior devido ao mal funcionamento de algumas armadilhas fotográficas, que falharam em registrar o horário de registro de várias fotografias de tatus. O que levaria a uma estimativa equivocada da atividade noturna destes pequenos mamíferos.

Por último, o quarto conjunto de variáveis foi a presença humana próxima a cada estação de captura. Para isto consideramos a distância de cada ponto até o vilarejo mais próximo, e a presença de cachorros e outros animais domésticos como indício de atividade humana em cada estação de captura. A distância de cada ponto de armadilha até o vilarejo mais 
próximo foi calculada através do programa ArcGis 10.1, sendo considerado como ponto a ser medida a distância, a borda da primeira construção humana, como casas e muros, até o ponto exato de cada estação de captura. As variáveis que consideram a presença de outras espécies foram estimadas através de um índice de registro. Este índice consistiu no número de registros de determinada espécie em cada ponto amostral, divido pela soma de todos os registros desta espécie. Apesar de não ser tão refinado quanto estimativas de ocupação para determinar a distribuição de uma espécie, este índice fornece um valor plausível do volume de atividade de cada espécie em cada ponto, sendo que nos locais onde uma espécie é mais presente/ativa, o índice tenderá a seguir o mesmo padrão.

Todas estas variáveis foram testadas em relação à correlação entre elas através do teste de correlação de Spearman. Caso alguma correlação significativa fosse encontrada, as duas variáveis em questão não seriam incluídas na mesma análise para evitar viés nos resultados. No entanto, nenhum par de variáveis amostrado neste estudo apresentou valores significativos de correlação entre eles. Sendo assim, todas as variáveis descritas acima foram utilizadas para as três espécies de mesocarnívoros estudadas (com a exceção da frequência da jaguatirica e do lobinho nos modelos de sua própria espécie).

\section{$\underline{\text { Análise dos dados }}$}

Modelos de Ocupação: Até alguns anos atrás, o método mais frequentemente empregado para análise da ocorrência e distribuição das espécies era a utilização de modelos lineares generalizados binomiais (Binomial GLM) ou regressões logísticas (Kéry, 2010). Estes modelos estimavam a probabilidade de uma espécie com dados do tipo "presença/ausência". Estes são dados binários para quando determinado organismo é encontrado (1) ou não (0) em uma amostra espacial. No entanto, estes métodos desconsideram um fator fundamental, a detectabilidade, $\mathrm{p}$, da maioria das espécies é imperfeita. Ou seja, uma espécie nem sempre será 
detectada onde ela ocorre - $(\mathrm{p}<1)$ - (MacKenzie e Kendall, 2002; Pellet e Schmidt, 2005). Em outras palavras, estes dados de presença/ausência são provenientes de dois processos estocásticos aninhados: (1) o real estado do sistema (ocupado/não ocupado) e (2) a observação do estado do sistema (detectado/não detectado) (Kéry et al., 2010).

Em decorrência disto, muitos estudos anteriores não modelam a verdadeira ocorrência das espécies da forma como pretendido (Kéry, 2010). No entanto, com o recente desenvolvimento e aprimoramento dos modelos de ocupação (MacKenzie e Kendall, 2002; MacKenzie et al., 2006) pode-se estimar a verdadeira distribuição das espécies sem o viés causado pela sua detectabilidade (Kéry, 2010). Estes modelos de ocupação estimam a probabilidade da ocorrência de uma espécie corrigindo pela detecção imperfeita, utilizando a informação de repetidos dados de presencia/ausência (MacKenzie et al., 2006; Sollmann et al., 2012)

A construção destes modelos segue a seguinte lógica: o estado real do sistema apresenta apenas dois resultados possíveis para cada local amostrado, ocupado ou não ocupado. Portanto, a ocorrência de uma espécie em determinado local, $z(i)$ é uma distribuição binária, podendo ser modelada como uma variável aleatória de Bernoulli (Kéry, 2010), no qual:

\section{z(i) $\sim \operatorname{Bernoulli}(\psi(i))$,}

$z$ representa a ocupação real, (onde $z(i)=1$ significa que o site i está ocupado pela espécie, e $z(i)=0$, que não está). $\psi$, portanto, é a probabilidade de sucesso da distribuição, e consequentemente, $\boldsymbol{\psi}(\boldsymbol{i})$, representa a probabilidade de ocupação do site $\boldsymbol{i}$. Esta probabilidade de ocupação $(\psi(i))$ pode ser modelada como uma função logit de qualquer variável ambiental escolhida. Neste ponto chegaríamos às mesmas conclusões de estudos anteriores ao desenvolvimento dos modelos de ocupação. No entanto, como visto anteriormente, a detecção 
é imperfeita $(\boldsymbol{p}<1)$. Portanto, é necessário incluir outro fator, $\boldsymbol{p}(\boldsymbol{i}, \boldsymbol{j})$, que é a probabilidade de detecção no local i e na amostragem $\boldsymbol{j}$. Esta probabilidade também pode ser modelada como uma função logit. Esta probabilidade de detecção, $\boldsymbol{p}(\boldsymbol{i}, \boldsymbol{j})$, é condicional à ocupação real, $z(i)$, na qual:

$$
\mu(i, j)=z(i) * p(i, j)
$$

sendo $\boldsymbol{\mu}(\boldsymbol{i}, \boldsymbol{j})$, então, a probabilidade de detecção incondicional, no qual zero quando $\boldsymbol{z}(\boldsymbol{i})$ $=0$, e $\boldsymbol{p}(\boldsymbol{i}, \boldsymbol{j})$, quando $\boldsymbol{z}(\boldsymbol{i})=1$. Por fim, a história de capturas da espécie obtida no estudo $-\boldsymbol{y}(\boldsymbol{i}, \boldsymbol{j})$ (Onde $\boldsymbol{y}(\boldsymbol{i}, \boldsymbol{j})=1$, a espécie foi detectada no local $\boldsymbol{i}$ durante a amostragem $\boldsymbol{j}$, e $\boldsymbol{y}(\boldsymbol{i}, \boldsymbol{j})=0$, não detectada) é descrita no modelo como uma distribuição aleatória de Bernoulli com a probabilidade de sucesso $\boldsymbol{\mu}(\boldsymbol{i}, \boldsymbol{j})$ :

$y(i, j) \mid z(i) \sim$ Bernoulli $(\mu(i, j))$.

Neste estudo, a ocorrência dos mesocarnívoros foi estimada através destes modelos de ocupação (MacKenzie et al., 2006). Todas as análises foram realizadas no programa R através do pacote 'unmarked'. Os modelos foram construídos e selecionados em duas etapas. Primeiramente foram construídos modelos de detecção, no qual foram considerados os efeitos de todas as variáveis e de suas interações na probabilidade de detecção (p) de cada espécie enquanto a probabilidade de ocupação, $(\psi(i))$, foi fixada como nula, ou seja, sem o efeito de nenhuma variável. A partir deste ponto, os modelos de detecção selecionados foram utilizados para a seleção dos melhores modelos de ocupação, utilizando as variáveis de detecção selecionadas no primeiro passo junto a todas as variáveis e suas interações na probabilidade de ocupação, chegando-se assim, nos modelos que melhor se ajustam aos dados disponíveis. A seleção de modelos foi realizada através do Critério de Informação de Akaike (AIC) ajustado para amostras pequenas (AICc). Foram considerados como modelos selecionados aqueles que 
apresentaram valores de $\triangle \mathrm{AICc}$ menores do que 2. Os modelos selecionados foram então testados pelo seu ajuste aos dados, através do teste de Goodness of fit, empregado pelo programa $\mathrm{R}$ (ver resultados no apêndice).

\section{Resultados}

Foram obtidos 1.374 registros das três espécies de mesocarnívoros amostrados em conjunto, sendo: 352 registros da jaguatirica, 921 do lobinho e 101 registros do gato-do-mato. Cada um destes três mesocarnívoros possuiu um diferente grupo de variáveis afetando suas probabilidades de detecção (Tabelas 3.1, 3.2 e 3.3) e ocupação (Tabelas 3.4, 3.5 e 3.6). No entanto, fatores relacionados à presença de espécies de potenciais presas aparentam ser a maior influência na determinação da ocupação destes carnívoros no Parque Nacional da Serra da Capivara.

Tabela 3.1: Seleção de modelos de detecção (p) para a análise de ocupação $^{1}$ da Jaguatirica no Parque Nacional da Serra da Capivara

\begin{tabular}{lrrr}
\hline Modelo de Detecção & AICc & \multicolumn{1}{c}{$\Delta$ AICc } & \multicolumn{1}{c}{ AICwt } \\
\hline Altitude & 706.67 & 0 & 0.5191 \\
Domésticos & 710.41 & 3.75 & 0.0797 \\
Onça-Pintada & 710.54 & 3.87 & 0.075 \\
Densidade de Pontos de Água & 711.35 & 4.68 & 0.0499 \\
Onça-Pintada e Parda & 711.38 & 4.72 & 0.0491 \\
Cães + Domésticos & 711.39 & 4.72 & 0.049 \\
Distância à Povoados & 712.11 & 5.44 & 0.0341 \\
Constante & 712.46 & 5.79 & 0.0287 \\
Onças + Cães & 712.47 & 5.8 & 0.0286 \\
Tatus & 713.36 & 6.69 & 0.0183 \\
Cães + Domésticos & 713.72 & 7.06 & 0.0152 \\
Onça-Parda & 713.86 & 7.19 & 0.0142 \\
Roedores & 714.1 & 7.43 & 0.0126 \\
Distância à Fontes de Água & 714.13 & 7.46 & 0.0124 \\
Roedores + Tatus & 715.23 & 8.57 & 0.0072 \\
Onça-Parda + Cães & 715.32 & 8.65 & 0.0069 \\
\hline
\end{tabular}

${ }^{1}$ Probabilidade de ocupação fixada em constante 
Tabela 3.2: Seleção de modelos de detecção (p) para a análise de ocupação $^{1}$ da Lobinho no Parque Nacional da Serra da Capivara

\begin{tabular}{lrrr}
\hline Modelo de Detecção & \multicolumn{1}{c}{ AICc } & \multicolumn{1}{c}{$\Delta$ AICc } & \multicolumn{1}{c}{ AICwt } \\
\hline Jaguatirica & 766.69 & 0 & 0.4881 \\
Roedores + Tatus & 769.25 & 2.56 & 0.1356 \\
Tatus & 770.48 & 3.79 & 0.0732 \\
Onça-Parda + Cães & 771.62 & 4.93 & 0.0415 \\
Onça-Pintada + Parda + Cães & 771.74 & 5.06 & 0.0389 \\
Cães & 772.16 & 5.48 & 0.0316 \\
Onça-Pintada + Onça-Parda & 772.43 & 5.74 & 0.0277 \\
Onça-Pintada & 772.62 & 5.94 & 0.0251 \\
Nulo & 772.69 & 6.01 & 0.0242 \\
Onça-Parda & 772.92 & 6.24 & 0.0216 \\
Roedores & 772.97 & 6.28 & 0.0211 \\
Altitude & 773.5 & 6.81 & 0.0162 \\
Cães + Domésticos & 773.82 & 7.13 & 0.0138 \\
Distância à Fontes de Água & 774.07 & 7.39 & 0.0122 \\
Domésticos & 774.22 & 7.54 & 0.0113 \\
Distância à Povoados & 774.68 & 7.99 & 0.009 \\
Densidade de Pontos de Água & 774.69 & 8.01 & 0.0089 \\
\hline
\end{tabular}

${ }^{1}$ Probabilidade de ocupação fixada em constante

Tabela 3.3: Seleção de modelos de detecção (p) para a análise de ocupação ${ }^{1}$ do Gato-do-Mato no Parque Nacional da Serra da Capivara

\begin{tabular}{lccc}
\hline Modelo de Detecção & AICc & $\Delta$ AICc & AICwt \\
\hline Densidade de Pontos de Água + Altit & 460.24 & 0 & 0.5835 \\
Densidade de Pontos de Água & 463.15 & 2.91 & 0.136 \\
Altitude & 464.94 & 4.7 & 0.0556 \\
Tatus & 465.46 & 5.21 & 0.043 \\
Onça-Pintada & 466.71 & 6.47 & 0.023 \\
Nulo & 466.78 & 6.54 & 0.0222 \\
Roedores + Tatus & 467.34 & 7.1 & 0.0167 \\
Jaguatirica & 467.46 & 7.22 & 0.0158 \\
Onça-Parda & 467.57 & 7.32 & 0.015 \\
Onça-Pintada + Onça-Parda & 467.59 & 7.35 & 0.0148 \\
Domésticos & 468.43 & 8.18 & 0.0097 \\
Distância à vilarejos & 468.5 & 8.25 & 0.0094 \\
Distância à fontes de água & 468.55 & 8.3 & 0.0092 \\
Lobinho & 468.75 & 8.51 & 0.0083 \\
Roedores & 468.77 & 8.52 & 0.0082 \\
Cães & 468.78 & 8.54 & 0.0082 \\
Onça-Pintada + Parda + Cães & 469.31 & 9.07 & 0.0063 \\
Lobinho + Jaguatirica & 469.41 & 9.17 & 0.006 \\
Onça-Parda + Cães & 469.56 & 9.32 & 0.0055 \\
Cães + Domésticos & 470.42 & 10.18 & 0.0036 \\
\hline
\end{tabular}

${ }^{1}$ Probabilidade de ocupação fixada em constante 
O modelo de detecção que melhor se adequou aos dados para a jaguatirica foi a influência da altitude na probabilidade de registro. Com a utilização desta variável na construção dos modelos de ocupação, foram selecionados os modelos que incluem a presença de espécies de roedores e da Onça-pintada na probabilidade de ocupação da jaguatirica. Os roedores apresentaram uma relação positiva - quanto maior a frequência destas espécies, maior também foi a probabilidade de ocupação da jaguatirica. O efeito da presença da Onça-pintada, ao contrário, foi negativo, indicando que a jaguatirica parece evitar os mesmos locais nos quais o predador de topo possui maior presença.

Para o lobinho, o modelo de detecção selecionado foi o que incluiu a frequência da jaguatirica como um fator importante, sendo que quanto maior a frequência, menor foi a probabilidade de detecção do lobinho. Considerando este modelo, os modelos de ocupação selecionados foram os que incluíram a frequência das espécies de roedores e de tatus na distribuição deste mesocarnívoro, ambas variáveis apresentando uma relação positiva. Por fim, o Gato-do-mato apresentou uma menor probabilidade de detecção em estações de captura perto de um maior número de pontos de água e em altitudes mais elevadas. Com estas duas variáveis fixadas na construção dos modelos de ocupação, foram selecionados os modelos que apresentaram o efeito da presença de animais domésticos e de cachorros, afetando, de forma negativa, a ocupação deste pequeno mesocarnívoro. 
Tabela 3.4: Seleção de modelos de ocupação (psi) para a análise da distribuição da Jaguatirica no Parque Nacional da Serra da Capivara (Detecção fixada em

\begin{tabular}{|c|c|c|c|}
\hline \multicolumn{4}{|l|}{ Altitude) } \\
\hline Modelo de Ocupação & $\mathrm{AICc}$ & $\triangle \mathrm{AICc}$ & AICwt \\
\hline Roedores & 704.51 & 0 & 0.1885 \\
\hline Onça-Pintada + Roedores & 704.79 & 0.28 & 0.1636 \\
\hline Onça-Pintada & 706.24 & 1.73 & 0.0793 \\
\hline Roedores + Tatus & 706.51 & 2 & 0.0694 \\
\hline Nulo & 706.67 & 2.16 & 0.0641 \\
\hline Cães & 706.99 & 2.48 & 0.0546 \\
\hline Onça-Pintada + Onça-Parda & 707.23 & 2.72 & 0.0483 \\
\hline Domésticos & 707.5 & 2.98 & 0.0424 \\
\hline Distância à fontes de água & 707.68 & 3.17 & 0.0386 \\
\hline Tatus & 707.76 & 3.25 & 0.0371 \\
\hline Onça-Parda & 707.79 & 3.28 & 0.0366 \\
\hline Cães + Domésticos & 707.89 & 3.38 & 0.0348 \\
\hline Onça-Parda + Cães & 707.98 & 3.46 & 0.0333 \\
\hline Onça-Pintada + Parda + Cães & 707.99 & 3.48 & 0.0332 \\
\hline Altitude & 708.52 & 4.01 & 0.0254 \\
\hline Distância à vilarejos & 708.66 & 4.15 & 0.0237 \\
\hline Densidade de Pontos de Água & 708.66 & 4.15 & 0.0237 \\
\hline
\end{tabular}

Tabela 3.5: Seleção de modelos de ocupação (psi) para a análise da distribuição do Lobinho no Parque Nacional da Serra da Capivara (Detecção fixada em Jaguatirica)

\begin{tabular}{lcrr}
\hline Modelo de Ocupação & \multicolumn{1}{l}{ AICc } & \multicolumn{1}{c}{$\Delta$ AICc } & \multicolumn{1}{c}{ AICwt } \\
\hline Tatus & 763.58 & 0 & 0.2973 \\
Roedores + Tatus & 764.63 & 1.05 & 0.1758 \\
Distância à fontes de água & 766.01 & 2.43 & 0.0883 \\
Nulo & 766.69 & 3.11 & 0.0629 \\
Roedores & 766.96 & 3.39 & 0.0547 \\
Cães & 767.36 & 3.78 & 0.0449 \\
Domésticos & 767.76 & 4.18 & 0.0368 \\
Onça-Pintada & 768.41 & 4.83 & 0.0266 \\
Jaguatirica & 768.45 & 4.87 & 0.026 \\
Onça-Parda & 768.46 & 4.88 & 0.0259 \\
Cães + Domésticos & 768.5 & 4.92 & 0.0254 \\
Altitude & 768.52 & 4.94 & 0.0252 \\
Densidade de Pontos de Água & 768.59 & 5.01 & 0.0243 \\
Distância à vilarejos & 768.67 & 5.09 & 0.0234 \\
Onça-Pintada + Roedores & 768.82 & 5.24 & 0.0216 \\
Onça-Parda + Cães & 769.06 & 5.48 & 0.0192 \\
Onça-Pintada + Onça-Parda & 770.15 & 6.57 & 0.0111 \\
Onça-Pintada + Parda + Cães & 770.92 & 7.34 & 0.0076 \\
\hline
\end{tabular}


Tabela 3.6: Seleção de modelos de ocupação (psi) para a análise da distribuição do Gato-do-Mato no Parque Nacional da Serra da Capivara (Detecção fixada em Densidade de Água + Altitude)

\begin{tabular}{lccr}
\hline Modelo de Ocupação & AICc & $\Delta$ AICc & AICwt \\
\hline Domésticos & 458.66 & 0 & 0.2088 \\
Cães + Domésticos & 459.83 & 1.17 & 0.1163 \\
Nulo & 460.24 & 1.58 & 0.0947 \\
Roedores & 460.83 & 2.17 & 0.0707 \\
Jaguatirica & 461.56 & 2.9 & 0.049 \\
Cães & 461.74 & 3.08 & 0.0448 \\
Distância à vilarejos & 461.78 & 3.12 & 0.0439 \\
Distância à fontes de água & 461.92 & 3.26 & 0.041 \\
Densidade de Pontos de Água & 461.96 & 3.3 & 0.0402 \\
Tatus & 462.08 & 3.42 & 0.0378 \\
Lobinho & 462.17 & 3.51 & 0.0361 \\
Onça-Parda & 462.19 & 3.53 & 0.0358 \\
Altitude & 462.24 & 3.58 & 0.0349 \\
Onça-Pintada & 462.24 & 3.58 & 0.0349 \\
Roedores + Tatus & 462.75 & 4.09 & 0.0271 \\
Onça-Pintada + Roedores & 462.83 & 4.17 & 0.026 \\
Jaguatirica + Lobinho & 463.51 & 4.85 & 0.0185 \\
Onça-Parda + Cães & 463.72 & 5.06 & 0.0166 \\
Onça-Pintada + Onça-Parda & 464.19 & 5.52 & 0.0132 \\
Onça-Pintada + Parda + Cães & 465.69 & 7.03 & 0.0062 \\
\hline
\end{tabular}

\section{Discussão}

De acordo com a previsão inicial de que carnívoros se distribuem de acordo com a disponibilidade de suas presas (um efeito botton-up), os dois maiores mesocarnívoros aqui amostrados mostraram a estimativa de ocupação maior nos locais onde a frequência de espécies de roedores e tatus também foi maior. No entanto, a hipótese principal, de que neste ambiente árido os mesocarnívoros se distribuiriam na paisagem de acordo com a disponibilidade de água, não foi sustentada. Estudos anteriores mostraram o efeito que a presença de água pode ter para diversas espécies de mamíferos em ambientes secos (James et al., 1999; O’Brien e Waddell, 2006). A distribuição de espécies herbívoras ${ }^{10}$, por exemplo, é influenciada marcadamente por estas fontes de água (Redfern et al., 2003; Valeix et al., 2008), principalmente em períodos

\footnotetext{
${ }^{10}$ Herbívoros aqui significam espécies pastadoras e podadoras, do Inglês Grazers and browzers
} 
secos, no qual estes animais tendem a ocorrer nas proximidades da água, causando até mesmo, em alguns casos, um efeito significante na vegetação circundante (Parker e Witkowski, 1999). Esta concentração de espécies herbívoras próxima a fontes de água tem o potencial de atrair animais predadores, que então ocorreriam próximo à água não apenas para o seu consumo próprio (Destefano et al., 2000), mas também para espreitar e capturar prováveis presas (de Boer et al., 2010; Destefano et al., 2000).

A maior presença de espécies herbívoras em torno das fontes de água artificiais do Parque Nacional da Serra da Capivara, foi constatada previamente por Wolff (2001). Naquele estudo, algumas espécies como o Veado-catingueiro (Mazama gouazoubira) possuíam maior taxa de registro nestes locais. Este autor (Wolff, 2001) encontrou o mesmo efeito nas espécies de grandes carnívoros, a Onça-pintada e Onça-parda, que também possuíam uma maior taxa de registro próxima aos poços de água. Samuel Astete, em sua tese de doutorado (Astete, 2012) obteve resultados similares, observando que regiões próximas aos pontos de água apresentaram maior adequabilidade de habitat para os veados e para as duas espécies de onças. Estes resultados estão de acordo com os vários estudos realizados com grandes mamíferos em regiões áridas (Parker e Witkowski, 1999; Redfern et al., 2005; Smit e Grant, 2009). No entanto, espécies de granívoros menores como roedores, por exemplo, não dependem de grandes quantidades de água livre como as espécies de herbívoros maiores (Wolff, 2001). Assim, provavelmente não haveria concentração maior e mais notável de pequenos mamíferos em regiões próximas aos poços de água. Com efeito, os mesocarnívoros amostrados neste estudo, que possuem sua dieta composta majoritariamente por pequenos mamíferos granívoros (roedores) e se distribuíram preferencialmente em relação a estes, não apresentaram nenhuma relação com a disponibilidade de água. 
A exceção foi o gato-do-mato, que apesar de não ter sua distribuição afetada pela água como os dois mesocarnívoros maiores, apresentou uma detecção menor com a maior disponibilidade de água. Esta espécie é considerada sensível ao efeito da presença humana (Emanuelle et al., 2011; Tortato et al., 2013), o que aparentemente refletiu-se nos resultados aqui obtidos, com sua menor ocorrência em locais com maior frequência de animais domésticos. De fato, fontes de água atraem a presença de espécies domesticadas, como gado e cães (James et al., 1999). Além disto, os pontos de água do Parque Nacional da Serra da Capivara são visitados periodicamente por funcionários do Parque, para a manutenção do volume de água (FUMDHAM, 1994), o que aumenta a presença humana nestes locais. O gatodo-mato, portanto, pode estar menos ativo e se movimentar menos nestas áreas devido à presença humana, diminuindo assim a sua chance de detecção nestes locais. Os outros dois mesocarnívoros podem ser relativamente tolerantes à presença humana (Kolowski e Alonso, 2010; Michalski et al., 2006), portanto, o efeito negativo da presença de espécies domésticas, ou mesmo uma relação negativa à presença de água não foi encontrada.

Em relação à presença de carnívoros maiores, como esperado, a jaguatirica pareceu evitar os locais nos quais a Onça-Pintada apresentou maior frequência de ocorrência. O efeito que predadores maiores podem ter sobre mesocarnívoros é bem documentado e estudado (Cove et al., 2012; Crooks e Soulé, 1999; Elmhagen e Rushton, 2007; LaPoint et al., 2014; Ritchie e Johnson, 2009). Em uma floresta em Belize, verificou-se que a Onça-Pintada limita o nicho espacial da jaguatirica, quando estas espécies ocorrem em simpatria (Davis, 2009). O efeito negativo de carnívoros maiores sobre mesopredadores é resultado tanto de uma competição por recursos, caso exista sobreposição trófica, quanto pela predação intraguilda (Ritchie e Johnson, 2009). Estudos sobre a alimentação da jaguatirica e da Onça-Pintada indicam que, provavelmente devido à grande disparidade existente de suas massas corporais, estas espécies não apresentam alto índice de sobreposição de suas dietas (Abreu et al., 2008; Chinchilla, 1997; 
Foster et al., 2010; Moreno et al., 2006). Portanto, a distribuição apresentada aqui pela jaguatirica, com estimativas de ocupação menores em locais no qual a Onça-Pintada é mais frequente, é mais provavelmente um comportamento direcionado a evitar encontros com o predador maior, reduzindo a probabilidade de interações agonísticas e eventual predação intraguilda (Lesmeister e Nielsen, 2015; Ritchie e Johnson, 2009), e não uma resposta em relação à disponibilidade de itens alimentares.

A literatura indica que o lobinho, possui dieta com elevada sobreposição em relação à da jaguatirica (Gatti et al., 2006; Juarez e Marinho, 2002), o que poderia levar estas espécies a se evitarem não apenas pela possibilidade de encontros antagônicos, mas também pela competição por alimento. No presente estudo não houve segregação espacial do lobinho em relação à jaguatirica, mas ele apresentou uma probabilidade de detecção menor nos locais onde a jaguatirica é mais frequente. Isto sugere que o lobinho, apesar de preferir, assim como a jaguatirica, ocorrer em locais com maior frequência de roedores, parece apresentar menor atividade e/ou mobilidade nestes locais. Isto pode indicar que esta espécie de canídeo tenha comportamento mais cuidadoso em locais com maior frequência da espécie de felino maior, porém ocorrendo nestes locais, de maneira similar ao encontrado em outros estudos realizados em diferentes localidades (Maffei et al., 2007). Da mesma forma, a presença da jaguatirica também não foi um fator importante para a ocorrência do gato-do-mato, apesar da sugestão na literatura de que a espécie de felino maior teria um efeito negativo desproporcional sobre as espécies menores (Oliveira et al., 2010).

Os diferentes fatores amostrados neste estudo podem agir em conjunto para a determinação dos padrões de distribuição temporal destes mesocarnívoros no Parque Nacional da Serra da Capivara. É interessante notar que cada uma das espécies de mesocarnívoros apresentou um conjunto diferente de variáveis afetando sua ocupação. Desta forma, o presente 
estudo salienta a importância de se considerar um conjunto mais amplo de variáveis quando se trata dos fatores associados à distribuição de espécies. Vários estudos anteriores consideraram poucos, ou mesmo apenas um conjunto de variáveis - ambientais, predadores, humanas - em suas análises (Clare et al., 2015; Sarmento et al., 2010; Schuette et al., 2013; Sollmann et al., 2012). O fator aqui selecionado como provavelmente o mais importante na distribuição de duas espécies, as suas presas, raramente é considerado (Jones et al., 2016; Weckel et al., 2006).

Se considerássemos menos grupos os resultados poderiam ser absolutamente enviesados, sugerindo relações que não são realmente importantes no ambiente natural. Por exemplo, se não considerássemos os grupos de presas, a distribuição do lobinho seria dada como influenciada pela água ou mesmo nula, o que seria um resultado equivocado conforme nossa observação e análise. Da mesma forma, os resultados aqui obtidos devem ser vistos com cuidado, pois variáveis que poderiam se mostrar extremamente importantes para a distribuição destas espécies não puderam ser incluídas como, por exemplo, a densidade de cobertura vegetal, um fator previamente indicado como importante na distribuição da jaguatirica (Harveson et al., 2004). De qualquer modo, os dados obtidos no presente estudo indicam que, mesmo em um ambiente extremo, árido, e de baixa produtividade como a caatinga, a disponibilidade de presas é um fator de extrema relevância para a distribuição dos mesocarnívoros. 


\section{Referências Bibliográficas.}

Abreu KC, Moro-Rios RF, Silva-Pereira JE, Miranda JMD, Jablonski EF e Passos FC (2008) Feeding habits of ocelot (Leopardus Pardalis) in Southern Brazil. Mammalian Biology 73:407-411.

Astete S (2012) Ecologia e conservação da onça-pintada e da onça parda no Parque Nacional serra da capivara, Piauí. Tese de Doutorado. Universidade de Brasília

Carbone CJ e Gittleman L (2002) A common rule for the scaling of carnivore density. Science 295:2273-6.

Chamberlain M e Leopold B (2002) Spatio-temporal relationships among adult raccoons (Procyon lotor) in central Mississippi. The American Midland Naturalist 148:297-308.

Chinchilla F (1997) La dieta del Jaguar (Panthera onca), el Puma (Felis concolor) y el Manigordo (Felis pardalis) (Carnivora: Felidae) en el Parque Nacional Corcovado, Costa Rica. Revista De Biologia Tropical 45:1223-1229.

Clare JDJ, Anderson EM e Macfarland DM (2015). Predicting bobcat abundance at a landscape scale and evaluating occupancy as a density index in central Wisconsin. The Journal of Wildlife Management 79:469-480.

Collier BA, Groce J, Morrison M, Newnam J, Campomizzi A, Farrel S, Mathewson H, Snelgrove R, Carrol R e Wilkins R (2012) Predicting patch occupancy in fragmented landscapes at the rangewide scale for an endangered species: an example of an american warbler. Diversity \& Distributions 18:158-167.

Cove M, Jones B e Bossert EA (2012). Use of camera traps to examine the mesopredator release hypothesis in a fragmented midwestern landscape. The American Midland Naturalist 168:456-465.

Crooks KR e Soulé ME (1999) Mesopredator release and avifaunal extinctions in a fragmented system. Nature 400:563-566.

Davis ML (2009). Densities, habitat-use, and mesopredator release of the ocelot in Belize. Tese de Doutorado.Virginia Polytechnic Institute and State University.

De Boer WF, Vis MJP, De Knegt HJ, Rowles C, Kohi EM, Van Langevelde F, Peel M, Pretorius Y, Skidmore AK, Slotow R, Van Wieren SE e Prins HHT (2010) spatial 
distribution of lion kills determined by the water dependency of prey species. Journal Of Mammalogy 91:1280-1286.

Destefano S, Schmidt S e Devos J (2000) Observations of predator activity at wildlife water developments in southern Arizona. Journal Of Range Management 53:255-258.

Di Bitetti MS, Paviolo A e De Angelo C (2006) Density, habitat use and activity patterns of ocelots (Leopardus Pardalis) in the Atlantic Forest of Misiones, Argentina. Journal of Zoology 270:153-163.

Elmhagen B, Rushton SP (2007) Trophic control of mesopredators in terrestrial ecosystems: top-down or bottom-up? Ecology Letters 10:197-206.

Mendonça LET, Souto CM, Andrelino LL, Souto WMS, Vieira WLS e Alves RNN (2011) Conflitos entre pessoas e animais silvestres no semiárido paraibano e suas implicações para conservação. Sitientibus série ciências biológicas 11:185-199.

Foster, RJ, Harmsen BJ, Valdes B, Pomilla C e Doncaster CP (2010) Food habits of sympatric jaguars and pumas across a gradient of human disturbance. Journal Of Zoology 280:309-318.

FUMDHAM (Fundação Museu do Homem Americano) (1994) Parque Nacional da Serra da Capivara. Alinea publicações editora, Teresina, Piauí.

Gatti A, Bianchi R, Rosa CRX e Mendes SL (2006). Diet of two sympatric carnivores, Cerdocyon thous and Procyon cancrivorus, in a restinga area of espirito santo state, Brazil. Journal of tropical ecology 22:227-230

Gehrt S e Clark WR (2003) Raccoons, coyotes, and reflections on the mesopredator release hypothesis. Wildlife Society Bulletin 31:836-842.

Harveson P, Tewes M e Anderson G (2004) Habitat use by ocelots in south texas: implications for restoration. Wildlife Society Bulletin 32:948-954.

Herfindal I, Linnell JDC, Odden J, Nilsen EB e Andersen R (2005) Prey density, environmental productivity and home-range size in the eurasian lynx (Lynx lynx). Journal of Zoology 265:63-71.

James CD, Landsberg J, Morton SR (1999) Provision of watering points in the australian arid zone: a review of effects on biota. Journal of Arid Environments 41:87-121. 
Jones B, Cove M, Lashley M e Jackson V (2016) Do coyotes Canis latrans influence occupancy of prey in suburban forest fragments? Current Zoology 62:1-11.

Juarez KM e Marinho-filho J (2002) Diet, habitat use, and home ranges of sympatric canids in central Brazil. Journal of Mammalogy 83:925-933.

Kerr JT (1997) Species richness, endemism, and the choice of areas for conservation. Conservation Biology 11:1094-1100.

Kéry M (2010) Introduction to WinBUGS for ecologists: a bayesian approach to regression, ANOVA and related analyses. Academic Press.

Kéry M, Gardner B e Monnerat C (2010) Predicting species distributions from checklist data using site-occupancy models. Journal Of Biogeography, 37:1851-1862.

Kolowski J e Alonso A (2010) Density and activity patterns of ocelots (Leopardus pardalis) in northern Peru and the impact of oil exploration activities. Biological Conservation 143:917-925.

Lantschner MV, Rusch V e Hayes JP (2012) Habitat use by carnivores at different spatial scales in a plantation forest landscape in Patagonia, Argentina. Forest Ecology and Management 269:271-278.

Lapoint SD, Belant JL e Kays RW (2014) Mesopredator release facilitates range expansion in fisher. Animal Conservation 18:50-61.

Lesmeister DB e Nielsen CK (2015) Spatial and temporal structure of a mesocarnivore guild in midwestern North America. Wildlife Monographs:191, 1-61.

Loreau M e Holt RD (2004) Spatial flows and the regulation of ecosystems. The American Naturalist 163:606-615.

Mackenzie D e Kendall W (2002) How should detection probability be incorporated into estimates of relative abundance? Ecology 83:2387-2393.

Mackenzie D, Nichols JD, Royle JA, Pollock KH, Bailey LL e Hines JE (2006) Occupancy estimation and modeling: inferring patterns and dynamics of species occurrence. Academic Press.

Maffei L, Paredes R, Segundo A e Noss A (2007) Home range and activity of two sympatric fox species in the bolivian dry Chaco. Canid News 10:1-7. 
McCann KS, Rasmussen JB e Umbanhowar J (2005) The dynamics of spatially coupled food webs. Ecology Letters 8:513-523.

Michalski F, Crawshaw PG, Oliveira TG e Fabián ME (2006) Notes on home range and habitat use of three small carnivore species in a disturbed vegetation mosaic of southeastern. Mammalia 70:52-57

Miller B, Dugelby B, Foreman D, Río CM, Noss R, Phillips M, Reading R, Soulé ME, Terborgh J e Willcox L (2001) The importance of large carnivores to healthy ecosystems. Endangered Species Update 18:202-210.

Moreno RS, Kays RW, Samudio R (2006) Competitive release in diets of ocelot (Leopardus pardalis) and puma (Puma concolor) after jaguar (Panthera onca) decline. Journal of Mammalogy 87:808-816.

Morrison, J.C., Sechrest, W., Dinerstein, E., Wilcove, D.S., Lamoreux, J.F., 2007. Persistence Of Large Mammal Faunas As Indicators Of Global Human Impacts. Journal Of Mammalogy 88, 1363-1380.

Nilsen, E.B., Herfindal, I., Linnell, J.D.C., 2005. Can Intra-Specific Variation In Carnivore Home-Range Size Be Explained Using Remote-Sensing Estimates Of Environmental Productivity? Ecoscience 12, 68-75.

O'Brien, C., Waddell, R., 2006. Wildlife Use Of Water Catchments In Southwestern Arizona. Wildlife Society Bulletin 34, 582-591.

O’Brien, T.G., 2011. Abundance, Density And Relative Abundance: A Conceptual Framework, In: Camera Traps In Animal Ecology. P. 71-96.

Oliveira, T., Tortato, M., Silveira, L., Kasper, C., Mazim, F., Lucherinii, M., Jacomo, A., Ssoares, J., Marques, R., Sunquist, M., 2010. Ocelot Ecology And Its Effect On The Small-Felid Guild In The Lowland Neotropics, In: Macdonald, D.W., Loveridge, A. (Orgs.), Biology And Conservation Of Wild Felids. Oxford University Press, Oxford, P. $563-574$.

Ordeñana, M. A, Crooks, K.R., Boydston, E.E., Fisher, R.N., Lyren, L.M., Siudyla, S., Haas, C.D., Harris, S., Hathaway, S. A, Turschak, G.M., Keith, A, Vuren, D.H. Van, 2010. Effects Of Urbanization On Carnivore Species Distribution And Richness Effects Of Urbanization On Carnivore Species Distribution And Richness. Journal Of Mammalogy 
$91,1322-1331$.

Palomares, F., Caro, T., 1999. Interspecific Killing Among Mammalian Carnivores. American Naturalist 153, 492-508.

Palomares, F., Ferreras, P., 1996. Spatial Relationships Between Iberian Lynx And Other Carnivores In An Area Of South-Western Spain. Journal Of Applied Ecology 33, 5-13.

Parker, A.., Witkowski, E.T.., 1999. Long-Term Impacts Of Abundant Perennial Water Provision For Game On Herbaceous Vegetation In A Semi-Arid African Savanna Woodland. Journal Of Arid Environments 41, 309-321.

Pellet, J., Schmidt, B., 2005. Monitoring Distributions Using Call Surveys: Estimating Site Occupancy, Detection Probabilities And Inferring Absence. Biological Conservation $123,27-35$.

Petracca, L.S., Ramirez-Bravo, O.E., Hernandez-Santin, L., 2013. Occupancy Estimation Of Jaguar Panthera Onca To Assess The Value Of East-Central Mexico As A Jaguar Corridor. Oryx 48, 1-8.

Pia, M. V., Renison, D., Mangeaud, A., De Angelo, C., Haro, J.G., 2013. Occurrence Of Top Carnivores In Relation To Land Protection Status, Human Settlements And Rock Outcrops In The High Mountains Of Central Argentina. Journal Of Arid Environments $91,31-37$.

Prugh, L.R., Stoner, C.J., Epps, C.W., Bean, W.T., Ripple, W.J., Laliberte, A.S., Brashares, J.S., 2009. The Rise Of The Mesopredator. Bioscience 59, 779-791.

Redfern, J., Grant, R., Biggs, H., Getz, W., 2003. Surface-Water Constraints On Herbivore Foraging In The Kruger National Park, South Africa. Ecology 84, 2092-2107.

Redfern, J.V., Grant, C.C., Gaylard, A., Getz, W.M., 2005. Surface Water Availability And The Management Of Herbivore Distributions In An African Savanna Ecosystem. Journal Of Arid Environments 63, 406-424.

Ritchie, E.G., Johnson, C.N., 2009. Predator Interactions, Mesopredator Release And Biodiversity Conservation. Ecology Letters 12, 982-98.

Sarmento, P.B., Cruz, J., Eira, C., Fonseca, C., 2010. Modeling The Occupancy Of Sympatric Carnivorans In A Mediterranean Ecosystem. European Journal Of Wildlife Research 57, 
$119-131$.

Schuette, P., Wagner, A.A.P., Wagner, M.E., Creel, S., 2013. Occupancy Patterns And Niche Partitioning Within A Diverse Carnivore Community Exposed To Anthropogenic Pressures. Biological Conservation 158, 301-312.

Sergio, F., Hiraldo, F., 2008. Intraguild Predation In Raptor Assemblages: A Review. Ibis $150,132-145$.

Smit, I.P.J., Grant, C.C., 2009. Managing Surface-Water In A Large Semi-Arid Savanna Park: Effects On Grazer Distribution Patterns. Journal For Nature Conservation 17, 6171.

Sollmann, R., Furtado, M.M., Hofer, H., Jácomo, A.T. A., Tôrres, N.M., Silveira, L., 2012. Using Occupancy Models To Investigate Space Partitioning Between Two Sympatric Large Predators, The Jaguar And Puma In Central Brazil. Mammalian Biology Zeitschrift Für Säugetierkunde 77, 41-46.

Terborgh, J., Lopez, L., Nuñez, P., Rao, M., Shahabuddin, G., Orihuela, G., Riveros, M., Ascanio, R., Adler, G.H., Lambert, T.D., Balbas, L., 2001. Ecological Meltdown In Predator-Free Forest Fragments. Science (New York, N.Y.) 294, 1923-6.

Tortato, F.R., Tortato, M.A., Koehler, E., 2013. Short Communication POULTRY PREDATION BY Leopardus Wiedii AND Leopardus Tigrinus ( CARNIVORA : FELIDAE ) IN SOUTHERN BRAZIL. English 3, 51-53.

Trovati, R.G., De Brito, B. A, Duarte, J.M.B., 2007. Área De Uso E Utilizaçao De Habitat De Cachorro-Do-Mato (Cerdocyon Thous Linnaeus, 1766) No Cerrado Da Região Central Do Tocantins, Brasil. Mastozoología Neotropical 14, 61-68.

Valeix, M., 2011. Temporal Dynamics Of Dry-Season Water-Hole Use By Large African Herbivores In Two Years Of Contrasting Rainfall In Hwange National Park, Zimbabwe. Journal Of Tropical Ecology 27, 163-170.

Valeix, M., Fritz, H., Matsika, R., 2008. The Role Of Water Abundance, Thermoregulation, Perceived Predation Risk And Interference Competition In Water Access By African Herbivores. African Journal Of Ecology 46: 402-410.

Weckel, M., Giuliano, W., Silver, S., 2006. Jaguar (Panthera Onca) Feeding Ecology: Distribution Of Predator And Prey Through Time And Space. Journal Of Zoology 270, 
25-30.

Wolff, F., 2001. Vertebrate Ecology In Caatinga: A. Distribution Of Wildlife In Relation To Water. B. Diet Of Pumas (Puma Concolor) And Relative Abundance Of Felids. University Of Missouri. (Thesis). 


\section{Epílogo}

Esta tese apresentou dados e informações inéditas para um grupo de espécies cujo conhecimento é escasso, os mesocarnívoros, em uma região onde quase não existem trabalhos sobre a ecologia de carnívoros, a Caatinga. Apesar dos fatores intrínsecos deste ambiente semiárido terem efeitos particulares sobre estes animais, tanto na dimensão temporal, como espacial, a ocorrência da jaguatirica e do lobinho foi maior quando em sintonia com a ocorrência de presas. Na distribuição temporal, principalmente, os padrões destas espécies foram um reflexo quase exato da atividade destas presas. Por outro lado, enquanto o gato-domato não teve sua distribuição espaço-temporal relacionada fortemente à disponibilidade de roedores, este mesocarnívoro parece ser mais sensível à presença humana e de espécies de predadores maiores, apresentando atividade menor em momentos nos quais carnívoros maiores estão mais ativos, e evitando locais com a presença de cães e outros animais domésticos.

De maneira similar, a jaguatirica evitou os mesmos locais em que a Onça-Pintada foi mais frequente, não evitando, no entanto, os mesmos horários de atividade do predador maior. Assim, a presença da Onça-Pintada pode ter um efeito negativo sobre a distribuição espacial da jaguatirica, e não temporal. O efeito negativo que a Onça-Pintada pode ter sobre a ocorrência da jaguatirica no Parque Nacional da Serra da Capivara pode ser sugerido também pela diminuição populacional deste mesocarnívoro no ano em que foi detectada uma maior população de Onças-Pintadas. Assim, o aumento das populações do carnívoro de topo pode levar, a longo prazo, à diminuição, ou mesmo extinção local, da população deste mesocarnívoro. Isto pode ter um efeito cascata sobre outras espécies. Por exemplo, a jaguatirica possui o potencial de afetar a ocorrência de espécies de felinos menores. No entanto isto não

foi encontrado neste estudo. É possível que a pressão exercida pela Onça-Pintada esteja diminuindo a população deste mesopredador a níveis nos quais ele se torne um fator não 
importante para felinos menores. Apenas a continuidade deste estudo, com amostragens em um período maior, poderia clarificar os efeitos em longo prazo que estas interações entre espécies carnívoras podem ter.

Por último, o lobinho, uma espécie generalista, manteve sua população estável e apresentou distribuição espaço-temporal relacionada apenas a espécies de presas. Assim este pequeno canídeo não parece possuir interações fortes com as espécies de felinos que coexistem na Serra da Capivara. As diferenças ecológicas, tanto fisiológicas e/ou comportamentais deste canídeo em relação às espécies de felinos, podem facilitar a coexistência destes animais. Por fim, a mensagem principal deste estudo é a de que, mesmo neste ambiente semiárido, estes três mesopredadores se distribuem principalmente em relação à disponibilidade de presas, enquanto que felinos parecem ser influenciados também pela presença de efeitos provenientes do topo da cadeia. Assim, posteriores estudos devem sempre levar em consideração a presença de presas e de outras espécies, competidoras ou predadoras, em estudos que procurem verificar os padrões de distribuição espaço-temporal de mesocarnívoros, não apenas na Caatinga ou em outras regiões áridas, mas também em todos os locais no qual ocorrem. 


\section{Apêndice}

Resultados dos testes Goodness of fit para cada modelo de ocupação selecionado.

Modelos selecionados para a jaguatirica:

Modelo 1 ( $\psi($ Roedores), p(Altitude))

Goodness of fit $(\mathrm{T} 0=577)$

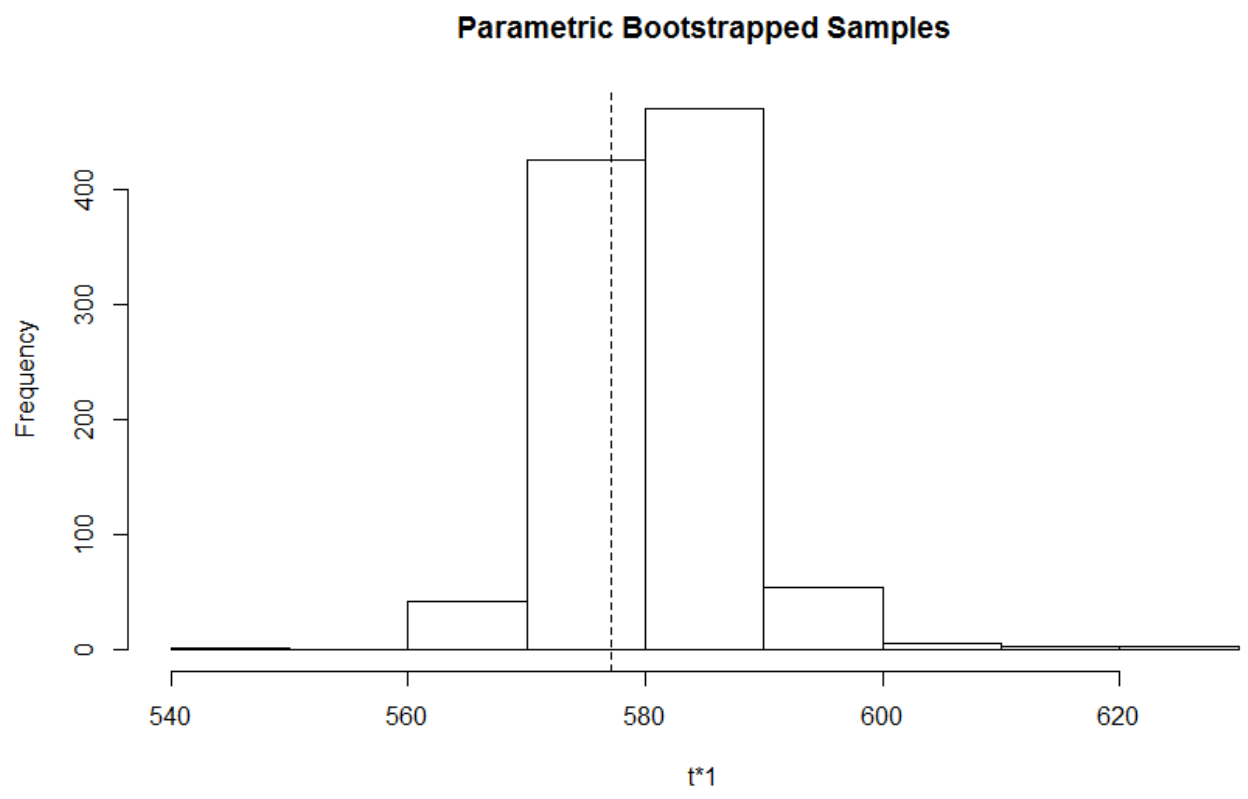

Modelo 2 ( $($ (Onça-pintada + Roedores), p(Altitude))

Goodness of fit $(\mathrm{T} 0=581)$ 


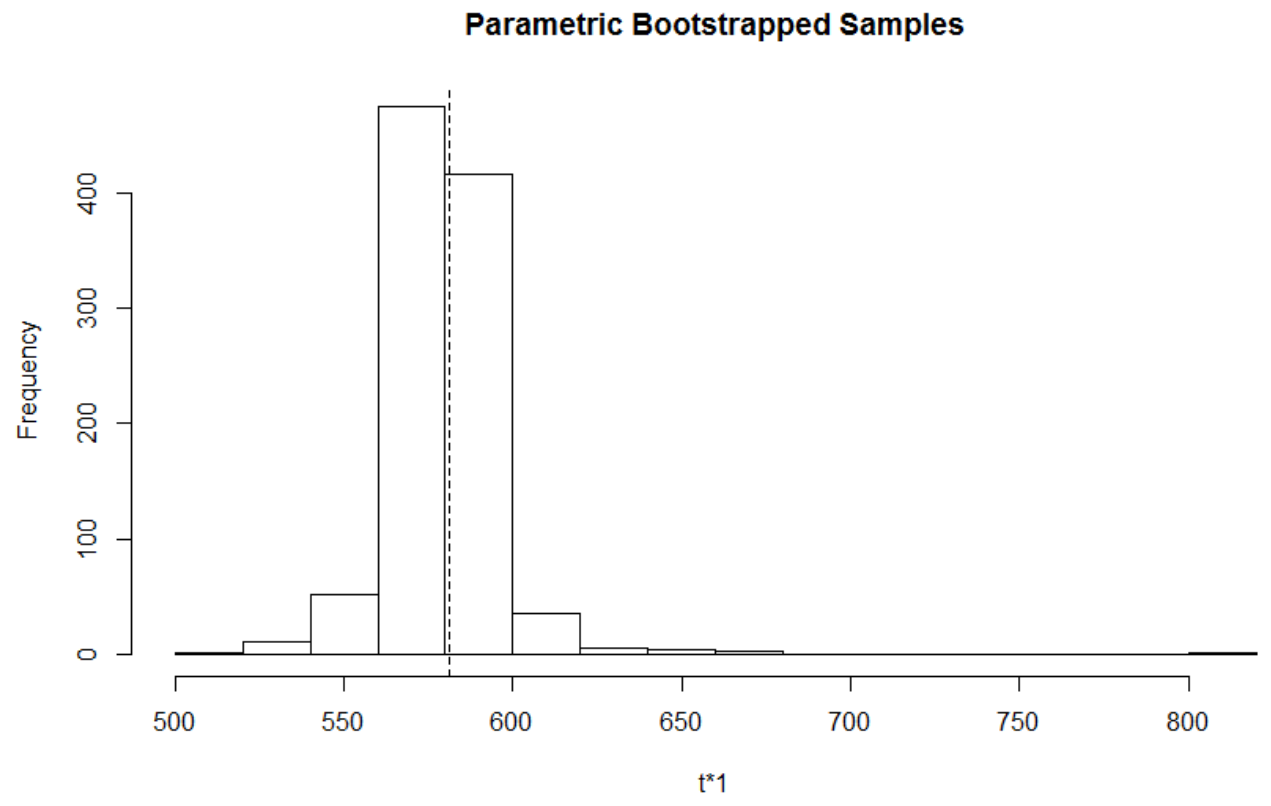

Modelo 3 ( $\psi($ Onça-pintada), p(Altitude))

Goodness of fit $(\mathrm{T} 0=589)$

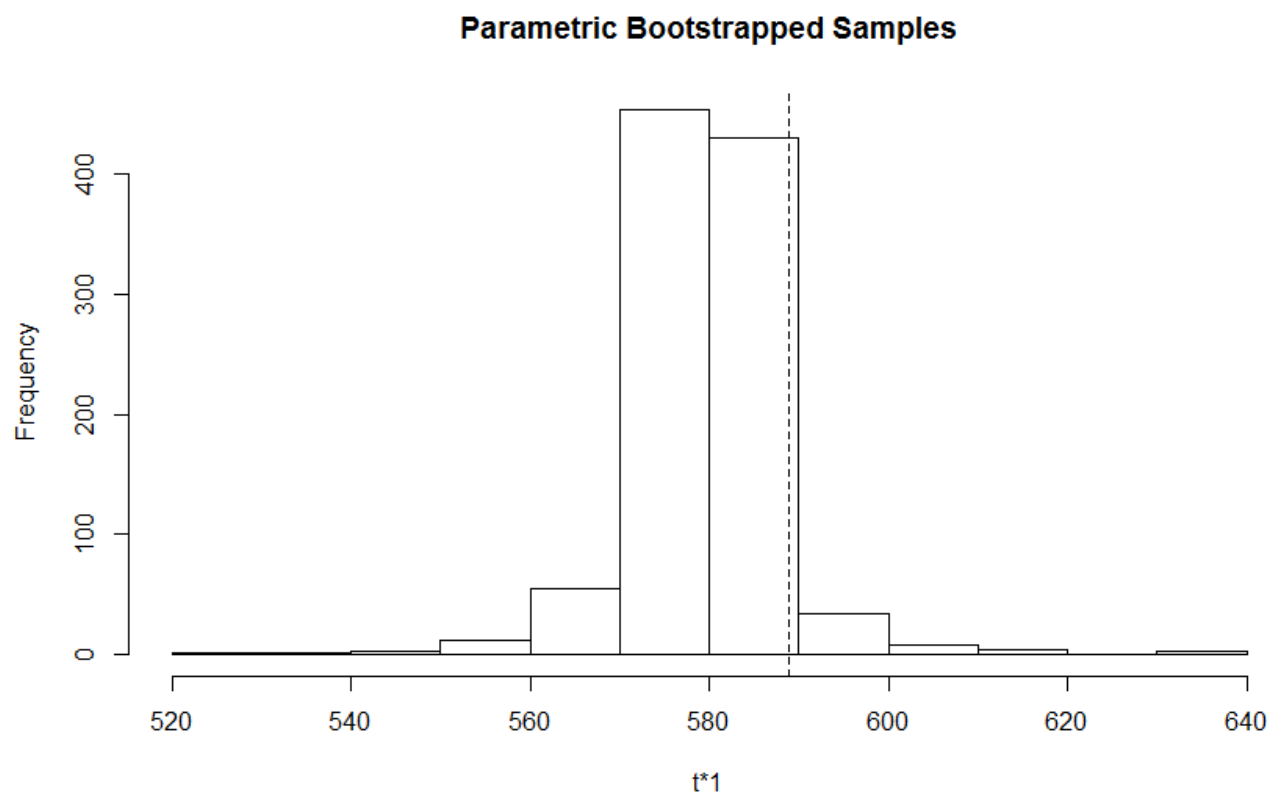

Modelos selecionados para o gato-do-mato:

Modelo 1 ( $\psi($ Animais domésticos), p(Altitude))

Goodness of fit $(\mathrm{T} 0=568)$ 


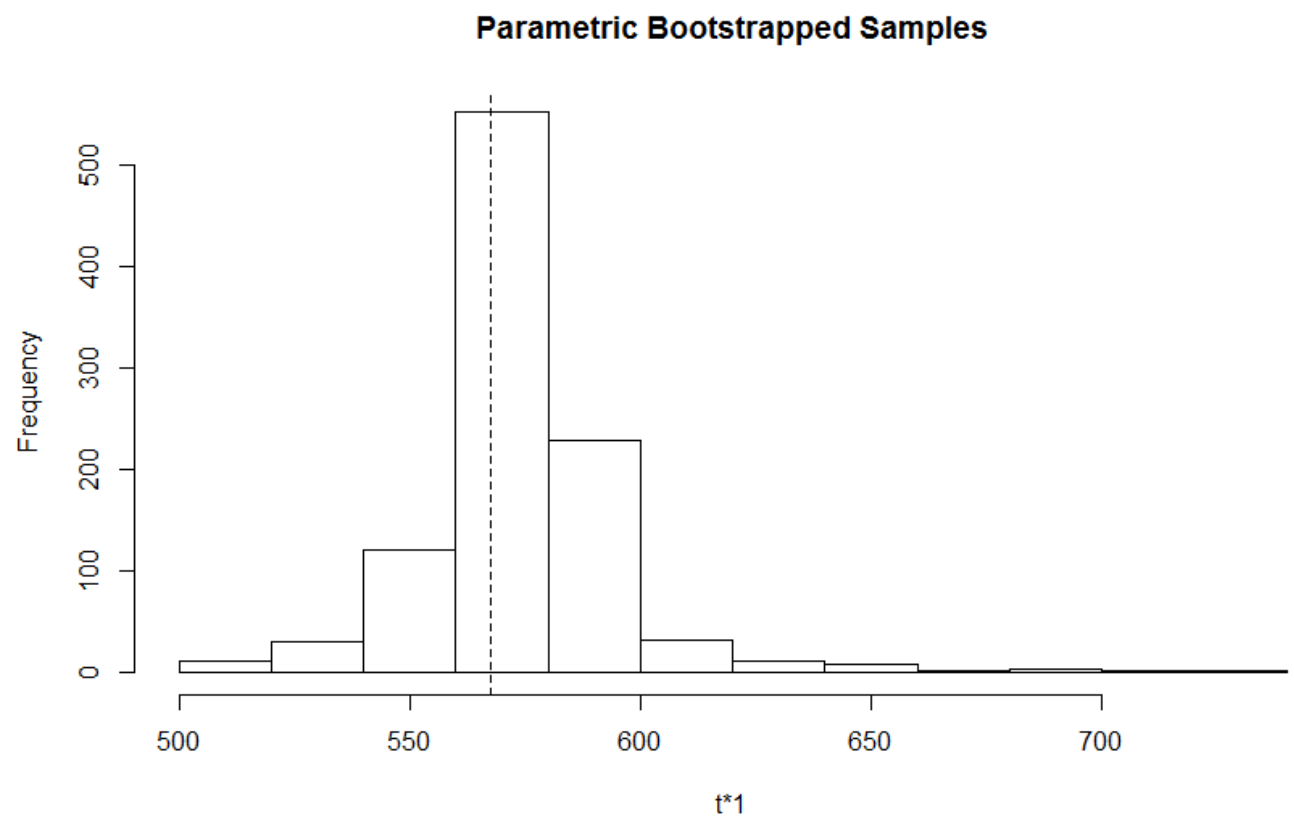

Modelo 1 ( $($ (Animais domésticos + Cães), p(Altitude))

Goodness of fit $(\mathrm{T} 0=566)$

Parametric Bootstrapped Samples

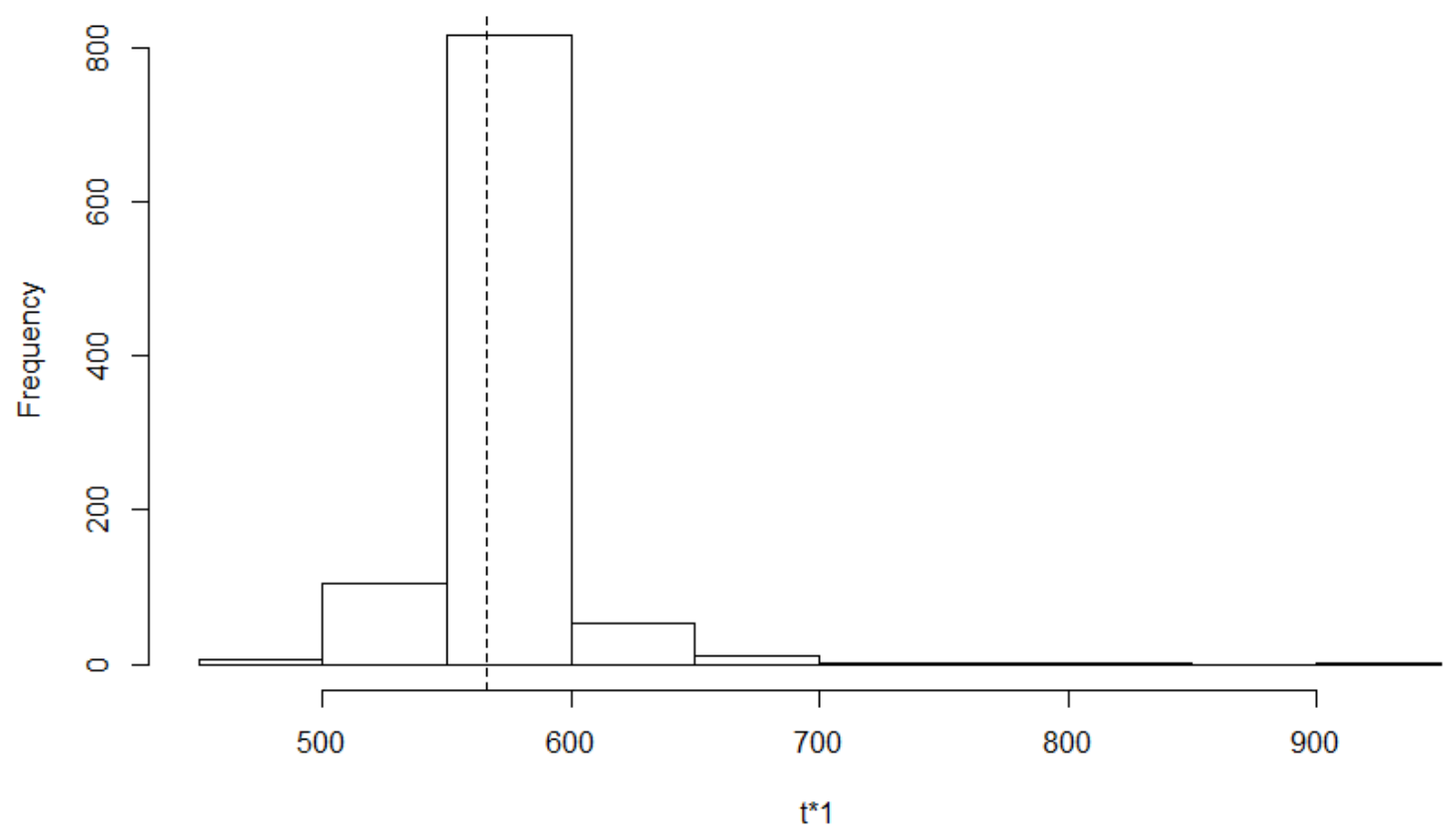

Modelos selecionados para o gato-do-mato:

Modelo 1 ( $\psi($ Tatus), p(Jaguatirica)) 
Goodness of fit $(\mathrm{T} 0=569)$

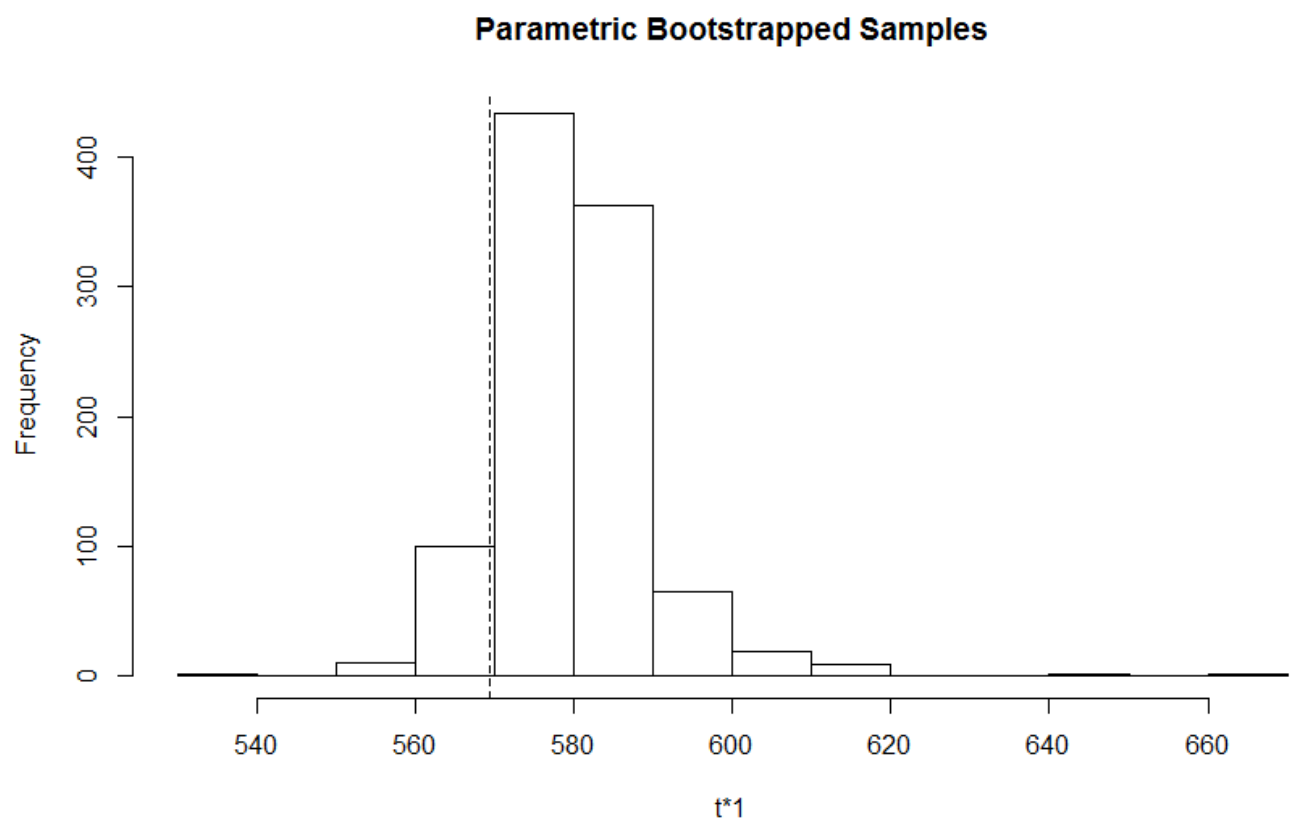

Modelo 2 ( $\psi($ Tatus + Roedores $), \mathbf{p}($ Jaguatirica $))$

Goodness of fit $(\mathrm{T} 0=569)$

Parametric Bootstrapped Samples

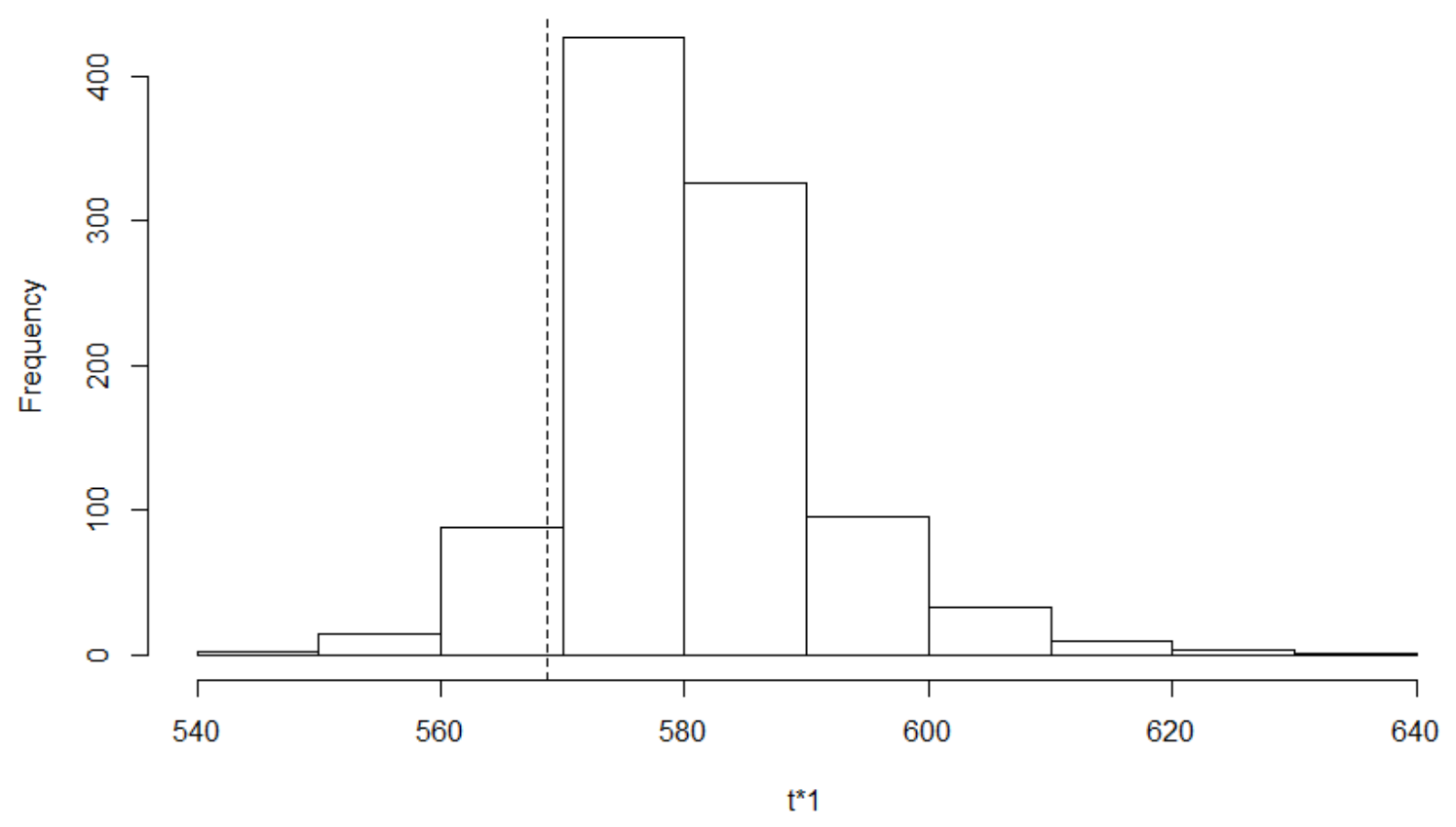

